University of Louisville

ThinkIR: The University of Louisville's Institutional Repository

Electronic Theses and Dissertations

$5-2017$

\title{
The particulars about particulates : metal exposure and self- regulation of children living near coal ash.
}

Clara G. Sears

University of Louisville

Follow this and additional works at: https://ir.library.louisville.edu/etd

Part of the Epidemiology Commons

\section{Recommended Citation}

Sears, Clara G., "The particulars about particulates : metal exposure and self-regulation of children living near coal ash." (2017). Electronic Theses and Dissertations. Paper 2699.

https://doi.org/10.18297/etd/2699

This Doctoral Dissertation is brought to you for free and open access by ThinkIR: The University of Louisville's Institutional Repository. It has been accepted for inclusion in Electronic Theses and Dissertations by an authorized administrator of ThinkIR: The University of Louisville's Institutional Repository. This title appears here courtesy of the author, who has retained all other copyrights. For more information, please contact thinkir@louisville.edu. 
THE PARTICULARS ABOUT PARTICULATES: METAL EXPOSURE AND SELFREGULATION OF CHILDREN LIVING NEAR COAL ASH

By

Clara G. Sears

MS, University of Louisville, 2014

BA, Goshen College, 2012

\author{
A Dissertation \\ Submitted to the Faculty of the \\ School of Public Health and Information Sciences \\ of the University of Louisville \\ in Partial Fulfillment of the Requirements \\ for the Degree of
}

Doctor of Philosophy in Public Health Sciences

Department of Epidemiology and Population Health

University of Louisville

Louisville, Kentucky

May 2017 

THE PARTICULARS ABOUT PARTICULATES: METAL EXPOSURE AND SELFREGULATION OF CHILDREN LIVING NEAR COAL ASH

\author{
By \\ Clara G. Sears \\ MS, University of Louisville, 2014 \\ BA, Goshen College, 2012 \\ A Dissertation Approved on
}

April 19, 2017

by the following Dissertation Committee:

Dr. Kristina M Zierold, $\mathrm{PhD}, \mathrm{MS}$

Dr. Guy Brock, PhD

Dr. Kathy Baumgartner, PhD

Dr. Kira Taylor, $\mathrm{PhD}$

Dr. Carol Hanchette, PhD 


\section{ACKNOWLEDGEMENTS}

I would like to express my deepest gratitude to my mentor and dissertation committee chair, Dr. Kristina Zierold. Your guidance and encouragement has taught me the importance of perseverance, creativity, and confidence in my professional career. You have been an exemplary role model, and your influence will have an immeasurable impact on my future research. I would like to thank my dissertation committee members: Dr. Kathy Baumgartner, Dr. Kira Taylor, Dr. Carol Hanchette, and Dr. Guy Brock. I appreciate you giving your time and expertise to help me throughout my graduate career and while completing this dissertation. I would also like to thank Abby Burns, Lindsay Tompkins, Chisom Odoh, Jack Pfeiffer, and Diana Kuo for their friendship and work on this project.

Very special thanks are extended to Dr. Kandi Walker and Dr. Joy Hart. Thank you for your never-ending support and for teaching me how to make research fun. Thank you to my parents, Lonnie and Sandi Sears, for showing me that there is nothing I cannot accomplish. Thanks to my siblings, Sophie and Dietrich Sears, for bringing joy to my life throughout stressful times. Thank you to Caroline Bontrager Kelly for joining me on a crazy Louisville adventure back in 2012 and always being there for me ever since. A huge heartfelt thank you to my partner, Nicholas Wesman. There is no possible way I could have completed this dissertation without your support, love, and patience.....and grammatical edits throughout this entire document. 
Finally, I would like to acknowledge the community members and the funding source that made this research possible: National Institutes of Health, National Institute of Environmental Health Sciences, "Coal Ash and Neurobehavioral Symptoms in Children Aged 6-14 Years Old" (Grant: 5 R01 ES024757; Principal Investigator (PI): Dr. Kristina Zierold). 


\title{
ABSTRACT \\ THE PARTICULARS ABOUT PARTICULATES: METAL EXPOSURE AND SELF- REGULATION OF CHILDREN LIVING NEAR COAL ASH
}

\author{
Clara G. Sears
}

April 19, 2017

The use of coal combustion for electricity and the storage of coal combustion byproducts known as coal ash occur across the United States and around the world. The most abundant type of coal ash, fly ash, contains small particles with metals, some of which are known neurotoxins. Fly ash is currently stored in open-air landfills and surface impoundments that allow fugitive dust to escape into surrounding communities, potentially exposing children to small neurotoxic particles.

This dissertation uses preliminary data from a larger cross-sectional study to investigate the relationship between particulate matter exposure, metal exposure, and problems with self-regulation. Recruitment of this study sample, the first 78 of 300 participants, occurred between September 2015 and December 2016. Exploratory spatial data analysis was used to assess how living near fly ash storage is related to indoor particulate matter concentration and exposure to metals. Linear regression models were used to assess the relationship between fly ash exposure, particulate matter exposure, and self-regulation. Furthermore, Bayesian kernel machine regression for variable selection and regression models were used to explore the relationship between metal concentration in particulate matter and children's self-regulation. 
The most abundant metal found in fly ash particles was aluminum. The concentration of aluminum in indoor $\mathrm{PM}_{10}$ was significantly related to distance from the fly ash landfills and an Environmental Justice Index used to identify vulnerable populations. In addition, children with higher aluminum exposure were found to perform more poorly on the Behavioral Assessment and Research System Continuous Performance and Selective Attention Tests, indicating general inattention problems. These results are based on a small preliminary sample and should therefore be interpreted with caution. Future studies will further investigate the relationship between aluminum exposure, children's metal body burden, and cognitive control. 
TABLE OF CONTENTS

PAGE

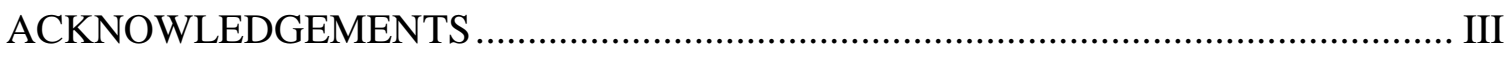

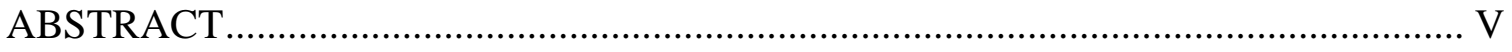

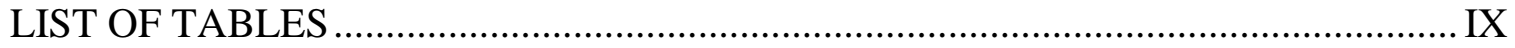

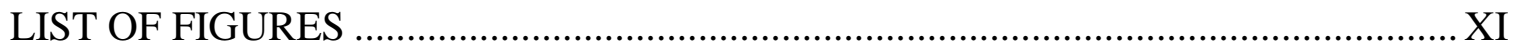

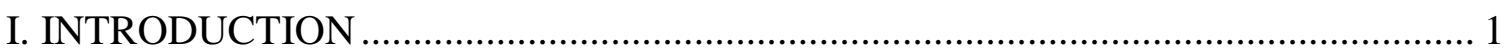

II. OBJECTIVE, SPECIFIC AIMS, AND HYPOTHESES ……………………............ 3

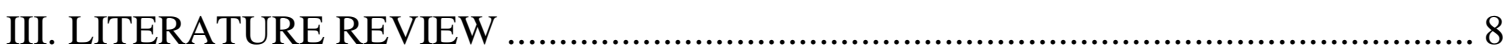

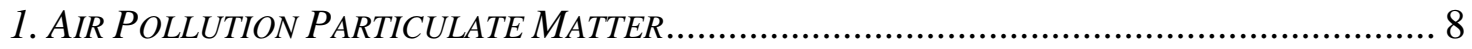

2. COAL FLY ASH PRODUCTION AND STORAGE ………………………………….... 10

2a. Experimental and Occupational Studies Evaluating Coal Ash Exposure............ 11

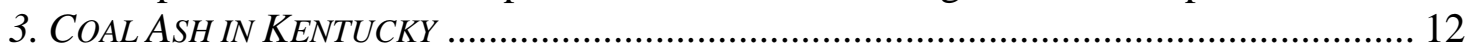

3a. Description of Cane Run Station.................................................................... 13

3b. Description of Mill Creek Station.................................................................. 14

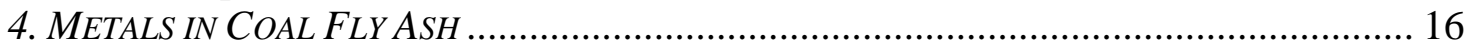

5. CHILDREN'S EXPOSURE TO METALS AND PARTICULATE MATTER AND BRAIN

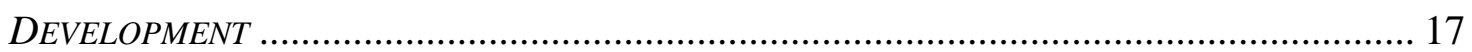

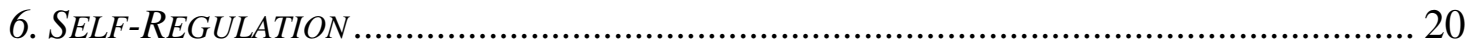

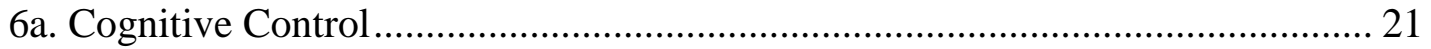

6b. Behavioral and Emotional Control ............................................................... 23

7. EPIDEMIOLOGIC STUDIES EVALUATING COGNITIVE CONTROL AND SELF-REGULATION IN

POPULATIONS EXPOSED TO PARTICULATE MATTER AND METALS..................................... 24

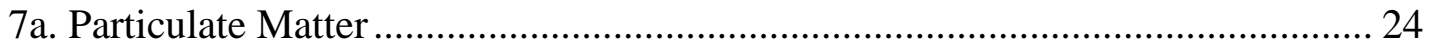

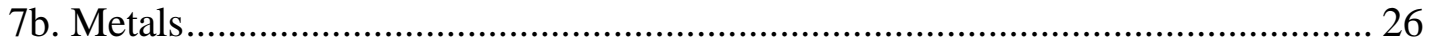

7c. Research Gaps in Exposure Assessment ......................................................... 29

7d. Research Gaps in Assessment of Neurobehavioral Outcomes ........................... 30

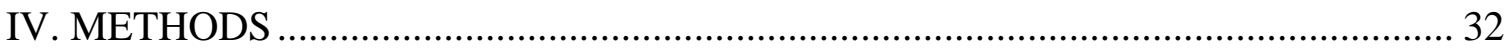

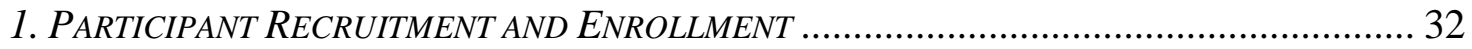

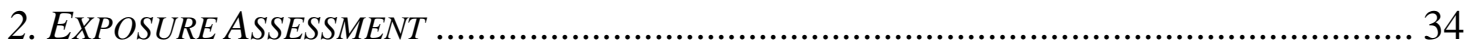

2a. Measures of Indirect Exposure to $\mathrm{PM}_{10}$ and Metals Inside the Home................. 34

2b. Measure of Direct Exposure to Metals ............................................................... 35

3. ASSESSMENT OF COGNITIVE CONTROL AND DEFICIENT EMOTIONAL SELF-REGULATION 36

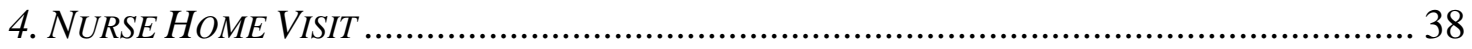

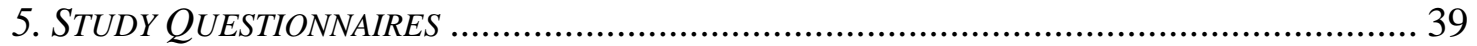

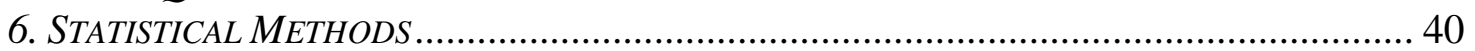

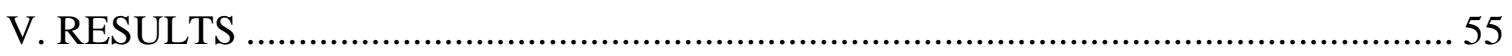




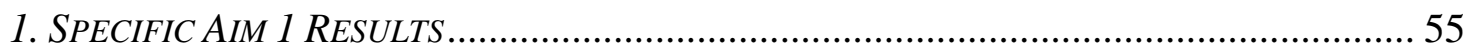

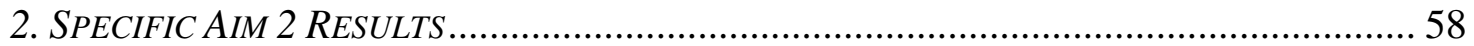

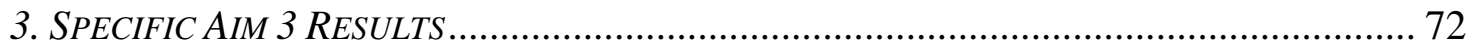

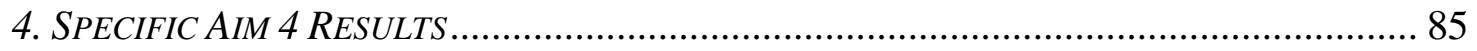

5. SPECIFIC AIM 5 RESULTS.................................................................................... 88

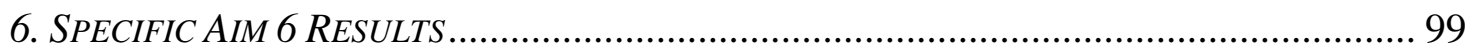

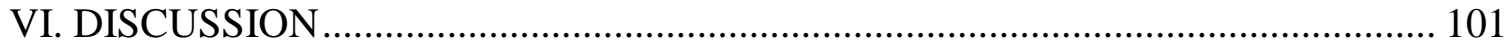

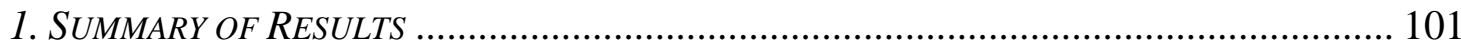

1a. Relationship Between Exposure to $\mathrm{PM}_{10}$, Fly Ash, Metals ............................ 101

1b. Relationship Between Exposure to Fly Ash, $\mathrm{PM}_{10}$, Metals and Cognitive Control

1c. Relationship Between Exposure to Fly Ash, PM 10 $_{10}$, Metals and DESR ............ 107

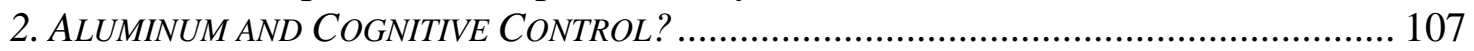

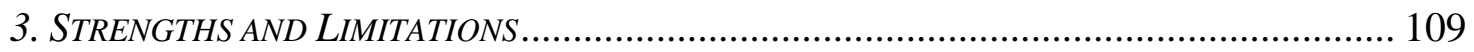

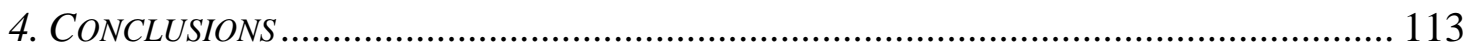

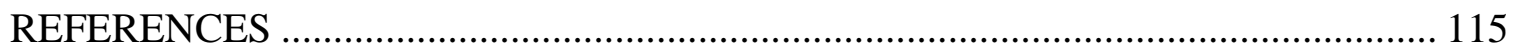

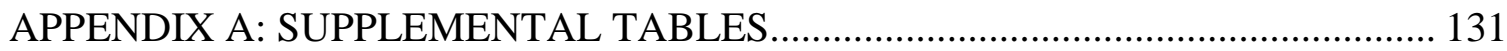

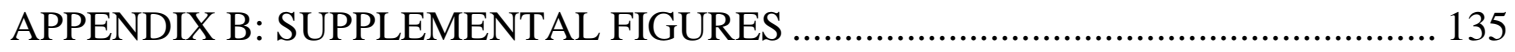

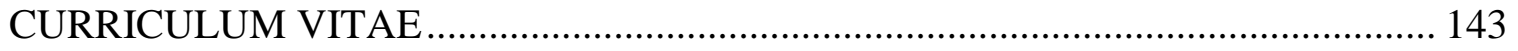




\section{LIST OF TABLES}

1. Table 1. Characteristics of Mill Creek Surface Impoundments...............................15

2. Table 2. Concentration of Metals in Fly Ash Particles ( $\mathrm{ppm}$ )..............................55

3. Table 3. $\mathrm{PM}_{10}$ Concentration $\left(\mu \mathrm{g} / \mathrm{m}^{3}\right)$ and Fly Ash Exposure...............................56

4. Table 4. Concentration of Metals in $\mathrm{PM}_{10}\left(\mu \mathrm{g} / \mathrm{m}^{3}\right)$ from Indoor Air Sample.........57

5. Table 5. Comparison between Natural-Log of Metal Concentrations $\left(\mu \mathrm{g} / \mathrm{m}^{3}\right)$

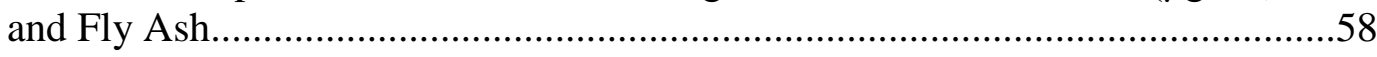

6. Table 6. Distance from Mill Creek Landfill to Homes $(\mathrm{km})$ and Fly Ash..............59

7. Table 7. Distance from Cane Run Landfill to Homes $(\mathrm{km})$ and Fly Ash...............59

8. Table 8. Relationship between Distance from Mill Creek $(\mathrm{km})$ and Natural-Log of Metal Concentration $\left(\mu \mathrm{g} / \mathrm{m}^{3}\right)$. 61

9. Table 9. Relationship between Distance from Cane Run (km) and Natural-Log of Metal Concentration $\left(\mu \mathrm{g} / \mathrm{m}^{3}\right)$.

10. Table 10. Comparison of Environmental Justice Index between Homes with

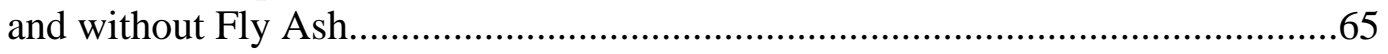

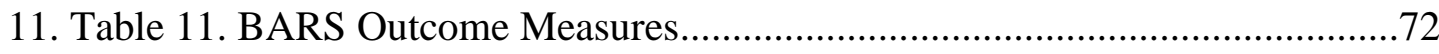

12. Table 12. CPT Errors and Potential Covariates........................................................74

13. Table 13. CPT Response Latency and Potential Covariates...................................76

14. Table 14. SAT Errors and Potential Covariates.......................................................77

15. Table 15. Fly Ash in Homes and Potential Covariates............................................78

16. Table 16. Linear Regression Coefficients for Fly Ash and BARS Outcomes........80

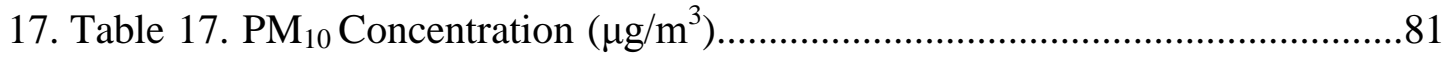


18. Table 18. $\mathrm{PM}_{10}$ Concentration $\left(\mu \mathrm{g} / \mathrm{m}^{3}\right)$ and Potential Covariates .82

19. Table 19. Linear Regression Coefficients for $\mathrm{PM}_{10}$ (Natural-Log transformed)

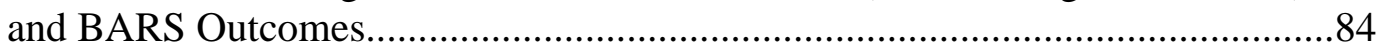

20. Table 20. DESR Score and Potential Covariates..................................................86

21. Table 21. Direction of Univariate Exposure-Response Relationship Suggested

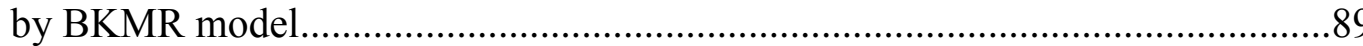

22. Table 22. Aluminum $\left(\mu \mathrm{g} / \mathrm{m}^{3}\right)$ and Potential Covariates.....................................91

23. Table 23. Linear Regression Coefficients for Aluminum $\left(\mu \mathrm{g} / \mathrm{m}^{3}\right)$ and BARS Outcomes. .94

24. Table 24. MES Score and Potential Covariates...................................................96

25. Table 25. Linear Regression Coefficients for MES and BARS Outcomes............98

26. Supplemental Table 1. Descriptive Statistics for EJ Index and Components......131

27. Supplemental Table 2. Univariate Analysis for Environmental Indicator and Metal Concentration in $\mathrm{PM}_{10}$ (Natural-Log transformed).

28. Supplemental Table 3. Univariate Analysis for Demographic Index and Metal Concentration in $\mathrm{PM}_{10}$ (Natural-Log transformed) 132

29. Supplemental Table 4. Adjusted Regression Coefficients for the Association between Metal Concentrations $\left(\mu \mathrm{g} / \mathrm{m}^{3}\right)$ and Neurobehavioral Outcomes. 133

30. Supplemental Table 5. Linear Regression Coefficients for Aluminum ( $\left.\mu \mathrm{g} / \mathrm{m}^{3}\right)$ and BARS Outcomes with Outlier Adjusted. 


\section{LIST OF FIGURES}

1. Figure 1. Comparison of Environmental Justice Index and Fly Ash Presence......64

2. Figure 2. Comparison of Environmental Justice Index and $\mathrm{PM}_{10}$ Concentration..67

3. Figure 3. Comparison of Environmental Justice Index and Aluminum Concentration.

4. Figure 4. Comparison of Environmental Justice Index and Titanium Concentration

5. Figure 5. Comparison of Environmental Justice Index and Silicon

Concentration.

6. Supplemental Figure 1. Comparison of Environmental Justice Index and Arsenic Concentration.

7. Supplemental Figure 2. Comparison of Environmental Justice Index and Chromium Concentration.

8. Supplemental Figure 3. Comparison of Environmental Justice Index and Manganese Concentration

9. Supplemental Figure 4. BKMR Univariate Analysis with CPT Errors and Metal Concentrations $\left(\mu \mathrm{g} / \mathrm{m}^{3}\right)$

10. Supplemental Figure 5. BKMR Univariate Analysis with CPT Response Latency and Metal Concentrations $\left(\mu \mathrm{g} / \mathrm{m}^{3}\right)$

11. Supplemental Figure 6. BKMR Univariate Analysis with SAT Errors and Metal Concentrations $\left(\mu \mathrm{g} / \mathrm{m}^{3}\right)$.

12. Supplemental Figure 7. BKMR Univariate Analysis with DESR Score and Metal Concentrations $\left(\mu \mathrm{g} / \mathrm{m}^{3}\right)$. 


\section{INTRODUCTION}

The production and storage of coal combustion residuals (CCR), primarily coal ash, is a growing environmental issue and public health concern in communities across the United States. According to the American Coal Ash Association (ACAA), in 2014 coal fired plants generated almost 130 million tons of CCR, which is being stored in open-air landfills and surface impoundments across 47 states $(1,2)$. Current coal ash storage methods expose surrounding communities to coal ash that has leached into the groundwater and escaped as fugitive dust emission in the air (3). The EPA estimates that 6 million people, including 1.5 million children, are exposed to coal ash (4).

Coal ash particles have been found to contain radioactive elements and varying concentrations of metals including arsenic, cadmium, lead, manganese, and mercury (57). Fly ash, the main component of coal ash, has the potential to be particularly hazardous because the spherical particles are predominately less than $10 \mu \mathrm{m}$ in diameter $\left(\mathrm{PM}_{10}\right)(8$, 9). Spencer and Drake (1987) reported that the concentration of metals in fly ash can be two times greater than the concentration found in coal (10). Thus, inhalable fly ash particles, potentially comprised of concentrated metals, are capable of penetrating deep into the lungs and bloodstream.

Children have an increased risk of exposure to fly ash. Children have higher rates of respiration relative to adults, increased hand-to-mouth behavior, and a tendency to play near the ground which increases exposure to ambient particulate matter $(11,12)$. In addition, some of the metals in fly ash are neurotoxins (13-16); and exposure to 
particulate matter and neurotoxic metals during rapid growth in the early stages of life can disrupt developmental processes and result in neurological dysfunction in the frontal cortex $(12,16,17)$. The frontal cortex, which is essential for cognitive control and selfregulation, is one of the last areas of the brain to develop and therefore susceptible to environmental exposures during childhood $(12,18)$.

This dissertation research will investigate the impact of exposure to particulate matter and metals in fly ash on cognitive control and emotional self-regulation in children living near two large coal-burning power plants in Kentucky.

Findings from a 2012-2014 pilot study in neighborhoods surrounding the coalburning power plants indicated that parents living in this area were very concerned about fugitive dust found in and around their homes and the potential effects on their children's health. Many participants mentioned problems with inattention, hyperactivity, and behavior as major concerns (19)(Sears and Zierold, unpublished).

Based on previous research on the neurotoxicity of metals and particulate matter, as well as findings from the pilot study, it is hypothesized that particulate matter and metal exposure will be associated with cognitive control problems and deficient emotional self-regulation in children. 


\section{OBJECTIVE, SPECIFIC AIMS, AND HYPOTHESES}

The overall objective of the study is to characterize exposure to fly ash, $\mathrm{PM}_{10}$, as well as metals, and investigate the relationship with cognitive control and self-regulation of children living near two coal-burning power plants in Louisville, Kentucky. In order to do this, the subsequent aims will explore the following three research questions:

1) How is exposure to fly ash related to $\mathrm{PM}_{10}$ and metal exposure, and is there a geospatial gradient of exposure in the area surrounding the power plants?

2) Are exposures to fly ash, $\mathrm{PM}_{10}$, and metals associated with children's cognitive control?

3) Are exposures to fly ash, $\mathrm{PM}_{10}$, and metals associated with children's emotional self-regulation?

These research questions will be explored through the subsequent six specific aims.

\section{Specific Aim 1:}

To characterize indoor fly ash, $\mathrm{PM}_{10}$ concentration, and metal exposure in homes throughout Louisville, Kentucky.

To explore this aim, the following will be done:

a) Characterize the elemental composition of fly ash particles.

b) Characterize the relationship between fly ash and $\mathrm{PM}_{10}$ concentrations in homes.

c) Characterize metal concentrations found in $\mathrm{PM}_{10}$ and the relationship with fly ash in homes. 
Hypothesis: Fly ash particles will contain common metals found in coal, such as aluminum and titanium, in addition to trace elements like lead, cadmium, and arsenic. Homes found to have fly ash will have greater concentrations of metals found in fly ash particles and overall greater concentrations of $\mathrm{PM}_{10}$ compared to homes with no evidence of fly ash.

\section{Specific Aim 2:}

To use Geographic Information Systems (GIS) to assess how proximity to coal-burning power plants and socio-demographic factors are related to $\mathrm{PM}_{10}$ concentration, metal concentrations, and fly ash exposure.

\section{To explore this aim, the following will be done:}

a) Assess the relationship between fly ash exposure, $\mathrm{PM}_{10}$ concentration, and proximity to coal-burning power plants.

b) Assess the relationship between metal concentrations in $\mathrm{PM}_{10}$ and proximity to coal-burning power plants.

c) Develop an Environmental Justice Index and assess its relationship with indoor $\mathrm{PM}_{10}$, fly ash and metal exposure.

Hypothesis: Homes closer to the coal-burning power plants in areas of lower socioeconomic levels will be more likely to have indoor fly ash and greater concentrations of $\mathrm{PM}_{10}$. In addition, homes closer to coal-burning power plants will have greater concentrations of metals that are most abundant in fly ash particles. 


\section{Specific Aim 3:}

To assess the relationship between $\mathrm{PM}_{10}$ concentration, fly ash exposure, and cognitive control.

To explore this aim, the following will be done:

a) Assess the relationship between indoor fly ash exposure and BARS Continuous Performance (CPT) and Selective Attention Test (SAT) measures.

b) Assess the relationship between indoor $\mathrm{PM}_{10}$ exposure and BARS CPT and SAT measures.

Hypothesis: Children exposed to greater concentrations of indoor $\mathrm{PM}_{10}$ and fly ash will have worse cognitive control, and thus, perform more poorly on the BARS Continuous Performance and Selective Attention Tests than children exposed to lower concentrations of $\mathrm{PM}_{10}$ and no fly ash found in air filters.

\section{Specific Aim 4:}

To assess the relationship between $\mathrm{PM}_{10}$ concentration, fly ash exposure, and deficient emotional self-regulation (DESR).

To explore this aim, the following will be done:

a) Assess the relationship between indoor fly ash exposure and DESR.

b) Assess the relationship between indoor $\mathrm{PM}_{10}$ concentration and DESR. 
Hypothesis: Children exposed to greater concentrations of indoor $\mathrm{PM}_{10}$ and fly ash will be more deficient in self-regulation than children exposed to lower concentrations of $\mathrm{PM}_{10}$ and found not to have fly ash indoors.

\section{Specific Aim 5:}

To assess the relationship between metal exposure and cognitive control using Bayesian Kernel Machine Regression (BKMR) and linear regression models.

To explore this aim, the following will be done:

a) Identify metals in $\mathrm{PM}_{10}$ that are potentially related to BARS CPT and SAT measures using BKMR.

b) Assess the relationship between concentrations of metals in indoor $\mathrm{PM}_{10}$ and BARS CPT and SAT measures.

c) Assess the relationship between metal mixtures in indoor $\mathrm{PM}_{10}$ and BARS CPT and SAT measures.

Hypothesis: Children living in homes with $\mathrm{PM}_{10}$ containing higher concentrations of metals will commit more errors and have more variable reaction times on the BARS CPT and SAT. Higher concentration of metals known to be neurotoxins, like manganese, arsenic, chromium, and cadmium, will have the greatest impact on cognitive control.

\section{Specific Aim 6:}

To assess the relationship between metal exposure and DESR using Bayesian Kernel Machine Regression (BKMR) and negative binomial regression. 
To explore this aim, the following will be done:

a) Identify metals in $\mathrm{PM}_{10}$ that are potentially related to DESR using BKMR.

b) Assess the relationship between concentrations of metals in indoor $\mathrm{PM}_{10}$ and DESR.

c) Assess the relationship between metal mixtures in indoor $\mathrm{PM}_{10}$ and DESR.

Hypothesis: Children exposed to greater concentrations of metals in $\mathrm{PM}_{10}$ will be more deficient in self-regulation than children exposed to lower concentrations of metals. Higher concentration of metals known to be neurotoxins, like manganese, arsenic, lead, and cadmium, will have the greatest impact on DESR because of the ability to disrupt cognitive and behavioral control. 


\section{LITERATURE REVIEW}

\section{Air Pollution Particulate Matter}

Any fumes or particles suspended in the ambient air are classified as particulate air pollution. Particulates can be produced through industrial or natural processes. There are two types of particulate matter (PM), primary and secondary. Primary PM is a direct result of an industrial or natural process. One example of a process producing primary particles is emissions from smoke stacks. After the primary PM is produced, additional chemical processes occur naturally as the particles travel through the atmosphere, yielding secondary PM $(20,21)$.

PM is classified by aerodynamic properties. According to the EPA, all particles with a diameter of $10 \mu \mathrm{m}$ or less $\left(\mathrm{PM}_{10}\right)$ are inhalable. $\mathrm{PM}_{10}$ is further broken down into subcategories: coarse particles with a diameter $10 \mu \mathrm{m}$ to $2.5 \mu \mathrm{m}$, fine particles with a diameter less than $2.5 \mu \mathrm{m}\left(\mathrm{PM}_{2.5}\right)$, and ultrafine particles with a diameter less than 0.1 $\mu \mathrm{m}$. Many coarse particles are generated naturally from the Earth's crust, through industrial processes, and motor vehicle traffic. Fine particles are mainly produced from

combustion processes. These particles are able to absorb chemicals from the surrounding environment and attach them to their surfaces often generating secondary particles of sulfates and nitrates (20-23). 
All $\mathrm{PM}_{10}$ could potentially cause damage to human tissue when inhaled; however, fine particles are able to travel deeper into alveolar-gas exchange regions of the lung and pass through blood vessels to potentially affect various organ systems $(20,22)$. One of the first studies to evaluate the health impacts of long-term exposure to PM was the Harvard Six-Cities Study, a prospective cohort study initiated in 1974. This landmark study demonstrated that the mortality rate of adults was strongly associated with levels of fine particles in air pollution, even when adjusting for covariates $(21,24)$. Since that publication, the body of evidence characterizing the negative health consequences of $\mathrm{PM}_{10}$ exposure in adult populations has blossomed. Exposure to $\mathrm{PM}_{10}$ has been linked to increased risk of lower respiratory symptoms, decreased lung function, and chronic cough (23), chronic obstructive pulmonary disease (25), lung cancer mortality (26), sleep problems (27), and cardiovascular problems (28) .

The EPA notes that children are among the population of people especially vulnerable to adverse health effects from inhalation of $\mathrm{PM}_{10}(22)$. Studies have found that due to children's increased respiration rate and smaller lung size, children inhale a larger dose of particulate matter compared to adults. An early study conducted in Utah by Pope III et. al. (1992) found reduced peak expiratory flow and worse respiratory symptoms in both symptomatic and asymptomatic children exposed to PM $(11,21)$. More recent studies with children have found that $\mathrm{PM}_{10}$ exposure is associated with decreased lung function (29), wheezing (30), asthma exacerbations (31), and sleep problems (32). Prenatal exposure to PM has also been linked to low birth weight and preterm birth (33, 34). 
Components of coal combustion by-products are classified as $\mathrm{PM}_{10}$ and therefore may be potentially hazardous when fugitive emissions escape into surrounding communities. Evidence characterizing the relationship between PM exposure and neuropsychological development will be discussed in depth in a subsequent chapter after an introduction to coal fly ash.

\section{Coal Fly Ash Production and Storage}

Coal combustion used to produce electricity creates by-products known as coal ash through a process called condense-volatilization. During this process, trace elements initially found in the coal are not released, but instead concentrated into small coal ash particles (35). The total concentration of trace elements including nickel, vanadium, aluminum, arsenic, beryllium, cadmium, copper, zinc, lead, mercury, selenium, radon, and molybdenum varies based on the amount originally contained in the coal $(8,9,21)$.

Fly ash, the most predominant form of coal ash (80\%), is composed of combustible material that is carried by a flue gas stream until it cools and condenses into smooth spherical particles (8). The unique shape of fly ash particles is due to a glass matrix composed mostly of silicon, aluminum, iron, cadmium, and oxygen. Studies have found that the exact size of fly ash particles varies, but the average range of respirable particles is between 1.98 and $5.64 \mu \mathrm{m}(9)$.

Sixty percent of the bottom ash and fly ash produced in the United States is stored in piles, landfills, or holding ponds (8). These open forms of storage allow the fly ash particles to be re-suspended into the ambient air, creating significant fugitive dust emissions. In the Clean Air Act, the EPA defines these emissions as those that cannot 
"reasonably pass through a stack, chimney, vent, or other functionally-equivalent opening" (36). Therefore, a fugitive emission can be any particulate matter, liquid, or gases emitted by a facility that is not confined (36). As these particles travel through the air, they can also attract new surface particles such as polycyclic aromatic hydrocarbons (PAHs) (9, 21).

\section{2a. Experimental and Occupational Studies Evaluating Coal Ash Exposure}

A recent experimental study conducted by Smith et al. (2012) in which rats were exposed through nasal inhalation only to coal ash particles suspended in air raise concerns about occupational exposure to coal ash (37). After exposure to an occupationally relevant dose of coal ash for four hours over a three-day period, the rats accrued $32 \mu \mathrm{g}$ of coal ash per rat, of which $25 \%$ was found in the head, $20 \%$ was in the tracheobronchial region and 50\% was found in the pulmonary tissue (37). Exposure to coal ash significantly increased neutrophils in blood, lung tissue, and bronchoalveolar lavage fluid. There was also a significant increase in macrophages found in the bronchoalveolar lavage fluid $(21,37)$.

Early occupational studies conducted in the 1950s-1970s in populations of power plant workers investigated the impact of coal ash exposure on respiratory health. No conclusive evidence suggesting exposure to fly ash caused pneumoconiosis was found, but some evidence supported a link between exposure to pulverized fly ash and decreased lung function (38).

An early occupational study by Bencko et al. (1980) focused more specifically on occupational exposure to metals in coal combustion power plants (39). This retrospective study compared causes of death for workers in power plants combusting coal with high 
levels of arsenic to power plants combusting coal with lower arsenic levels. Bencko et al. (1980) found that in facilities combusting coal with higher arsenic levels, deaths from malignant tumors were more frequent in younger workers and individuals that had been employed at the facility for a shorter period of time compared to similar workers in facilities combusting coal with lower arsenic levels (39). Further investigation by Bencko et al. (1988) found abnormal levels of various proteins in the blood of power plant workers exposed to higher levels of arsenic (40).

More recent occupational studies have found that exposure to coal ash may cause genotoxic effects and disrupt biological processes $(41,42)$. Zeneli et al. (2016) found workers exposed to fly ash had significantly higher levels of arsenic, mercury, zinc, and selenium in blood serum compared to healthy residents of a rural area (41). Workers also had lower levels of superoxide dismutase and glutathione peroxidase, which could hinder antioxidant defense mechanisms combating reactive oxygen species (41). The mixture of metals found in the small coal ash particles may play a primary role in the genotoxic and biological effects found in occupational studies $(41,42)$.

\section{Coal Ash in Kentucky}

Kentucky produces approximately 9 million tons of coal ash per year, which is the fifth highest in the nation. Of Kentucky’s 43 coal ash ponds, 21 are over 25 feet tall or contain over 500 acre-feet of coal ash (43). Current state/federal regulations exempt coal combustion waste from being a hazardous waste, but classify it as a special waste. This allows the coal ash to be used as ingredients in manufacturing products like cement, 
concrete, structural fill, and roofing granules. Coal ash that is not recycled in other products is stored in surface impoundments and landfills (43).

\section{3a. Description of Cane Run Station}

The Cane Run station occupies 510 acres in southwest Louisville, and is owned and operated by LG\&E and KU Energy, LLC, which is a PPL Corporation. The powergenerating station was opened in the fall of 1954, and operated three units, constructed 1962-1969, and five newer combustion turbines. In 2015, Cane Run started using the first natural gas-generating unit in the state, which will replace a majority of the 800 megawatts that had been produced by coal burning in the three old units. Approximately 1.5 million tons of high sulfur coal, primarily from western Kentucky and southern Indiana, were used each year when Cane Run was operating all of the coal-burning units (44-46).

The Cane Run Station has one landfill and one slurry pond for the storage of coal ash. In tandem with the switch to natural gas, LG\&E plans to cap and close both the slurry pond and landfill by April 2017 (46, 47). Between 2011 and 2013, LG\&E was fined multiple times for fugitive dust and odors escaping from storage units into nearby residential neighborhoods $(48,49)$.

The Cane Run surface impoundment is classified as a high-hazard dam due to its size and proximity to residential neighborhoods, but it is currently considered "inactive". The ash pond is undergoing the process of being dewatered, covered, and seeded. While in use, the surface impoundment stored fly ash, bottom ash, boiler slag, and flue gas desulfurization solids. Despite being in the closure process there is still the risk for fugitive dust from the ash pond due to wind erosion and dry conditions. In addition, there 
is risk for fugitive dust from mechanical and maintenance activities around the pond as well as on paved and unpaved roads around the site (50). The Cane Run landfill became inactive in October 2015 and thus does not have to report on activity related to dust control (50).

\section{$\underline{\text { 3b. Description of Mill Creek Station }}$}

The Mill Creek Generating station, LG\&E and KU Energy's largest coal-fired power plant, is located on 544 acres in southwest Louisville. The plant was completed in the early 1970s in response to rapid urbanization in Louisville. Currently, Mill Creek generates 1,472 megawatts of electricity by burning approximately 4.8 million tons of coal each year in four units built in the late 1970s-early 1980s. All four units have electrostatic precipitators and flue gas desulfurization to help reduce emissions (51).

Mill Creek has a surface impoundment and special waste landfill used to store coal ash. The landfill contains approximately 12.985 million cubic yards of CCR and has a maximum elevation of $598 \mathrm{ft}$. The surface impoundment consisting of five ponds has been classified as a high-hazard dam due to its size and proximity to residential areas (52). The volume and range in elevation of the CCR and water reported for the Ash Treatment Basin, Construction Runoff Pond, and Clearwell Pond are in Table 1 (53-56). 


\begin{tabular}{|c|c|c|c|c|c|}
\hline Pond & $\begin{array}{c}\text { CCR } \\
\text { Volume } \\
\text { (million } \\
\text { cubic yards) }\end{array}$ & $\begin{array}{c}\text { CCR } \\
\text { Elevation } \\
\text { (feet) }\end{array}$ & $\begin{array}{c}\text { Water } \\
\text { Volume } \\
\text { (million } \\
\text { cubic yards) }\end{array}$ & $\begin{array}{c}\text { Water } \\
\text { Elevation } \\
\text { (feet) }\end{array}$ & $\begin{array}{l}\text { Water } \\
\text { depth } \\
\text { (feet) }\end{array}$ \\
\hline $\begin{array}{c}\text { Ash } \\
\text { Treatment } \\
\text { Basin }\end{array}$ & 6.251 & 425 to 427 & 0.509 & 454.8 & 0 to 29 \\
\hline $\begin{array}{l}\text { Construction } \\
\text { Runoff Pond }\end{array}$ & 0.049 & 432 to 441 & 0.03 & 444.9 & 3.9 to 13 \\
\hline $\begin{array}{c}\text { Clearwell } \\
\text { Pond }\end{array}$ & 0.013 & 436 to 445 & 0.034 & 454.7 & 9.7 to 19 \\
\hline
\end{tabular}

Mill Creek has identified five potential sources of fugitive dust emissions: fly ash handling, landfill, unpaved roads, paved roads, and surface impoundments. Fly ash is first collected in bins via an enclosed blower system located on the southwest side of the plant. After collection, the fly ash is prepared for transportation using wet or dry methods. For fly ash being transported to the landfill, it is combined with water and transported in an open top truck. Dry fly ash being transported off-site is loaded into an enclosed truck using an air chute. Fugitive dust may be generated during this process while transfer of material and truck loading occurs. Fugitive dust may also be released from the landfill due to erosion by wind and mechanical activity around the landfill. Paved and unpaved roads can be sources of fugitive dust emission due to vehicle traffic on dry road conditions where CCR material has fallen out from transportation vehicles. Fugitive dust can escape from surface impoundments when they become dry and with windy conditions. In addition, activities related to the mechanical maintenance of the landfill can release fugitive dust (52). 
The EPA requires coal ash storage facilities to implement, document, and publish measures taken to reduce fugitive dust emissions and maintain integrity of storage units to prevent contamination of the environment (57).

\section{Metals in Coal Fly Ash}

Because fly ash contains harmful trace metals like manganese, arsenic, lead, and cadmium, the potential for environmental contamination due to leaching from storage units is of great concern $(8,58)$. The leachability of metals from fly ash particles can be affected by the $\mathrm{pH}$ of the surrounding environment and availability of metals in the fly ash particle matrix (35). Flues et al. (2013) found that the availability of metals in fly ash particles was different from the total concentration of metals and varied from that of coal. A majority of metals, including cadmium and aluminum, had higher availability in coal than coal ash; however, coal ash contained higher availability of arsenic and molybdenum. The most available metals (greater than $40 \%$ ) in the ash particles were arsenic, cadmium, and molybdenum. Arsenic in particular was found to have a higher availability in coal ash particles than coal $(21,35)$. Analysis of the metal composition of coal fly ash leachate found the most predominant constituents to be sodium, silicon, potassium, calcium, magnesium, iron, manganese, zinc, and sulphate. Experimental research evaluating the potential effects of the leachate suggests the mixture has the potential to be genotoxic to vegetation and humans (59).

The leaching of toxic metals was of particular concern after the failure of a storage dike-pond that occurred at the Tennessee Valley Authority Kingston Fossil plant in December of 2008. Over 4.1 million cubic meters of coal fly ash was released into the 
surrounding area covering 300 acres and contaminating the Emory River (60). Before dredging, Bednar et al. (2013) analyzed water samples from the Kingston site and found toxic metals including arsenic, selenium, barium, manganese, and molybdenum. Dredging reduced levels of these metals in the environment, but it did not completely remove them $(5,21)$.

Even when large spill events do not occur and leachate is not of concern, some evidence suggests residents of areas surrounding coal-burning power plants are exposed, prenatally and during childhood, to neurotoxins associated with developmental and cognitive delays in children $(61,62)$. Coal consumption was found to be a primary contributor to lead-containing PM, while PM levels were significantly related to the blood lead levels of Shanghai children living near coal-burning facilities (61). In addition, prenatal exposure to polycyclic aromatic hydrocarbons (PAH) in areas surrounding a coal-burning power plant in Tongliang, Chongquing, China was found to be associated with decreased motor and language development (62).

\section{Children's Exposure to Metals and Particulate Matter and Brain Development}

The effect of chronic fly ash inhalation on children has not been studied extensively; however, research evaluating how other PM of similar size enter and impact the body raises concerns about the ability of fly ash to act as a vehicle for neurotoxic metals to enter the bloodstream and brain.

In experimental models, some PM has been found to pass directly through the nasal olfactory pathway into the circulatory system and brain $(63,64)$. Other particulates that are inhaled are deposited in the lungs and leach genotoxic compounds that activate 
macrophages and epithelial cells in the alveolar. This immune response creates elevated levels of inflammatory markers, cytokines, and reactive oxygen species that induce fibrosis (38). After PM accumulates in the lungs, it may also penetrate into the capillaries, enter the bloodstream, and impact biological mechanisms beyond the respiratory system. Chronic exposure to PM has been found to cause chronic inflammation and elevated levels of cytokines in the body and brain increasing the risk for central nervous system (CNS) disease $(21,63,64)$.

Children's developing brains are at great risk for exposure to neurotoxic PM and metals circulating in the bloodstream because the blood-brain barrier is not fully formed. The brain is one of the last organs to fully develop and during periods of rapid growth the brain and central nervous system is especially susceptible to damage from neurotoxins, even at low levels that may not be harmful to adults $(18,65-67)$. Children are also at greater risk for experiencing neurotoxic effects compared to adults because their stilldeveloping metabolic pathways are less efficient at breaking down and excreting toxins (18). Both prenatal and postnatal exposure to PM, metals, and other neurotoxic industrial chemicals may disrupt normal brain development and maturation leading to functional impairments (65).

Calderon-Garciduenas (2008) conducted a case control study comparing the cognitive function and brain abnormalities of children and dogs from Mexico City, a city with PM and ozone levels well above the USA National Ambient Air Quality Standards, to a nearby city with low pollution levels. Participants had no health conditions or risk factors for mental or cognitive conditions and were all considered to be of a middle class socioeconomic level. When adjusting for age and gender, children living in Mexico City 
had significantly more cognitive deficits than those living in the less polluted city. In addition, more children and dogs in Mexico City had white matter lesions in the prefrontal cortex. Furthermore, there was an upregulation of inflammatory genes in the white matter of the dogs' frontal cortex. Ultrafine particles were also found in the dogs' frontal lobes demonstrating the ability of the particles to pass the blood-brain barrier and potentially contribute to the neuroinflammation in the frontal cortex (68). More recent pathology studies conducted by Calderon-Garciduenas (2016) of postmortem children found that PM specifically targeted the prefrontal cortex and nanoparticles accumulated in cells (69).

The impact of the particles on the surrounding tissue can vary based on the PM composition, and particles containing metals may be especially neurotoxic (69). High concentrations of metals commonly found in PM, including manganese, nickel, and chromium, were found in the frontal cortex and associated with neuroinflammation in children exposed to high levels of PM air pollution (69). In studies evaluating the neurophysiological effects of childhood lead exposure, observations have noted decreased brain volume, connectivity, and metabolic content capable of disrupting cognitive and behavioral functions (18). Children's exposure at school to PM with copper was also been found to be associated with reduced functional connectivity of the frontalbasal ganglia circuits (70).

Historically, recognition of chemicals as neurotoxins has resulted after severe, adverse outcomes were observed in workers exposed to high doses. These findings usually led to subsequent experimental and observational studies eventually recognizing that toxic effects occur, especially for children, at much lower levels of exposure than 
those observed in occupational studies. Epidemiologic studies evaluating the neuropsychological impact of exposures to industrial chemicals are crucial to identifying previously unrecognized neurotoxins because they are able to detect smaller, but still significant, impacts on neurodevelopment and cognitive functioning $(18,65)$.

Epidemiological studies have provided a majority of the scientific evidence of an association between exposure to various neurotoxins and problems with cognitive control and self-regulation. These studies will be discussed in a subsequent chapter after a brief introduction to the neuropsychological outcomes.

\section{Self-Regulation}

Margolis and colleagues (2016) conceptualize self-regulation as "successfully achieving control in cognitive, behavioral and emotional domains" (pg.852), which is a helpful construct for understanding and assessing self-regulation in environmental epidemiology studies (71). The prefrontal cortex is essential for generating processes related to attention, inhibition, behavior, and emotion, and therefore, critical for achieving self-regulation $(71,72),(73)$. A vast network of circuits allows the prefrontal cortex to control posterior cortical and subcortical areas, the basal ganglia, and cerebellum through top-down regulation (72).

If exposure to PM containing metals targets and disrupts development of circuits in the prefrontal cortex during adolescence, then it can be hypothesized that this disruption could cause functional deficits in regulation of cognitive control and executive function resulting in impaired self-regulation. Thus, assessment of cognitive control individually and in combination with control in behavioral and emotional domains, may 
serve as useful psychological measures of neurotoxic damage to functioning of the prefrontal cortex.

\section{6a. Cognitive Control}

Cognitive control is a set of processes involved with the execution and maintenance of desired behaviors while inhibiting inappropriate responses (71). These processes may be assessed by evaluating performance on neuropsychological tests of attention and inhibition.

Attention. Attention refers to the process of devoting resources to that which is essential to reaching goals, focusing on and switching between tasks, or coordinating responses to carry out plans. The prefrontal cortex (PFC) is critical to the ability to sustain attention during tasks that may be interpreted as "boring"-i.e. when there are long delays between presentations of stimuli (73). The PFC controls sustained attention through top-down regulation of a vast network of connections with areas of the brain receiving sensory inputs. Control of sensory input allows the PFC to suppress stimuli that are irrelevant and process stimuli essential to completing tasks (73). The PFC interacts through tightly regulated processes with subcortical areas, the caudate nucleus and basal ganglia to control experiences requiring attention. Thus, lesions to the frontal cortex, like those found by Calderon-Garciduenas (2008), could disrupt these connections resulting in increased distractibility and impaired concentration $(68,72)$.

Response Inhibition. Inhibition can refer to the process of suppressing or delaying inappropriate actions (74-76). The ability to inhibit the impulse to act, which involves both the decision to inhibit an action and the act of suppression, can be measured by assessing response inhibition (76). 
Evidence from neuropsychological studies using neuroimaging and transcranial magnetic stimulation indicate the initiation of the stopping process occurs when sensory information about a stop stimulus is received in areas of the right prefrontal cortex, which generates a signal to the basal ganglia $(77,78),(75,79)$. In addition, evidence suggests activation of the pre-supplementary motor area (pre-SMA) occurs to generate a physical response $(80,81)$. The exact role of the PFC, basal ganglia, and pre-SMA in generating an inhibitory response are unknown, however, deficiencies and abnormalities in size, shape, glucose metabolism, blood flow, and brain activity in these areas of the brain have been noted in disorders with inhibitory deficits (75).

It is generally understood that the ability to sustain attention and stop or suppress an action or thought is critical for self-regulation, and the inability to do so is a characteristic of multiple childhood disorders including ADHD and Conduct Disorder $(75,76)$.

Continuous Performance Test. Neurotoxic exposures can have profound impacts on neurobiological systems but may not result in behaviors that reach diagnostic criteria for any specific disorder. For this reason, it is important to assess subclinical impacts of exposure on neuropsychological measures of cognitive control, such as attention and response inhibition (18). One of the most commonly used tasks to assess brain abnormalities causing combined attention and response inhibition problems is the Continuous Performance Test (CPT) (82).

The CPT was first developed in 1956 to compare problems with sustained attention between brain-damaged and non-brain-damaged individuals (83). Since its invention, the CPT has been adapted for administration through various formats to 
different study populations. A computerized version of the CPT is contained in the battery of neuropsychological tests of the Behavioral Assessment and Research System (BARS) developed by Dr. Diane Rohlman (84). The BARS consists of a computer program and a 9BUTTON response keyboard that rests over the keyboard of a standard laptop computer. The software was developed to provide instructions to children for completing the tasks (84). Outcome measures, including errors of omission and variation in response time from the CPT, can be used to assess attention problems.

The CPT can also be used to assess response inhibition by measuring a subject's ability to inhibit an initial prepotent response to an event (82). According to Barkley (1997), a prepotent response is, " that response for which immediate reinforcement (positive or negative) is available or has been previously associated with that response" (74). Using this framework for understanding response inhibition, errors of commission and variation in response time are able to assess inhibition by evaluating a subject's failure or delay in performing a prepotent response (76). It can be difficult to separate problems with attention from response inhibition using the CPT since both can indiscriminately impact performance on tests of attention (85). Thus, performance on all CPT outcome measures will be used in this dissertation as a general assessment of attention processes related to cognitive control.

\section{6b. Behavioral and Emotional Control}

Behavioral control is a set of motor processes that inhibit the urge to carry out acts without consideration of the consequences (71). These processes can be evaluated by assessment of aggression. Emotional control refers to mental processes that amplify, regulate, and maintain a steady emotional state so an individual does not constantly 
experience one extreme emotion or oscillate rapidly between extreme emotions $(71,86)$.

To assess these processes, characteristics of children's mood, including anxiety and depression, can be evaluated (71). Various circuits of the PFC are believed to play a role in the regulation of emotions, and the ability to control emotions may be crucial for behavioral control (86).

Emotional, behavioral, and cognitive control can be assessed in combination by evaluating emotional self-regulation. Deficient emotional self-regulation (DESR) is characterized by deficits in regulation of physiological arousal to strong emotions (87, 88). In addition, problems with emotional self-regulation include difficulties redirecting attention from strong emotions and coordinating responses to emotional activation. Symptoms of DESR include impatience, inattention, as well as becoming easily angered, frustrated, or excited (88). DESR can be assessed using the Child Behavior ChecklistDESR (CBCL-DESR) score, which is a combined score of Anxiety/Depression, Aggression, and Attention scales that profile overall self-regulation $(87,88)$.

\section{Epidemiologic Studies Evaluating Cognitive Control and Self-Regulation in Populations Exposed to Particulate Matter and Metals}

\section{$\underline{\text { 7a. Particulate Matter }}$}

Indoor PM exposure can originate from various outdoor sources including trafficrelated pollution and industrialized outdoor environments. Many recent studies have evaluated the association between exposure to PM primarily related to vehicle traffic and problems with attention, hyperactivity, or cognitive control $(89,90)$. In the majority of these studies, personal exposure to PM has often been estimated using proximity to roadways and/or fixed outdoor monitors to identify areas of higher traffic-related 
pollution (89). In an early study conducted in China, children attending schools in areas with higher density of traffic were found to perform more poorly on the CPT (90). However, many more recent studies evaluating the relationship between cognitive control, ADHD, and exposure to PM from traffic-related air pollution, have led to largely inconclusive results $(89,91)$.

A study conducted by Saenen et al. (2016) used various methods to assess and compare recent versus chronic indoor and outdoor exposure to PM and neurobehavioral performance of school-aged children $(n=310)$ in grades three to six (92). $\mathrm{PM}_{10}$ levels in schools were measured using portable devices to estimate children's recent exposure in the classroom. Past and present data from fixed monitoring stations and spatial temporal interpolation methods were used in order to estimate outdoor exposure at children's homes. A battery of neurobehavioral tests, including the CPT and Stroop test to evaluate attention and cognitive control, was performed at two different time points. The recent exposure assessment was conducted up to two days before the neurobehavioral tests while the chronic exposure was defined as the annual mean exposure for the year prior to testing. Children's recent indoor exposure to $\mathrm{PM}_{10}$ and $\mathrm{PM}_{2.5}$ at school was significantly related to poorer performance on the Stroop test (change in msec of response time per interquartile range increment of $\mathrm{PM}$ exposure: $\mathrm{PM}_{10}: \beta=42.7 ; 95 \% \mathrm{CI}=(-0.40,85.8)$; $\left.\mathrm{PM}_{2.5} \beta=50.2 ; 95 \% \mathrm{CI}=(8.55,91.8)\right)$, but not significantly related to performance on the CPT. Recent estimated outdoor PM exposure was not significantly related to scores on the Stroop or CPT tests; however, chronic estimates of outdoor residential $\mathrm{PM}_{10}$ and $\mathrm{PM}_{2.5}$ exposure were significantly associated with response times on both the Stroop test and CPT (92). These inconsistent results may be due to differences in the effects of 
chronic versus recent PM exposure on attention; however, it may be just as likely that the difference in exposure measurement techniques results in some exposure misclassification.

Overall, there is a need for more research on the impact of indoor PM exposure and neurobehavioral outcomes, and the relationship with socioeconomic factors (89). Few studies have characterized indoor air exposure to PM and assessed the association with problems related to cognitive control and self-regulation.

\section{$\underline{\text { 7b. Metals }}$}

A majority of research has focused on neurobehavioral outcomes associated with exposure to specific metals commonly found in PM, such as lead, arsenic, cadmium, or manganese.

In a study of 1,001 children in South Korea, Hong et al. (2015) found blood-lead levels to be significantly associated with errors of commission on the CPT and variability in response time in unadjusted statistical models (93). When adjusting for demographic factors and IQ, children with higher blood-lead levels committed significantly more errors of commission $(\beta=13.86 ; 95 \% \mathrm{CI}=(1.82,25.89))$. However, this relationship was attenuated when the model was adjusted for a variable indicating the presence of other environmental pollutants found in the urine $(\beta=12.27 ; 95 \% \mathrm{CI}=(-0.08,24.62)$. No significant relationship between measures of inattention and blood-lead levels was observed (93).

In a study of 1,001 children, Bhang et al. (2013) evaluated the association between low and high blood-manganese levels and errors of commission and omission on the CPT. In both unadjusted and adjusted models, there was no significant relationship 
between low manganese levels and errors of commission. However, high levels of bloodmanganese was significantly associated with increased number of commission errors on a computerized CPT ((High Mn ( $>21.45$ compared to normal 8.14<Mn<21.453), unadjusted ( $\mathrm{B}=8.05 ; \mathrm{p}=0.05)$; adjusted for demographic factors, IQ, and cotinine levels $(B=8.02 ; p=0.048)(94)$. Bhang et al. (2013) did not find a significant relationship between blood-manganese levels and errors of omission or the CBCL externalizing behavior score, which includes the aggression subscale ( $\mathrm{p}=0.34)(94)$.

In contrast to lead and manganese, studies evaluating exposure to arsenic and cadmium have found inconsistent associations with neurobehavioral performance. Rodriguez-Barranco et al. (2015) evaluated the association between urine-arsenic levels and sustained attention using BARS in 261 children. No significant association between commission or omission errors and urine-arsenic levels was observed on the CPT or SAT. However, children with greater levels of arsenic were found to have significantly longer response times on the BARS SAT (95). In a separate study of 259 children, Rodriguez-Barranco (2014) found no association between cadmium levels in urine or hair and commission errors, omission errors, or response time on the BARS CPT or SAT (96).

A review by Sanders (2015) found only three studies have evaluated the association between mixtures of metals and behavioral outcomes related to attention, response inhibition, or behavioral control outcomes (97). In these three studies, biomarkers of exposure were measured in a variety of ways, including blood, hair, or urine. All of the three studies, Boucher (2012), Ciesielski (2012), and Khan (2011), assessed binary combinations of lead with mercury, cadmium, or manganese; none assessed the effects of more than two metals (97-100). 
Boucher (2012) evaluated pre- and postnatal exposure to lead, PCBs, and mercury in the umbilical cord and blood of children and the association with event-related potentials recorded during tasks used to assess response inhibition, as well as behavioral outcome measures. Interactions between lead with PCBs or mercury were observed when evaluating the association between prenatal exposure and response inhibition. A significant association between commission errors on a go/no-go task and current bloodlead levels was observed. Blood-lead level was found to significantly impact brain activity, and this relationship was significantly affected by methlymercury exposure. Children with lower levels of methylmercury exposure had increased effects of bloodlead levels on brain activity (100).

Ciesielski (2012) used NHANES data to evaluate the association between parents' response to the question, "Has a representative from a school or health professional ever told you that the child had attention deficit disorder?" and urinary cadmium levels. The effects of a cadmium-lead interaction on the relationship between cadmium and parentreported ADHD was also assessed. There was no significant association between parentreported ADHD and urinary cadmium level, and the interaction between blood-lead and cadmium was not significant (98).

Khan (2011) evaluated the relationship between blood-arsenic and manganese, urinary arsenic, as well as arsenic and manganese levels in well water in a sample of 201 children in Bangladesh. While levels of arsenic in water, urine, and blood were strongly correlated, levels of manganese in water and blood were not. Externalizing behaviors were assessed using the Child Behavior Checklist-Teacher Report Form. There was no significant association between arsenic levels in water or blood and externalizing 
behaviors. There was, however, a significant association between manganese levels in water and externalizing behaviors in a model adjusted for demographics, maternal education, $\mathrm{BMI}$, arm circumference, and arsenic $(\mathrm{B}=2.59 ; 95 \% \mathrm{CI}=(0.81,4.37))$. There was no significant interaction between arsenic and manganese water levels (99).

These investigations provide some inconclusive evidence and illuminate gaps in the scientific literature assessing the association between exposure to PM, metals, and problems with cognitive and behavioral control in children.

\section{7c. Research Gaps in Exposure Assessment}

Characterizing indoor exposure to PM and metals is important, especially for children living in urban and industrialized areas. Recent studies have relied heavily on methodological designs that utilize model estimations of personal PM exposure from fixed outdoor monitoring stations, or use of outdoor ambient air pollution data to identify exposed and comparison populations $(89,91,92)$. Both of these methods could result in exposure misclassification when attempting to estimate individuals' indoor exposure.

In addition, many of the recent studies evaluating the association between exposure to metals and attention or behavioral problems in children consider the primary route of exposure to be through ingestion $(16,99)$. While the primary source of exposure to cadmium, manganese, lead, and arsenic during childhood is through ingestion, these metals and more also bind to PM in ambient air pollution and inhalation of these particles poses a public health threat (97). In addition, children living near fly ash storage may be exposed to an even greater concentration of particles naturally containing these metals. Exposure to metals via inhalation could present different levels of neuropsychological 
risk than exposure via ingestion due to the ability of PM containing metals to potentially pass from the lungs and airway directly into the circulatory system $(63,64)$.

Few studies have looked at the neurobehavioral impact of exposures to mixtures of metals (97). Children are often exposed to mixtures of metals simultaneously; thus, considering the neuropsychological effects of only one metal at a time may not accurately reflect real-life exposure, especially in urban and industrialized areas. It is important to evaluate the potential interactions or synergistic effects of metal mixtures and non-linear relationships between exposures and neuropsychological effects $(97,101)$.

Utilizing indoor air sampling techniques and more advanced statistical methods could help clarify why some studies only assessing exposure to one metal at a time can lead to inconclusive results in different populations.

\section{7d. Research Gaps in Assessment of Neurobehavioral Outcomes}

In addition to the limitations related to exposure estimates, use of interviews about behaviors instead of neurobehavioral tests to assess cognitive performance may also lead to inadequate assessment of behavior and cognitive control. Few studies have evaluated the association of neurotoxic exposures with both neurobehavioral measures of cognitive control and parent-reported behavior measures. Using only parent-reported instruments that align with diagnostic criteria may result in an under-detection of significant neurobiological impacts from neurotoxic exposures. Assessing both neuropsychological measures and behaviors may allow for the better detection of subphenotypes or endophenotypes missed when only assessing diagnostic categories (18). Using objective measures like neuropsychological assessment tests may also be less subjective than parent- or teacher-reported behavior. 
The construct of self-regulation used by Margolis (2016) to evaluate the relationship between an environmental exposure and neuropsychological outcomes is novel in epidemiological studies (71). The CBCL-DESR score provides an adequate overall assessment of cognitive, emotional, and behavioral control. Children with DESR and ADHD may experience worse long-term implications, more dysfunction, and more psychiatric co-morbidity (88). Therefore, it may be especially important to assess DESR in populations, like those living near coal ash in southwest Louisville, Kentucky, with high self-reported prevalence of ADHD (Sears and Zierold, unpublished). 


\section{METHODS}

The ongoing community-based study, funded by the National Institute of Environmental Health Sciences (Grant number: R01ES024757), is conducted by a multidisciplinary team including an environmental epidemiologist, health geographer, nurse, and psychologist. Since 2011, the principal investigator of the study, Dr. Kristina Zierold, has had a working relationship with leaders in the community and experienced success with recruiting participants for mixed-method studies. Since 2012, I have voluntarily participated in community meetings and recruitment of study participants. I have experience working with the community leaders and conducting a cross-sectional health survey in the community. Institutional Review Board approval for this study was obtained from the University of Louisville IRB NUMBER: 14.1069.

\section{Participant Recruitment and Enrollment}

For the five-year study, 300 children living within a 10-mile radius from a centroid between the two coal ash storage facilities will be recruited. For this analysis, 78 participants were recruited between September 2015 and December 2016. Utilizing GIS methods, buffers at two-mile intervals surrounding the centroid have been divided into four wedge-shape quadrants resulting in a total of 20 different sampling units at varying distances and directions from the coal ash storage locations. In each sampling unit, parents and children were recruited by working with community leaders to distribute fliers door-to-door. In addition, fliers and an introductory letter were mailed to residents 
in the recruitment area. Addresses of families with children that may be eligible for the study were obtained from LeadsPlease.com. Families were sent a letter explaining the study, as well as the same fliers that were distributed door-to-door. Recruitment occurred in all quadrants during all four seasons to assess the differences in exposure by season.

Parents of children (ages six to 14 years) interested in participating in the study were instructed to call the principal investigator or study cell phone. When the parent called, a brief overview of the study was given and an initial appointment was scheduled for the research study team to meet with the participant in their home. During the initial meeting, research team personnel explained the study in detail and if the parent and child met eligibility criteria, consent and assent were obtained. At the initial meeting the indoor air sampler was set up and lift samples were collected. The parent was also provided a folder with instructions for cutting nails, the Home Cleaning Questionnaire, the Environmental Health History Questionnaire, as well as the Child Behavior Checklist. In addition, an appointment was made for the psychologist to come into the home during the week while the air sample was being collected. After the indoor air sampling and neuropsychological testing, a nurse collected biometric measures, conducted a pediatric health history interview, and conducted a home environment assessment at a follow-up visit.

Participants that were recruited and completed all phases of the study between September 2015-Decemeber 2016 are included in this dissertation. 


\section{Exposure Assessment}

\section{2a. Measures of Indirect Exposure to PM 10 and Metals Inside the Home}

Indoor Air Sampling. One continuous sample of $\mathrm{PM}_{10}$ of the indoor air was collected for approximately a week. Personal Modular Impactors (PMI) (SKC, Inc) with polycarbonate membrane filters were placed in the main living area of each child's home, 1-1.5 meters above the ground, to simulate the breathing zone of the child. No smoking was allowed in the home during the sampling period.

After the sample period, the impactors were collected and gravimetric analysis was conducted to estimate the mass of $\mathrm{PM}_{10}$ collected on the polycarbonate membrane filter. The membrane filter was placed in a sealed holder and stored until it was shipped to Elemental Analysis, Inc. in Lexington, Kentucky for further analysis. The presence and elemental distribution of metals was determined in the air sample using Proton Induced X-Ray Emissions (PIXE).

In PIXE analysis, a proton beam is used to excite inner shell electrons in atoms of elements. Once the electrons are excited, they are expelled, leaving the shell vacant so that electrons from outer shells drop into the inner shells. Since the outer shells have a higher energy state, an x-ray is released when the electrons drop to the inner shell. The energy of x-rays released is proportional to the mass of the element and thus measuring the energy released can identify the elemental composition (102).

After PIXE, Optical Microscopy was used to visualize and capture the morphology of particles on the filter. If the presence of smooth spherical particles was noted on the filters, then the image of the particles was sent to the principal investigator. If the principal investigator determined that the particles could be coal ash based on the size and uniquely smooth spherical shape, then the sample underwent Scanning Electron 
Microscopy with an Energy Dispersive X-ray Analyzer (SEM-EDX) to further determine presence/absence of fly ash and the elemental composition of the fly ash particles. SEM uses a focused electron beam to construct a topographical image of particles' surfaces. Next, EDX is used to characterize the elemental composition of the particles. EDX identifies the composition of the particles based on the x-rays generated when hit with the electron beam. SEM-EDX can produce higher magnification at better resolutions than other microscopes, allowing for a more detailed visualization of the particle surface and its composition.

In addition to the PMI that was placed in participants' homes for a week, a continuous particle monitor called an EPAM was placed in homes in order to obtain continuous measurements of particles. The EPAM took a sample every minute.

Lift Sampling. The presence and elemental concentrations of metals and fly ash on surfaces in the child's bedroom were also measured using Stick-To-It Lift Tape (SKC, Inc). Three standard locations, a bedframe, window, and dresser, were identified in each participant's room. Dust particles that contact the adhesive area stick to the lift tape and the elemental profile of fly ash in the dust sample was analyzed using SEM-EDX.

\section{2b. Measure of Direct Exposure to Metals}

Toenail and Fingernail Samples. Toenails and fingernails from children were used to assess metal body burden. The slow growth-rate of nails allows samples to be a useful non-invasive measure of long-term exposure to metals commonly found in coal ash. Parents were asked to begin collecting their child's toenails and fingernails during the initial phone conversation, prior to the initial visit. During the initial visit, any nails the child had already cut were collected, in addition to any nails the child could collect 
during the visit. For each participant, approximately $150 \mathrm{mg}$ of nails were collected over the course of several months.

Once the total amount of nails was collected they were cleaned using one acetone wash and two deionized water washes. The nails were then dried and weighed a second time before being placed in a container to take to Elemental Analysis, Inc. for further analysis. At Elemental Analysis, Inc., individual's nails were cryogenically frozen, ground, and bound with a natural binding agent into a 3/8-inch pellet. The pellet was then analyzed by PIXE to determine the amount and type of elements in the sample.

\section{Assessment of Cognitive Control and Deficient Emotional Self-Regulation}

Behavioral Assessment Research System (BARS). Cognitive control was assessed using the BARS Continuous Performance Test (CPT) and Selective Attention Test (SAT). These computerized tests have been developed to evaluate neurobehavioral performance in children and adults exposed to environmental toxins (84). The system involves a 9BUTTON keyboard that is set over the keyboard of the laptop. All spoken instructions and reinforcements are standardized throughout the program.

CPT. The CPT was the first test administered in the battery of BARS tests. During the exam, a series of stimuli were presented and the child was instructed to only press a key when a single target appears. The test was set at a $20 \%$ target circle and lasted approximately eight minutes. While the test was being conducted, the computer system was recording the reaction time, errors of omission (failure to respond to target), and errors of commission (responding to non-target). Output from the CPT also included a d- 
prime variable, which is a measure of the participant's ability to detect targets from nontargets. The reliability for the correct latency measure was found to be 0.79 (103).

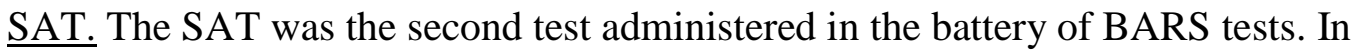
the SAT, two boxes appear on the screen, one on the left and one on the right. The child is asked to press one button with their left hand when a dot appears in the box on the left and press a button with their right hand when a dot appears in a box on the right side of the screen. When the dot appears outside of both boxes, the child is instructed to not press any button. The test was set at $80 \%$ target circle and lasted approximately one minute. The computer system records average response latency, number of correct and wrong responses both during instructional periods and during the test.

A child psychologist administered the BARS in the evening hours during weekdays at the child's home. For each assessment, another member of the research team was also present to record observations of the child during testing. Along with the CPT and SAT, the child also completed the BARS Symbol-Digit, Finger Tapping, Digit Span, and Matching-to-Sample Tests. Prior to the administration of the BARS, the child completed the Purdue Pegboard test to assess dexterity, the Beery-Buktenica Developmental Test of Visual-Motor Integration, and the Object Memory Test. The assessments were generally completed at a table with the child comfortably seated.

Child Behavior Checklist (CBCL). The CBCL is a parent-report instrument to assess cognitive, emotional, and social problems. The CBCL is left with the parents or guardians for approximately one week and returned upon completion. Based on parents' responses to the 124-item questionnaire, t-scores are calculated using standardized norms for age and gender. If a participant scores in the clinical or borderline range on any of the 
CBCL subscales, then the child psychologist followed-up with the parents or guardians of the participant by conducting a Structured Clinical Interview for Diagnosis of DSM Disorders (SCID).

\section{Nurse Home Visit}

After air sampling was completed a nurse scheduled an appointment with the parents to visit the home. The nurse's visit took approximately one hour to complete. While at the home, the nurse measured the participant's height, weight, oxygen levels, and blood pressure, as well as completed the Child Health History Interview and Environmental Home Assessment.

Child Health History Interview. The Child Health History Interview form included demographic information about the participant and parents, current and past diseases and medical problems, details about past hospitalizations, current medicationsprescription and over-the-counter, parents' perception of health and behavior, immunizations, details of complications and use of substances during pregnancy and delivery, breastfeeding, early childhood development, the child's current participation in school activities and behavior at school and at home, and a brief health history for immediate family living in the home.

\section{Environmental Home Assessment. The Environmental Home Assessment}

collected information about the characteristics of the home: type of house, age of home, type of foundation, number of floors, sources of heating and cooling, the presence of indoor pollutants (presence of molds, lead-based paints, asbestos, radon, environmental smoke), the nurse's assessment of the cleanliness of the home environment, details of the 
participants sleep environment (number of beds in room, allergens, pillows, bedding, flooring, etc), and home safety (renovations, lighting, poison control, fire hazards, appropriate storage of chemicals and hot liquids, window guards, etc.).

\section{Study Questionnaires}

Parents or guardians of the participants completed the Environmental Health History and Home Cleaning Questionnaires. The questionnaires were left with the parents or guardians for approximately one week and returned upon completion.

Environmental Health History. The Environmental Health History Questionnaire contained 108 questions with sections about: characteristics of the home - 23 questions; children's exposure behaviors - 10 questions; cleaning methods and supplies - 10 questions; use of pesticides, insecticides, herbicides - six questions; food and water sources - six questions; hobbies done in the home - six questions; parents' occupations 11 questions; surrounding hazardous sites - five questions; and pregnancy - 28 questions. The questions had multiple-choice fill-in bubbles with either Yes/No or Likert Scale (Never, Rarely, Sometimes, Frequently, As much as possible) response options. REMARK OMR software was used to scan the data and convert it into Excel files. Home Cleaning Questionnaire. The Home Cleaning Questionnaire contained nine multiple choice questions with fill-in bubbles. The questions were about frequency and methods used to clean the home in general, and the child's bedroom specifically. REMARK OMR software was used to scan the data and convert into Excel files. 


\section{Statistical Methods}

The overall objective of this study was to investigate exposure to fly ash, $\mathrm{PM}_{10}$, as well as metals, and assess the relationship with cognitive control and DESR in children living near coal-burning power plants. Overall, data from 78 participants enrolled in the study between September 2015 and December 2016 were considered for inclusion in this analysis. Three participants were excluded from the study because they did not complete all phases of the study. One additional participant was excluded from the analysis for Specific Aim 1 and 2 because the participant lived far beyond the study area therefore calculation of the EJ Index and assessment of the impact on distance from the power plants on exposure was not appropriate. Thus, the sample size for Aim 1 and Aim 2 is $n=$ 74 participants and the sample size for Aim 3 through Aim 6 is $n=75$ participants. Specific Aim 1: Characterize indoor fly ash, $P M_{10}$ concentration, and metal exposure in homes throughout Louisville, Kentucky.

Subaim (1a): The presence of fly ash indoors was determined from the indoor air samples. If any fly ash particles were found on the air filter, then the participant's home was classified as "Fly Ash Present". If no fly ash was found on the air filter then the participant's home was classified as "No Fly Ash Present". SEM-EDX analysis of fly ash particles was used to identify and quantify concentrations of metals and other elements most commonly found in fly ash particles. Descriptive statistics were calculated to characterize the composition of elements above the limit of detection (LOD) in fly ash particles.

Subaim (1b): $\mathrm{PM}_{10}$ concentration from air sampling conducted over one week was determined by gravimetric analysis. Descriptive statistics and Wilcoxon Rank-Sum p- 
values were calculated to compare $\mathrm{PM}_{10}$ concentrations in homes with fly ash present to homes with no fly ash.

Subaim (1c): Metal concentrations in $\mathrm{PM}_{10}$ were identified and quantified using PIXE analysis of the air filters. The concentrations of neurotoxic metals commonly found in fly ash (aluminum, arsenic, chromium, manganese, silicon, and titanium) were assessed in the overall $\mathrm{PM}_{10}$ sample from the air filters. For Specific Aim 1, the LOD was assigned for values below the LOD as a preliminary technique for assessing the distribution of exposure and summary statistics. Assigning the maximum possible concentration for values below the LOD biases the sample mean high, but provides a starting point for characterizing potential relationships between exposure and geography. The concentrations of these metals in $\mathrm{PM}_{10}$ were compared for homes with fly ash to homes without fly ash. Descriptive statistics and Wilcoxon Rank-Sum p-values were calculated to compare metal concentrations in homes with fly ash to homes without fly ash.

Specific Aim 2: Use Geographical Information Systems (GIS) to assess how proximity to coal-burning power plants and socio-demographic factors are related to $P M_{10}$ concentration, metal concentration, and fly ash exposure.

Subaim (2a): The geographical information system (GIS), ArcGIS version 10.2.2 (Esri), was used for exploratory data analysis. The geographer grant co-investigator approximated the latitude and longitude of the centroid of the coal ash landfills at Cane Run and Mill Creek Stations. Homes of participants were geocoded using address locators and 2015 U.S. Census Bureau Topologically Integrated Geographic Encoding and Referencing (TIGER) Line shapefiles for Jefferson and Bullitt County, Kentucky. 
The distance from the centroid of each coal ash landfill to individual homes was calculated using the "Near" tool in the ArcToolbox. Distances obtained in ArcGIS were exported and analyzed in SAS 9.4. The Wilcoxon Rank-Sum test was used to compare the median distance from each landfill to homes with fly ash and the median distance to homes with no fly ash.

$\mathrm{PM}_{10}$ concentrations were transformed using the natural logarithm and the relationship with proximity of homes to the landfills was assessed using simple linear regression. The natural logarithm was selected as the appropriate transformation by assessing the distribution and fit of linear regression models when $\mathrm{PM}_{10}$ concentrations were transformed using common transformations including common logarithm, square root, and inverse square root.

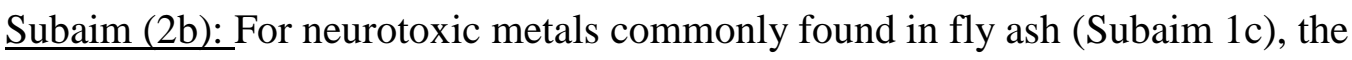
relationship between the concentration of metals in $\mathrm{PM}_{10}$ and proximity to the coalburning power plants $(\mathrm{km})$ was assessed. Metal concentrations were transformed using the natural logarithm. To assess the relationship between metal concentrations and proximity of the home to the coal ash landfills, simple linear regression was used. The Spearman Correlation Coefficients and p-values were also reported.

Subaim (2c): In ArcGIS, an environmental justice (EJ) index was calculated using a modified version of the formula established for the EPA's EJSCREEN environmental justice screening and mapping tool. This EJ index assesses environmental vulnerability by considering both environmental and socio-demographic data. The modified EJ Index formula used in this analysis is: 


\section{Equation 1. EJ Index}

EJ Index $=($ The Environmental Indicator $) \times($ Demographic Index $)$

The current version of EJSCREEN does not consider coal ash storage as one of the pre-selected environmental indicators. Thus, the process used in EJSCREEN to assess Proximity to Hazardous Waste Treatment, Storage, and Disposal Facilities was adapted to develop an Environmental Indicator for the calculation of the EJ index for Proximity to Coal Ash Storage. This Environmental Indicator was developed as follows:

\section{Equation 2. Environmental Indicator}

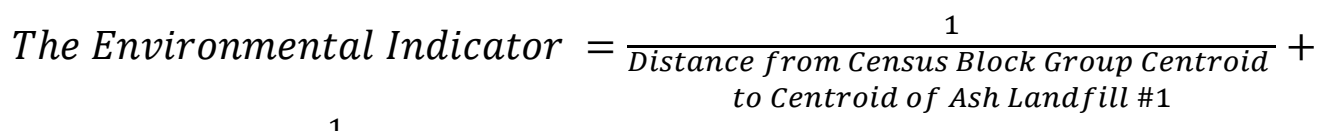
$\frac{1}{\text { Distance from Census Block Group Centroid }}$ to Centroid of Ash Landfill \#2

A point centroid for each Census block group polygon in and around the study area was determined. Using the "Near" tool in ArcGIS, the distance from each landfill centroid to every census block group centroid was calculated for all block groups. The distance was converted from feet to kilometers and the inverse of each distance was calculated in ArcGIS. For each census block group, the inverse distance from the two landfill centroids was summed to estimate the Environmental Indicator portion of the EJ Index.

In EJSCREEN and this analysis, the Demographic Index is based on the average of percent low-income and percent minority in the Census block group, which acts as a substitute measure for susceptibility to environmental exposures. Percent low-income is defined as the percent of people in the block group living in households with incomes 
less than or equal to twice the federal poverty level. Information about the total number of people living in each Census block group and the total number of people living below two times the federal poverty line was obtained from the 2014 U.S. Census Bureau American Community Survey (ACS) file C17002: Ratio of Income to Poverty Level in Past 12 Months.

Percent minority is defined as the percent of people in a block group that list their race as other than white alone. Information about the total population of a block group and the number of individuals that identified as a race other than white alone was obtained from the 2014 ACS file B02001: Race.

The ACS files were then imported into ArcGIS and joined to the TIGER/Line Jefferson and Bullitt shapefiles using the FIPS code. The Demographic Index was calculated using the Field Calculator and Equation 2. For each Census block group, the Demographic Index and Environmental Indicator were multiplied to obtain the EJ Index. A choropleth map was created with EJ Index quartiles to identify the more vulnerable block groups in the study area. The relationship between the EJ Index and fly ash presence, $\mathrm{PM}_{10}$ concentration, as well as metal exposure (From subaim 1c) in the homes was assessed visually by mapping the exposure to fly ash (Yes/No) or $\mathrm{PM}_{10}$ and Metal concentration as a point over the choropleth map of the EJ Index quartiles.

The relationship between the EJ Index and 1) fly ash presence in the home, 2) $\mathrm{PM}_{10}$ exposure, and 3) metal exposure was also assessed statistically. The EJ Index variable was exported from ArcGIS and analyzed using SAS 9.4. The median EJ Index score of homes with fly ash present was compared to homes with no fly ash present using the Wilcoxon Rank-Sum Test. The relationship of $\mathrm{PM}_{10}$ and metal concentrations with 
the overall EJ Index was assessed using simple linear regression. Two-sided p-values are reported and significance was determined at $\mathrm{p}<0.05$.

Specific Aim 3: Assess the relationship between PM 10 concentration, fly ash exposure, and cognitive control.

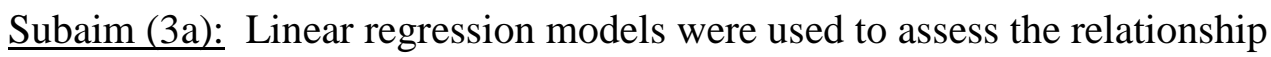
between the BARS outcome measures and fly ash exposure. The distributions of the BARS CPT and SAT omission errors and commission errors were assessed. For the BARS CPT, the number of omission and commission errors were combined to form a total CPT error variable. For the BARS SAT, omission and commission errors were also combined to form a total SAT error variable. In addition to the number of errors on the CPT and SAT, cognitive control was assessed by the response latency (msec) from the CPT.

Box-Cox power transformations were used to identify common transformations for the CPT errors, SAT errors, and response latency dependent variables. In linear regression models, CPT and SAT errors were transformed using the square root and response latency was transformed using the natural logarithm. Beta coefficients, 95\% confidence intervals, and p-values from three linear regression models with fly ash exposure (yes/no), age, and gender as independent variables, and 1) CPT errors, 2) SAT errors, or 3) response latency as the dependent variable, are reported.

Additional potential covariates considered for inclusion in multivariate linear regression models were child's body mass index (BMI), presence of lead paint in home, prenatal tobacco exposure, environmental tobacco smoke exposure, presence of pets indoors, and income level. 
BMI. BMI was calculated by dividing the child's weight $(\mathrm{kg})$ by their height $(\mathrm{cm})$ squared. The BMI was categorized into three groups: underweight (BMI $<18)$, normal weight $(\mathrm{BMI}=18-25)$, and overweight $(\mathrm{BMI}>25)$.

Lead Paint. The presence of lead paint in the home was assessed using the question, "Do you have lead paint in your home?" with response options, "no, yes, not sure" on the Environmental Health History Questionnaire. If the participant's parent indicated that their home had lead paint by responding "yes", then the participant was classified as having lead paint in their home; if the parent responded "no", then the participant was classified as not having lead paint. If participants' parents responded "not sure", then the year the home was built was considered to infer if lead paint might be present in the home. If the parent reported on the Environmental Health History Questionnaire that the home was built prior to 1978 and the parent was "not sure" if the home contained lead paint, then the home was classified as having lead paint present. If the home was built after 1978 and the parent was "not sure" if the home contained lead paint, then the home was classified as not having lead paint.

Prenatal Tobacco Exposure. Information about the mother's tobacco use during the participant's gestation period was assessed during the Pediatric Health History Interview and on the Environmental Health History Questionnaire. If the participant's parent indicated that tobacco was used during pregnancy on either one of the questionnaires then the participant was classified as exposed to prenatal tobacco. If the participant was adopted and use of tobacco products by the mother during pregnancy could not be determined then the participant's prenatal tobacco exposure was classified as 
"unsure". If a participant's parent indicated that no tobacco use occurred during pregnancy then the participant was classified as not exposed to prenatal tobacco.

Environmental Tobacco Smoke Exposure. Exposure to environmental tobacco smoke was assessed by the question "How frequently do people smoke inside?" with response options "never, rarely, sometimes, or frequently" on the Environmental Health History Questionnaire. Participants with parents that indicated that people smoke inside the home "rarely, sometimes, or frequently" were classified as exposed to environmental tobacco smoke. For one participant, information about exposure to environmental tobacco smoke was missing and tobacco use could not be inferred from the available data; thus, the participant was considered as not exposed to environmental tobacco smoke.

Indoor Pets. The presence of pets living indoors was determined by the question "Are there dogs or cats that spend most of the time inside" with response options "no, yes, or not sure" on the Environmental Health History Questionnaire. Participants that responded "yes" were classified as having pets indoors, and participants that responded "no" were classified as not having pets indoors. Information about pets indoors was missing for one participant. Based on the participant's response to questions about pets living at the home included in the Pediatric Health History, it was inferred that the participant did have pets; thus, the participant was classified as having pets indoors.

Income. The median household income for the Census block group (ACS, 2014) was used to estimate the socioeconomic level of each participant. ArcGIS was used to assign each participant the median income level for the block group in which their home 
was located. The household income was categorized as $\$ 46,111$ or less and more than $\$ 46,111$.

Frequency of Home Cleaning. The frequency at which participants clean their homes was assessed by the question "How frequently do you clean your entire home?" with response options " $<1$ time per week, 1 time per week, 2-3 times per week, 4-5 times per week, or 6-7 times per week" on the Home Cleaning Questionnaire. The distribution of the responses was assessed and re-categorized into two groups: participants that clean less than once a week and participants that clean more than once a week.

The relationships between each potential covariate and BARS outcome variables were assessed in univariate analysis. The relationships between the potential covariates, fly ash, and $\mathrm{PM}_{10}$ concentrations were also assessed in univariate analyses. Any potential covariate that was related to any of the exposures or BARS outcome measures at $\mathrm{p}<0.20$ was considered for inclusion in the adjusted linear models. Covariates were added to the model using stepwise procedures and included in the final adjusted models if they were significant in the model or improved the fit of the model. Collinearity was assessed and outliers were evaluated. Beta coefficients, $95 \%$ confidence intervals, and p-values from the final multivariate linear regression models are reported.

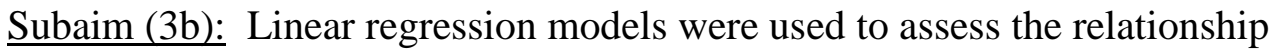
between the BARS outcome measures and $\mathrm{PM}_{10}$ concentration. The methods used to assess the relationship between fly ash exposure and the BARS outcomes for Subaim (3a) were repeated except with $\mathrm{PM}_{10}$ concentration as the independent exposure variable instead of the fly ash exposure variable. The three BARS outcome measures were transformed as described in Subaim (3a) and considered as the dependent variable in the 
linear regression models. $\mathrm{PM}_{10}$ concentrations were transformed using the common logarithm.

Beta coefficients, $95 \%$ confidence intervals, and p-values from three linear regression models with $\mathrm{PM}_{10}$ concentration, age, and gender as independent variables, and 1) CPT errors, 2) SAT errors, or 3) response latency as the dependent variable were reported. In addition, the same potential covariates assessed in Subaim (3a) were considered for inclusion in multivariate linear regression models. Beta coefficients, 95\% confidence intervals, and p-values from the final multivariate linear regression models were reported.

Specific Aim 4: Assess the relationship between PM10 concentration, fly ash exposure, and deficient emotional self-regulation (DESR).

Subaim (4a): The DESR score was calculated for each participant by summing the Anxious/Depressed, Attention Problems, and Aggressive Behavior Syndrome Scale standardized T-scores on the CBCL. The DESR score was analyzed as a continuous variable with higher scores indicating more severe problems with emotional selfregulation. The distribution of the DESR score was assessed and generalized linear models (GLM) negative binomial regression was used to estimate the relationship between the DESR score and fly ash exposure. The beta coefficient, 95\% confidence interval, and p-value were reported from the negative binomial model with the DESR score as the dependent outcome variable and fly ash exposure, age, and gender as independent variables.

Potential covariates considered for inclusion in the negative binomial regression model and the method used to fit the final multivariate model was the same as in Subaim 
(3a). The beta coefficient, 95\% confidence interval, and p-value for the relationship between fly ash exposure and the DESR score were reported.

Subaim (4b): A negative binomial regression model was also used to assess the relationship between the DESR score and the log-transformed $\mathrm{PM}_{10}$ concentration while adjusting for age and gender. The beta coefficient, $95 \%$ confidence interval, and p-value were reported from the negative binomial model with the DESR score as the dependent outcome variable and log-transformed $\mathrm{PM}_{10}$ concentration, age, and gender as independent variables.

Potential covariates considered for inclusion in the negative binomial regression model and the method used to fit the final multivariate model was the same as in Subaim (3a). The beta coefficient, $95 \%$ confidence intervals, and p-value for the relationship between $\mathrm{PM}_{10}$ exposure and the DESR score were reported.

\section{Specific Aim 5: Assess the relationship between metal exposure and cognitive control} using Bayesian Kernel Machine Regression (BKMR) and linear regression models.

Subaim (5a): Metal exposure was assessed using PIXE results of air filters used to collect indoor $\mathrm{PM}_{10}$. If the concentration of a metal or metalloid in $\mathrm{PM}_{10}$ was above the LOD in at least $10 \%$ of the air samples, then the metal was assessed as an independent exposure variable in the BKMR model. Metals or metalloids considered in the model included aluminum, silicon, titanium, chromium, manganese, iron, nickel, copper, zinc, and arsenic. Concentrations were assessed as continuous variables with values less than the LOD set equal to the LOD divided by the square root of two. This method for dealing with concentrations below the LOD was suggested with BKMR during conversations 
with Claus Henn at the 2016 Epidemiology Congress of the Americas, Environmental Mixtures Workshop.

BKMR was conducted in R using code developed by Bobb and Coull at Harvard Chan School of Public Health (2015) and presented at the 2016 Epidemiology Congress of the Americas, Environmental Mixtures Workshop by Claus Henn (101). Three BKMR models were constructed with the CPT errors, SAT errors, and response latency as the primary outcomes. For the models, the BARS variables $\left(\mathrm{Y}_{\mathrm{i}}\right)$ were regressed on a flexible function $\mathrm{h}()$ of all the metal exposures meeting the criteria for consideration:

$$
Y_{i}=\beta_{o}+h\left(X_{i 1}+X_{i 2}, \ldots X_{i M}\right)+Z^{\prime} \beta_{1}
$$

where $_{\mathrm{i}}=$ a subject, $X_{i}$ is a vector of $M$ metal exposure variables, $Z$ is potential confounders, and $\beta$ is a vector of coefficients.

This nonparametric technique analyzes numerous exposures while allowing for non-linear relationships and interactions. When the BKMR models were constructed the default priors for the kmbayes function in the bkmr package were used. The bkmr package was not used for Bayesian inference, only as a way to visualize the relationship between all of the elements and behavioral outcomes in order to identify which elements might be of interest to explore further in linear regression models.

Output from the BKMR models includes different functions for visualizing the exposure-response surface. Using one of these functions, the univariate relationship between each individual metal $\left(X_{i M}\right)$ and the BARS outcome variables were assessed while all other exposure variables were fixed to the $50^{\text {th }}$ percentile. Potential confounders included in the BKMR model were age, gender, and block group income level. Metals 
that appeared to have a relationship with any of the BARS outcome variables were further considered in linear regression models in the subsequent Subaim (5b).

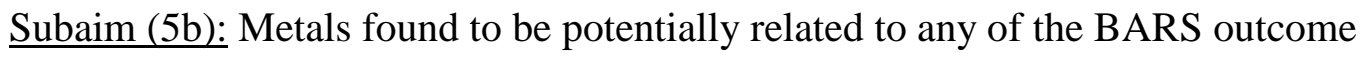
variables in the BKMR model were considered for further investigation. Results from the BKMR models suggested that one metal, aluminum, might be potentially related to all of the BARS outcome measures and the DESR score. Therefore, three linear regression models with aluminum concentration as the independent exposure variable and the BARS outcome measures transformed as described in Subaim (3a) were constructed. Beta coefficients, $95 \%$ confidence intervals, and p-values from the three linear regression models with aluminum concentration, age, and gender as independent variables, and 1) CPT errors, 2) SAT errors, or 3) response latency as the dependent variable were reported. In addition, the same potential covariates assessed in Subaim (3a) were considered for inclusion in multivariate linear regression models with aluminum concentration and BARS outcomes. Beta coefficients, 95\% confidence intervals, and pvalues from the final multivariate linear regression models were reported.

Subaim (5c): A total metal exposure score (MES) was developed for each child by ranking the children based on the concentration of individual metals in the $\mathrm{PM}_{10}$, summing each child's ranks, and grouping the scores into tertiles of total metal concentration. For analysis in the linear regression models the first and second tertiles were combined and compared to the highest tertile. Three linear regression models were constructed to assess the relationship between the MES and 1) CPT errors, 2) SAT errors, and 3) CPT response latency. The BARS outcome measures were considered as the 
dependent outcome variable and the MES, age, and gender were included as the independent exposure variable.

Three additional multivariate linear regression models were constructed using the same potential covariates and method to fit the final multivariate model in Subaim (3a). Beta coefficients, $95 \%$ confidence intervals, and p-values from the three linear regression models were reported.

Specific Aim 6: Assess the relationship between metal exposure and deficient emotional self-regulation (DESR) using Bayesian Kernel Machine Regression (BKMR) and negative binomial regression.

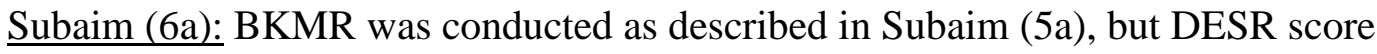
was used as the outcome variable instead of the BARS CPT and SAT outcome variables. Metals that appeared to have a relationship with the DESR score were further considered in negative binomial regression models in the subsequent Subaim (5b).

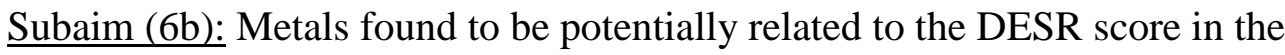
BKMR model were considered for further investigation. Results from the BKMR models suggested that aluminum might also be potentially related to DESR score. Therefore, a negative binomial regression model was constructed with aluminum concentration as the independent exposure variable and the DESR score as the dependent outcome variable. Beta coefficients, 95\% confidence intervals, and p-values from the negative binomial regression model with aluminum concentration, age, and gender as independent variables, and DESR score as the dependent variable were reported. In addition, the same potential covariates assessed in Subaim (3a) were considered for inclusion in multivariate linear regression models with aluminum concentration and DESR score. Beta 
coefficients, 95\% confidence intervals, and p-values from the final multivariate models were reported.

Subaim (6c): The relationship between the MES developed in Subaim (5c) and DESR score was assessed using negative binomial regression. Beta coefficients, 95\% confidence intervals, and p-values were reported from the negative binomial regression model with DESR score as the dependent variable and MES, age, and gender as independent variables.

Three additional multivariate linear regression models were constructed using the same potential covariates and method to fit the final multivariate model in Subaim (3a). Beta coefficients, $95 \%$ confidence intervals, and p-values from the negative binomial regression models were reported. 


\section{RESULTS}

1. Specific Aim 1 Results: Characterize fly ash, PM 10 concentration and metal exposure

(1a): Based on the fly ash particles reported by SEM/EDX, there were 99 particles of fly ash found in $33(44.6 \%)$ homes across the study area. However, some particles were contained in clusters; thus, data was only reported for the first 10 particles determined in the cluster. These results are based on the number of particles reported for the SEM/EDX that was completed. Descriptive statistics from the SEM-EDX analysis of fly ash particles are contained in Table 2 . The most abundant metal found in fly ash particles was aluminum and the most abundant metalloid was silicon.

Table 2. Concentration of Metals in Fly Ash Particles (ppm)

\begin{tabular}{lcccccccc}
\hline & $\mathbf{N}$ & Mean & SD & Min & P25 & Median & P75 & Max \\
\hline Aluminum & $75(75.8 \%)$ & 15.9 & 10.5 & 3.0 & 12.5 & 15.0 & 17.0 & 92.0 \\
Iron & $68(68.7 \%)$ & 9.0 & 12.5 & 1.0 & 4.0 & 6.0 & 9.0 & 68.0 \\
Titanium & $31(31.3 \%)$ & 1.3 & 0.9 & 0.5 & 1.0 & 1.0 & 1.5 & 4.0 \\
Potassium & $68(68.7 \%)$ & 2.5 & 1.5 & 0.5 & 1.3 & 2.5 & 3.0 & 9.0 \\
Silicon & $95(96.0 \%)$ & 25.5 & 14.3 & 1.0 & 19.0 & 22.0 & 28.0 & 60.0 \\
\hline
\end{tabular}

(1b): Table 3 contains a comparison of $\mathrm{PM}_{10}$ concentrations measured in homes where fly ash was found on the air filter compared to homes where no fly ash was found. There was no significant difference in the concentration of $\mathrm{PM}_{10}$ in homes with fly ash compared to those without fly ash $(\mathrm{p}=0.96)$. 
Table 3. $\mathrm{PM}_{10}$ Concentration $\left(\mu \mathrm{g} / \mathrm{m}^{3}\right)$ and Fly Ash Exposure

\begin{tabular}{lrrrrrrrrrr}
\hline & n & GM & SE & 95\% CI & Min & P25 & Median & P75 & Max & $\begin{array}{c}\text { P- } \\
\text { value* }\end{array}$ \\
\hline $\begin{array}{l}\text { No Fly } \\
\text { Ash }\end{array}$ & 41 & 17 & 1.3 & $(14.6,19.8)$ & 7.9 & 12.4 & 15.4 & 22.2 & 92.2 & 0.96 \\
$\begin{array}{l}\text { Fly } \\
\text { Ash }\end{array}$ & 33 & 17.2 & 1.6 & $(14.3,20.8)$ & 5.4 & 12.1 & 16.6 & 23.3 & 77.1 & \\
\hline *Wilcoxon Rank-Sum P-value & & & & & & & & \\
\hline
\end{tabular}

(1c): Results for the PIXE analysis of the $\mathrm{PM}_{10}$ can be found in Table 4. Silicon had the greatest concentration in $\mathrm{PM}_{10}$ followed by aluminum, titanium, chromium, manganese, and arsenic. 
Table 4. Concentration of Metals in $\mathrm{PM}_{10}\left(\mu \mathrm{g} / \mathrm{m}^{3}\right)$ from Indoor Air Sample

\begin{tabular}{|c|c|c|c|c|c|c|c|c|c|}
\hline & $\mathrm{n}(\mathrm{N}=74)$ & GM & SE & $95 \% \mathrm{CI}$ & Min & $\mathbf{P 2 5}$ & Median & P75 & Max \\
\hline Aluminum & $74(100 \%)$ & 0.0643 & 0.00538 & $(0.054,0.076)$ & 0.0175 & 0.0418 & 0.0557 & 0.0934 & 0.9704 \\
\hline Arsenic & $34(46.0 \%)$ & 0.0008 & 0.00006 & $(0.0007,0.001)$ & 0.0002 & 0.0005 & 0.0009 & 0.0013 & 0.0031 \\
\hline Chromium & $12(16.2 \%)$ & 0.0017 & 0.00015 & $(0.0014,0.0021)$ & 0.0009 & 0.0012 & 0.0014 & 0.0019 & 0.1378 \\
\hline Manganese & $32(43.2 \%)$ & 0.0015 & 0.00012 & $(0.0013,0.0017)$ & 0.0005 & 0.0009 & 0.0013 & 0.0023 & 0.0156 \\
\hline Silicon & $74(100 \%)$ & 0.3866 & 0.02428 & $(0.3411,0.4381)$ & 0.1034 & 0.2908 & 0.3747 & 0.5222 & 3.1891 \\
\hline Titanium & $43(58.1 \%)$ & 0.0068 & 0.00058 & $(0.0057,0.0080)$ & 0.0018 & 0.0040 & 0.0062 & 0.0107 & 0.1002 \\
\hline
\end{tabular}


There was no significant difference between the $\mathrm{PM}_{10}$ concentrations of aluminum, arsenic, chromium, manganese, silicon, or titanium measured in homes where fly ash was found compared to homes with no fly ash (Table 5).

Table 5. Comparison between Natural-Log of Metal Concentrations $\left(\mu \mathrm{g} / \mathrm{m}^{3}\right)$ and Fly Ash

\begin{tabular}{lccc}
\hline Median (IQR) & No Fly Ash (n=41) & Fly Ash (n=33) & P-value* \\
\hline Aluminum & $0.062(0.0767)$ & $0.0508(0.0340)$ & 0.06 \\
Arsenic & $0.0010(0.0008)$ & $0.0005(0.0007)$ & 0.18 \\
Chromium & $0.0016(0.0010)$ & $0.0012(0.0008)$ & 0.11 \\
Manganese & $0.0013(0.0019)$ & $0.0014(0.0010)$ & 0.53 \\
Silicon & $0.3918(0.2658)$ & $0.3598(0.2276)$ & 0.16 \\
Titanium & $0.0070(0.0086)$ & $0.0054(0.0042)$ & 0.15 \\
\hline *Wilcoxon Rank-Sum P-value & & & \\
\hline
\end{tabular}

2. Specific Aim 2 Results: Use GIS to assess how proximity and socio-demographic factors are related to exposure

(2a): Overall the mean distance $(\mathrm{km})$ of participants' homes from the centroid of the ash landfill at Mill Creek is 10.75 (standard deviation= 4.9) and the median distance is $6.88(\mathrm{Min}=1.54, \mathrm{P} 25=7.10, \mathrm{P} 75=14.22, \mathrm{Max}=20.35)$. The mean distance $(\mathrm{km})$ of participants' homes from the centroid of the ash landfill at Cane Run is 6.88 (standard deviation= 3.5) and the median distance is $6.18(\mathrm{Min}=0.83, \mathrm{P} 25=4.38, \mathrm{P} 75=8.99, \mathrm{Max}=$ 14.74). There was no significant difference in the distance from the landfills at Mill 
Creek or Cane Run for homes that had fly ash compared to those that did not have fly ash (Table 6 and Table 7).

Table 6. Distance from Mill Creek Landfill to Homes $(\mathrm{km})$ and Fly Ash

\begin{tabular}{lcccccccc}
\hline & n & Mean (SD) & Min & P25 & Median & P75 & Max & P-value* \\
\hline Fly Ash & 33 & $10.96(4.84)$ & 1.73 & 9.81 & 11.60 & 13.90 & 20.35 & 0.63 \\
No Ash & 41 & $10.59(5.02)$ & 1.54 & 6.38 & 10.67 & 14.49 & 19.61 & \\
& & & & & & & \\
\hline *Wilcoxon Rank-Sum p-value & & & & & & \\
\hline
\end{tabular}

Table 7. Distance from Cane Run to Homes $(\mathbf{k m})$ and Fly Ash

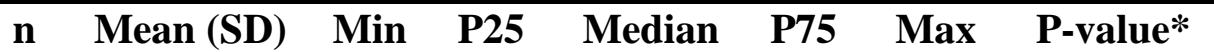

\begin{tabular}{lcccccccc}
\hline Fly Ash & 33 & $6.48(3.49)$ & 0.83 & 3.97 & 5.65 & 8.41 & 13.01 & 0.3 \\
No Ash & 41 & $7.20(3.66)$ & 0.87 & 4.54 & 7.16 & 9.15 & 14.74 &
\end{tabular}

*Wilcoxon Rank-Sum p-value

However, results from the simple linear regression models comparing the distance of participants' homes from each ash landfill to indoor $\mathrm{PM}_{10}$ concentrations suggest there may be a relationship between distance and indoor $\mathrm{PM}_{10}$. The distance from Mill Creek ash landfill to the participants' homes was inversely related to the log-transformed $\mathrm{PM}_{10}$ concentrations $(\beta=-0.015 ; 95 \% \mathrm{CI}=(-0.025,-0.005) ; \mathrm{p}=0.003)$. The distance from Cane Run landfill was positively related to the log-transformed $\mathrm{PM}_{10}$ concentration $(\beta=0.015$; $95 \% \mathrm{CI}=(0.002,0.029) ; \mathrm{p}=0.03)$. The observed positive relationship between distance from Cane Run landfill and $\mathrm{PM}_{10}$ concentration is due to the inverse relationship between 
distance from Mill Creek landfill and $\mathrm{PM}_{10}$ concentration. Many of the homes in the study area that were further away from Cane Run were closer to Mill Creek. Thus, the significant relationship between distance from Cane Run landfill and $\mathrm{PM}_{10}$ concentration is confounded by distance from Mill Creek landfill. Overall, results from the analysis for Subaim (2c) show that living near either power plant was associated with higher indoor $\mathrm{PM}_{10}$ concentrations.

(2b): Distance from the ash landfills to the participants' homes was related to the concentrations of aluminum, manganese, silicon, and titanium in $\mathrm{PM}_{10}$. The beta estimates, 95\% confidence intervals, and p-values from simple linear regression models with distance and the log of each metal concentration are in Table 8 and Table 9. Spearman Correlation Coefficients and p-values are also in Table 8 and 9. Homes closer to Mill Creek landfill had greater concentrations of aluminum, manganese, silicon, and titanium in $\mathrm{PM}_{10}$, while homes further away from Cane Run landfill had greater concentrations of aluminum, manganese, and silicon. Similar to the results in Subaim (2b), it appears the significant relationship between distance from Cane Run landfill and metal concentrations are confounded by distance from Mill Creek landfill. 
Table 8. Relationship between Distance from Mill Creek $(\mathbf{k m})$ and Natural-Log of Metal Concentration $\left(\mu \mathrm{g} / \mathrm{m}^{3}\right)$

\begin{tabular}{lcccc}
\hline & Beta $(95 \% \text { CI })^{1}$ & P-value $^{1}$ & $\begin{array}{l}\text { Correlation } \\
\text { Coefficient }\end{array}$ & P-value $^{2}$ \\
\hline Aluminum & $-0.057(-0.089,-0.026)$ & 0.0006 & -0.329 & 0.004 \\
Arsenic & $-0.004(-0.031,0.024)$ & 0.79 & 0.0068 & 0.95 \\
Chromium & $-0.028(-0.063,0.007)$ & 0.12 & -0.077 & 0.51 \\
Manganese & $-0.051(-0.081,-0.021)$ & 0.001 & -0.251 & 0.03 \\
Silicon & $-0.047(-0.070,-0.025)$ & 0.0001 & -0.400 & 0.0004 \\
Titanium & $-0.035(-0.069,-0.001)$ & 0.05 & -0.160 & 0.17 \\
$\begin{array}{l}\text { T Simple linear regression model results } \\
{ }^{2} \text { Spearman correlation test results }\end{array}$ & & & \\
\hline
\end{tabular}


Table 9. Relationship between Distance from Cane Run $(\mathbf{k m})$ and Natural-Log of Metal Concentration $\left(\mu \mathrm{g} / \mathrm{m}^{3}\right)$

\begin{tabular}{|c|c|c|c|c|}
\hline & $\operatorname{Beta}(95 \% \text { CI })^{1}$ & P-value ${ }^{1}$ & $\begin{array}{l}\text { Correlation } \\
\text { Coefficient }^{2} \\
\end{array}$ & P-value $^{2}$ \\
\hline Aluminum & $0.069(0.026,0.113)$ & 0.003 & 0.301 & 0.009 \\
\hline Arsenic & $-0.027(-0.064,0.010)$ & 0.16 & -0.140 & 0.23 \\
\hline Chromium & $0.012(-0.029,0.068)$ & 0.42 & -0.001 & 0.99 \\
\hline Manganese & $0.061(0.019,0.102)$ & 0.006 & 0.206 & 0.08 \\
\hline Silicon & $0.046(0.013,0.079)$ & 0.008 & 0.289 & 0.01 \\
\hline Titanium & $0.034(-0.033,0.100)$ & 0.16 & 0.150 & 0.20 \\
\hline
\end{tabular}


(2c): The EJ Index was calculated for every Census block group where a participant resided and for all surrounding block groups. The mean EJ index value is $10.72($ standard deviation $=8.3)$ and median is $7.93(\mathrm{Min}=2.18, \mathrm{P} 25=4.39, \mathrm{P} 75=16.48$, Max= 26.53). Descriptive statistics on the Environmental Indicator and Demographic Index components of the EJ Index are included in the Appendix: Supplemental Table 1. Descriptive Statistics for EJ Index and Components.

The EJ Index was split into quartiles and shown on the choropleth map (Figure 1) with lower values representing areas of less susceptibility and the higher percentiles representing more vulnerable block groups. Based on the EJ Index, the populations that are most susceptible to exposure to fly ash from the landfills are located closest to each coal-burning power plant, as well as along the northwestern border of Jefferson County. Despite being near both power plants, some block groups that are northeast of the southern power plant and southeast of the northern one are the least vulnerable because they have lower percentages of people living in poverty and lower percentages of minority populations.

Homes with fly ash present are indicated as a green dot, and homes with no fly ash are indicated with a blue dot. Overall homes with fly ash present had a slightly greater EJ Index score than homes with no fly ash present, but the difference in median score was not significant (Table 10). 
Figure 1. Comparison of Environmental Justice Index and Fly Ash Presence

Environmental Justice Index and Fly Ash in Home

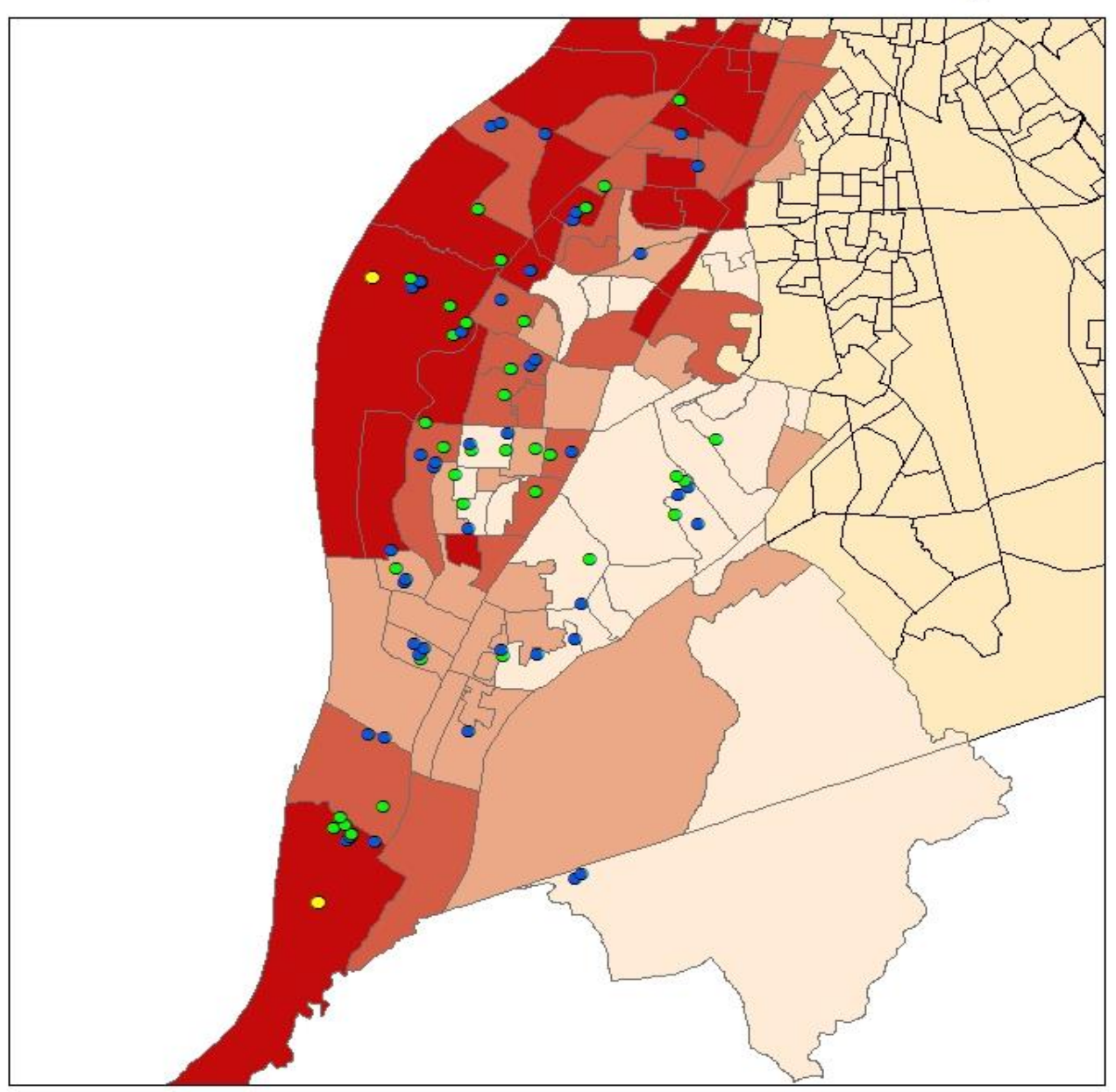

- No Fly Ash Present

- Fly Ash Present

EJ Index Quartile

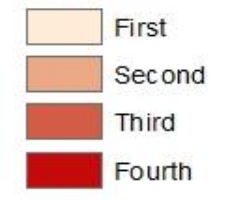

Coal Ash

Storage Facility 
Table 10. Comparison of Environmental Justice Index between Homes with and without Fly Ash

\begin{tabular}{lcccccccc}
\hline & n & Mean (SD) & Min & Q1 & Median & Q3 & Max & P-value* \\
\hline $\begin{array}{l}\text { Fly Ash } \\
\text { Present } \\
\text { No Ash }\end{array}$ & 33 & $11.63(8.71)$ & 2.18 & 4.26 & 8.07 & 20.18 & 26.52 & 0.64 \\
& 41 & $9.98(7.93)$ & 2.18 & 4.39 & 6.49 & 10.03 & 26.52 & \\
\hline
\end{tabular}


The choropleth map comparing indoor $\mathrm{PM}_{10}$ concentrations and the EJ Index suggests that homes closer to the ash landfills have greater $\mathrm{PM}_{10}$ concentrations (Figure 2). In addition, results from simple linear regression models with $\mathrm{PM}_{10}$ concentration and the EJ Index suggest that there is a significant correlation $(\beta=0.0094 ; 95 \% \mathrm{CI}=(0.004$, 0.015); $\mathrm{p}=0.002)$. People living in block groups that were closest to the power plants and along the northwestern border of Jefferson County had higher $\mathrm{PM}_{10}$ concentrations indoors. 
Figure 2. Comparison of Environmental Justice Index and $\mathrm{PM}_{10}$ Concentration

\section{Environmental Justice Index and Concentration of PM10 Measured in Home}

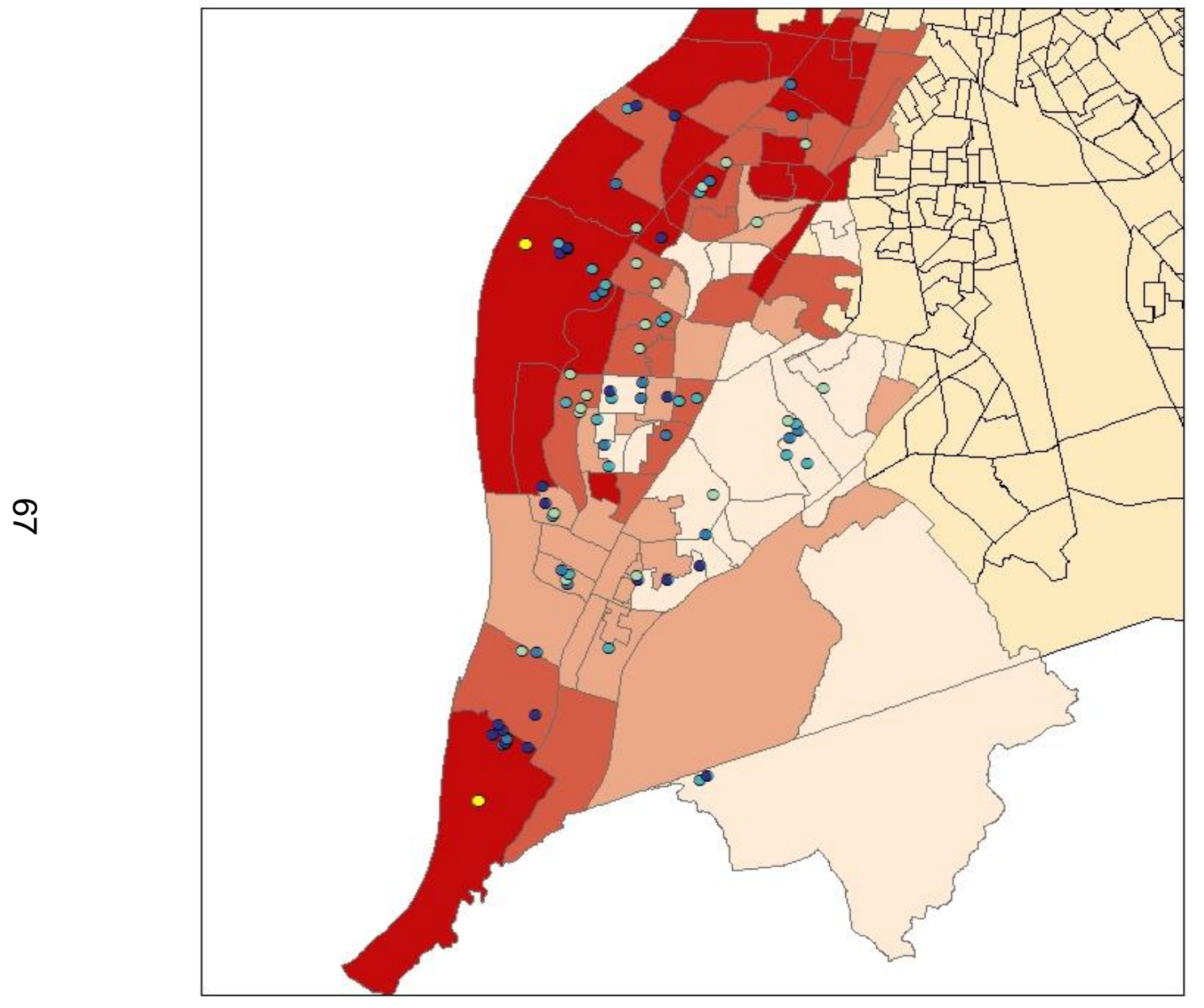

Concentration of PM10 (ug/m3)

- $5.37-12.12$

- $12.13-16.55$

- $16.56-24.21$

- $24.22-92.24$

\section{EJ Index Quartile}

$\square$ First

$\square$ second

Third

Fourth

Coal Ash

Storage Facility 
GIS was used to compare the EJ Index with concentrations of elements in $\mathrm{PM}_{10}$ that were also found to be abundant in fly ash particles in Subaim (1a). The relationship between the EJ Index and aluminum concentration in $\mathrm{PM}_{10}$ can be seen in Figure 3. Figure 4 shows the relationship between the EJ Index and titanium concentration. Figure 5 shows the relationship between the EJ Index and silicon concentration. Maps comparing the EJ Index to concentrations of arsenic, chromium, and manganese can be found in the Appendix: Supplemental Figure 1, Figure 2, and Figure 3.

Results from simple linear regression models comparing the natural log of metal concentrations to the EJ Index suggest there is a positive relationship between the EJ Index and metal exposure. Participants in block groups with higher EJ Index values had higher concentrations of aluminum $(\beta=0.020 ; 95 \% \mathrm{CI}=(0.0006,0.040) ; \mathrm{p}=0.05)$ and titanium $(\beta=0.035 ; 95 \% \mathrm{CI}=(0.016,0.055) ; \mathrm{p}=0.0005)$ in $\mathrm{PM}_{10}$. There was a borderline significant relationship between the EJ Index and silicon concentration in $\mathrm{PM}_{10}(\beta=$ $0.013 ; 95 \% \mathrm{CI}=(-0.013,0.040) ; \mathrm{p}=0.08)$. When the metal concentrations were compared to the Environmental Indicator and Demographic Index components of the EJ Index separately, the metal concentrations were found to be significantly related to the Environmental Indicator, but not the Demographic Index independently (Appendix: Supplemental Table 2 and Table 3 ). 
Figure 3. Comparison of Environmental Justice Index and Aluminum Concentration Environmental Justice Index and Concentration of Aluminum in Home

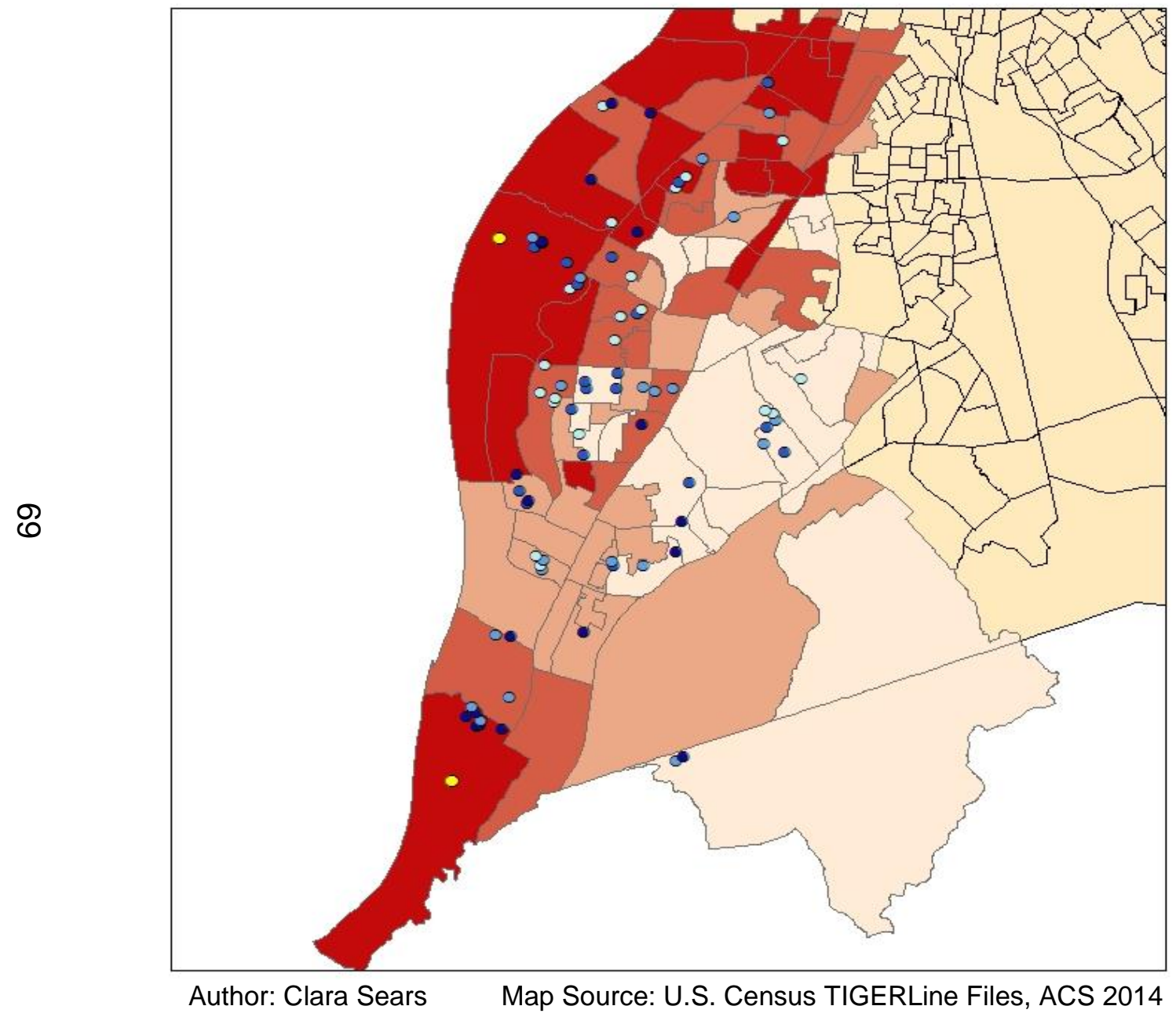

Concentration of Aluminum $\left(\mu \mathrm{g} / \mathrm{m}^{3}\right)$

$\circ \quad 0.018-0.042$

- $0.043-0.058$

- $0.059-0.105$

- $0.106-0.970$

EJ Index Quartile

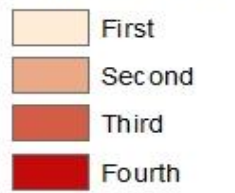

Coal Ash

Storage Facility 
Figure 4. Comparison of Environmental Justice Index and Titanium Concentration Environmental Justice Index and Concentration of Titanium in Home

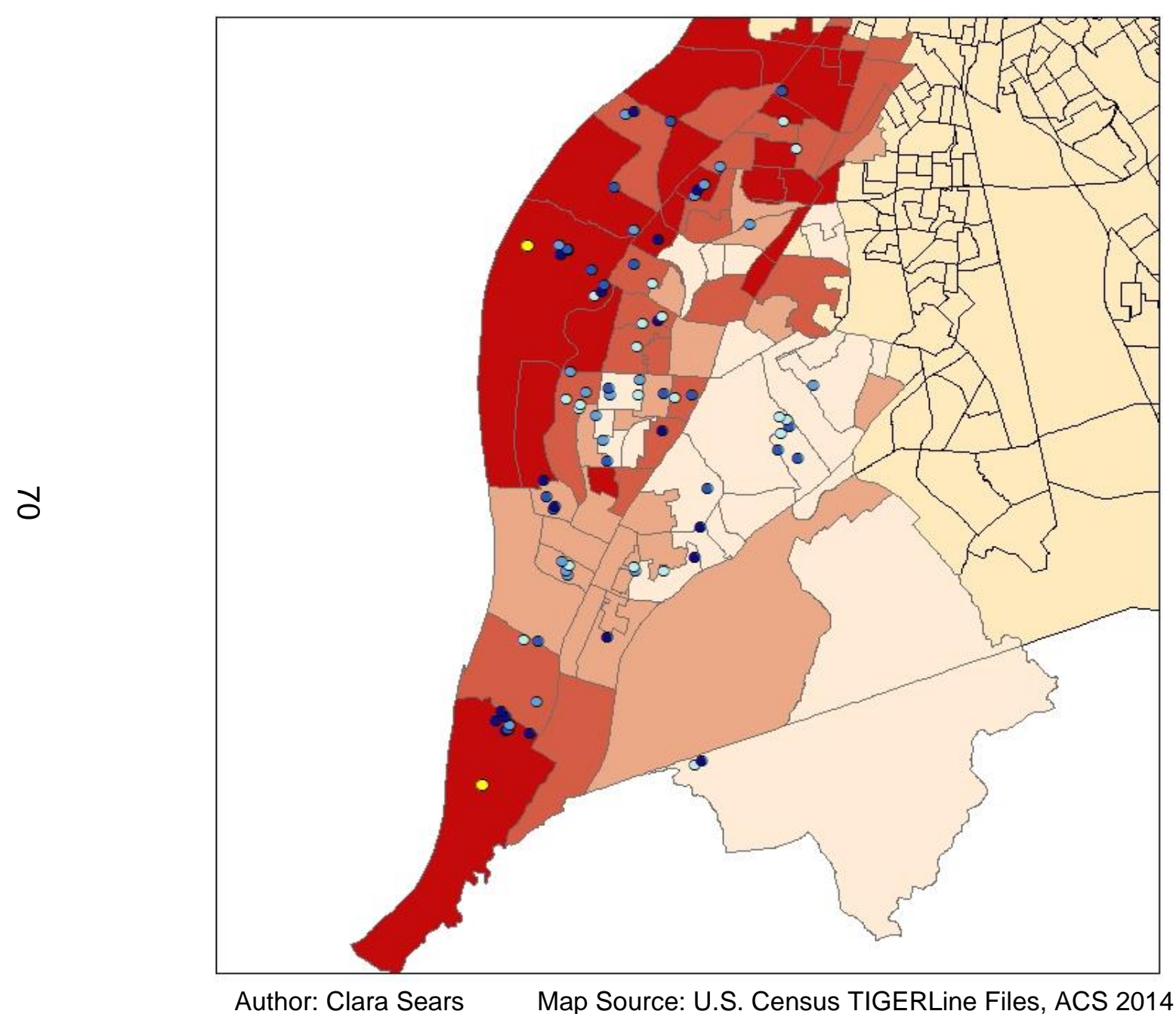

\section{Concentration of} Titanium $\left(\mu \mathrm{g} / \mathrm{m}^{3}\right)$

$0.0020-0.0040$

- $0.0041-0.0065$

- $0.0066-0.0111$

- $0.0112-0.1002$

EJ Index Quartile

$\square$ First

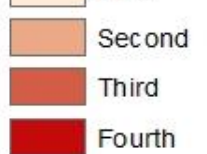

Coal Ash

Storage Facility 
Figure 5. Comparison of Environmental Justice Index and Silicon Concentration

\section{Environmental Justice Index and Concentration of Silicon in Home}

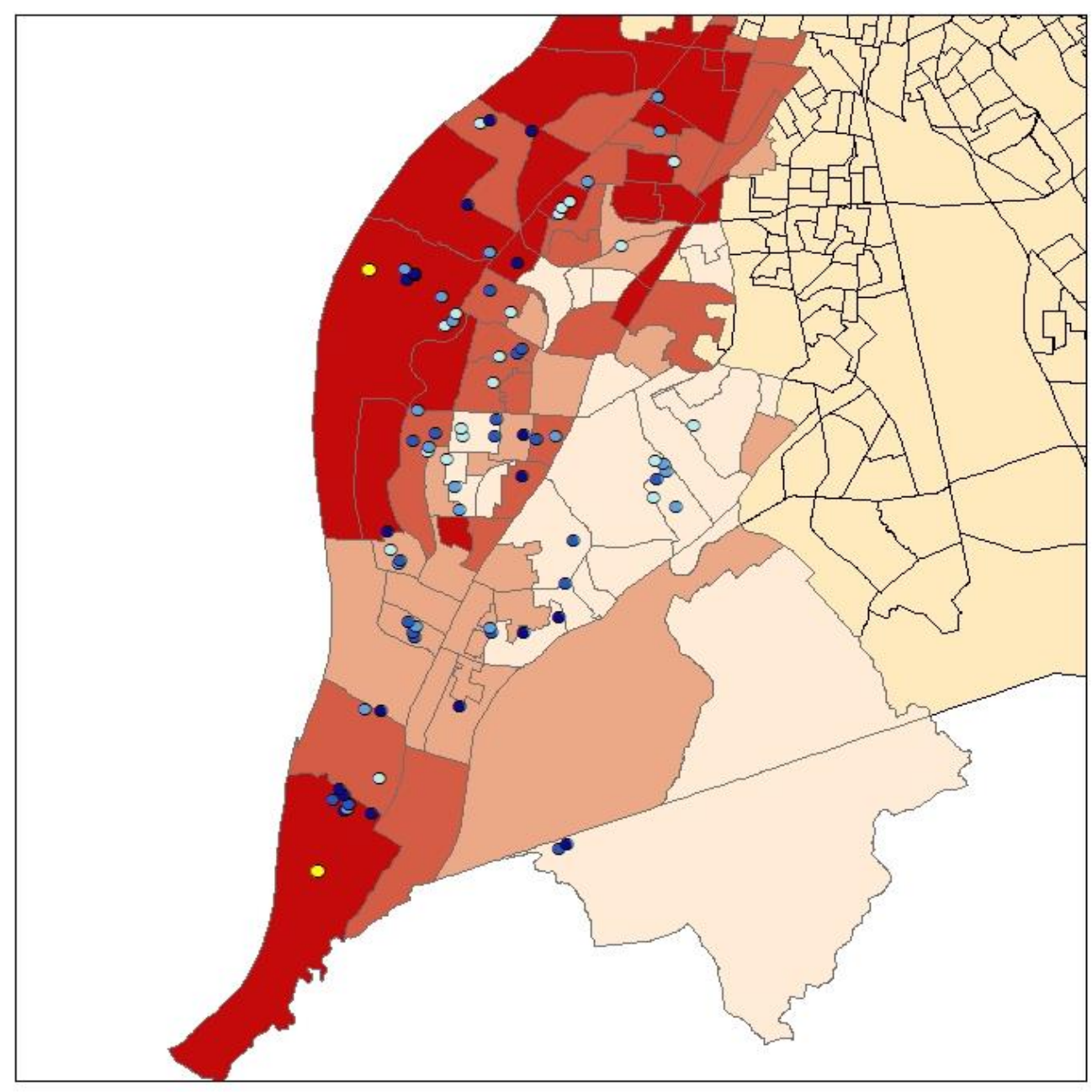

\section{Concentration of} Silicon $\left(\mu \mathrm{g} / \mathrm{m}^{3}\right)$

- $0.103-0.290$

- $0.291-0.375$

- $0.376-0.538$

- $0.539-3.189$

EJ Index Quartile

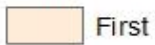

$\square$ Second

Third

Fourth

Coal Ash

Storage Facility 
3. Specific Aim 3 Results: Assess the relationship between PM10 concentration, fly ash exposure, and cognitive control.

Overall $n=75$ participants are included in the analysis for Specific Aim 3. Three participants were excluded because they did not complete all phases of the study. Approximately 51\% (38) of the study sample are males and 49\% (37) are females. The mean age is 11 (standard deviation= 2.53) and the median is $11(\mathrm{Min}=6, \mathrm{P} 25=8, \mathrm{P} 75=$ 13, Max=14). The primary outcome assessed in Specific Aim 3 is cognitive control, which was assessed using the BARS CPT and SAT. Descriptive statistics on the BARS outcome measures are included in Table 11.

Table 11. BARS Outcome Measures

\begin{tabular}{rcccccc}
\hline & Mean (SD) & Min & P25 & Median & P75 & Max \\
\hline Continuous Performance & & & & & & \\
Number of Errors & $10.0(9.5)$ & 0 & 4 & 7 & 14 & 55 \\
$\begin{array}{c}\text { Response Latency } \\
463.4(81.9)\end{array}$ & 314.9 & 407.4 & 456.2 & 500.1 & 671.1 \\
$\begin{array}{c}\text { Selective Attention } \\
\text { Number of Errors }\end{array}$ & $3.26(2.2)$ & 0 & 1 & 3 & 5 & 11 \\
\hline
\end{tabular}

Results from the univariate analysis comparing the number of CPT errors with potential covariates can be found in Table 12. Wilcoxon Rank-Sum p-values are reported. The number of CPT errors did not significantly differ by gender, age, BMI, environmental tobacco smoke exposure, presences of indoor pets, lead paint, frequency of home cleaning, or prenatal tobacco exposure. However, participants living in block groups with Median household incomes below $\$ 46,111$ did commit more errors on the CPT $(\mathrm{p}=0.01)$. Based on this univariate analysis, all multivariable linear models with 
CPT errors as the outcome measure at least considered age and income as potential covariates because significance in unvariate analysis was $p<0.20$. 
Table 12. CPT Errors and Potential Covariates

\begin{tabular}{|c|c|c|c|c|}
\hline & n (\%) & Mean (SD) & Median (IQR) & P-value \\
\hline Total & $75(100 \%)$ & $10.0(9.5)$ & $7.0(10.0)$ & \\
\hline Gender & & & & 0.7 \\
\hline Males & $38(50.7 \%)$ & $10.3(8.9)$ & $6.5(11.0)$ & \\
\hline Females & $37(49.3 \%)$ & $9.7(10.1)$ & $7.0(9.0)$ & \\
\hline Age & & & & 0.13 \\
\hline $6-10$ years & $33(44.0 \%)$ & $11.6(10.5)$ & $9.0(11)$ & \\
\hline 11-14 years & $42(56.0 \%)$ & $8.7(8.5)$ & $6.0(8.0)$ & \\
\hline BMI & & & & 0.76 \\
\hline Underweight $<18$ & $25(33.3 \%)$ & $11.0(11.2)$ & $8.0(8.0)$ & \\
\hline Normal 18-25 & $32(42.7 \%)$ & $9.5(8.3)$ & $6.0(10.0)$ & \\
\hline Overweight $>25$ & $18(24.0 \%)$ & $9.5(9.2)$ & $5.5(12.0)$ & \\
\hline Income & & & & 0.01 \\
\hline$\$ 46,111$ or less & $37(49.3 \%)$ & $12.9(11.2)$ & $11.0(12.0)$ & \\
\hline More than $\$ 46,111$ & $38(50.7 \%)$ & $7.2(6.3)$ & $5.0(6.0)$ & \\
\hline \multicolumn{5}{|l|}{ Environmental } \\
\hline Tobacco Exposure & & & & 0.45 \\
\hline No & $66(88.0 \%)$ & $10.1(9.5)$ & $7.5(10.0)$ & \\
\hline Yes & $9(12.0 \%)$ & $9.2(9.7)$ & $5.0(20.0)$ & \\
\hline Indoor Pets & & & & 0.4 \\
\hline No & $19(25.3 \%)$ & $10.3(7.7)$ & $8.0(9.0)$ & \\
\hline Yes & $56(74.7 \%)$ & $9.9(10.1)$ & $6.5(10.5)$ & \\
\hline Lead Paint & & & & 0.87 \\
\hline No & $58(77.3 \%)$ & $9.6(8.1)$ & $6.5(10.0)$ & \\
\hline Yes & $17(22.7 \%)$ & $11.5(13.3)$ & $7.0(10.0)$ & \\
\hline \multicolumn{5}{|l|}{ Frequency of Home } \\
\hline Cleaning & & & & 0.59 \\
\hline Less than once a week & $34(45.3 \%)$ & $8.9(7.6)$ & $6.0(8.0)$ & \\
\hline More than once a & & & & \\
\hline week & $41(54.7 \%)$ & $10.9(10.8)$ & $8.0(11.0)$ & \\
\hline \multicolumn{5}{|l|}{ Prenatal Tobacco } \\
\hline Exposure & & & & 0.96 \\
\hline No & $59(78.7 \%)$ & $10.3(9.9)$ & $8.0(10.0)$ & \\
\hline Yes & $10(13.3 \%)$ & $9.3(8.4)$ & $6.5(10.0)$ & \\
\hline Unsure & $6(8.0 \%)$ & $8.5(6.5)$ & $6.0(6.0)$ & \\
\hline
\end{tabular}


Results from the univariate analysis comparing the CPT response latency with potential covariates can be found in Table 13. Wilcoxon Rank-Sum p-values are reported. Gender $(\mathrm{p}=0.01)$ and age $(\mathrm{p}=0.0001)$ were significantly related to CPT response latency and therefore considered for inclusion in all multivariable linear regression models with response latency as the outcome. 
Table 13. CPT Response Latency and Potential Covariates

\begin{tabular}{|c|c|c|c|c|}
\hline & n (\%) & Mean (SD) & Median (IQR) & P-value \\
\hline Total & $75(100 \%)$ & $463.4(81.9)$ & $456.2(92.7)$ & \\
\hline Gender & & & & 0.01 \\
\hline Boys & $38(50.7 \%)$ & $438.1(69.1)$ & $437.3(100.3)$ & \\
\hline Girls & $37(49.3 \%)$ & $489.3(86.7)$ & $472.0(88.5)$ & \\
\hline Age & & & & 0.0001 \\
\hline 6-10 years & $33(44.0 \%)$ & $522.3(78.6)$ & $502.3(99.7)$ & \\
\hline 11-14 years & $42(56.0 \%)$ & $417.1(47.9)$ & $417.0(81.2)$ & \\
\hline BMI & & & & 0.27 \\
\hline Underweight $<18$ & $25(33.3 \%)$ & $484.4(88.6)$ & $478.8(96.3)$ & \\
\hline Normal 18-25 & $32(42.7 \%)$ & $464.9(88.4)$ & $447.5(91.4)$ & \\
\hline Overweight $>25$ & $18(24.0 \%)$ & $434.2(49.3)$ & $448.4(84.1)$ & \\
\hline Income & & & & 0.62 \\
\hline$\$ 46,111$ or less & $37(49.3 \%)$ & $459.0(81.1)$ & $456.2(78.5)$ & \\
\hline More than $\$ 46,111$ & $38(50.7 \%)$ & $467.6(83.6)$ & $456.4(86.8)$ & \\
\hline Environmental Tobacco & & & & \\
\hline Exposure & & & & 0.94 \\
\hline No & $66(88.0 \%)$ & $463.6(82.4)$ & $453.3(86.8)$ & \\
\hline Yes & $9(12.0 \%)$ & $461.5(82.4)$ & $469.4(108.6)$ & \\
\hline Indoor Pets & & & & 0.31 \\
\hline No & $19(25.3 \%)$ & $478.5(79.8)$ & $469.4(81.4)$ & \\
\hline Yes & $56(74.7 \%)$ & $458.2(82.7)$ & $445.9(94.8)$ & \\
\hline Lead Paint & & & & 0.68 \\
\hline No & $58(77.3 \%)$ & $464.2(82.5)$ & $462.5(86.8)$ & \\
\hline Yes & $17(22.7 \%)$ & $460.4(82.4)$ & $445.4(82.1)$ & \\
\hline Frequency of Home & & & & \\
\hline Cleaning & & & & 0.22 \\
\hline Less than once a week & $34(45.3 \%)$ & $446.0(59.9)$ & $438.6(69.9)$ & \\
\hline More than once a week & $41(54.7 \%)$ & $477.7(94.8)$ & $469.0(119.7)$ & \\
\hline Prenatal Tobacco & & & & \\
\hline Exposure & & & & 0.86 \\
\hline No & $59(78.7 \%)$ & $465.5(83.6)$ & $456.2(87.5)$ & \\
\hline Yes & $10(13.3 \%)$ & $464.3(90.8)$ & $465.6(107.0)$ & \\
\hline Unsure & $6(8.0 \%)$ & $441.3(53.1)$ & $441.9(73.6)$ & \\
\hline
\end{tabular}

Results from the univariate analysis comparing the number of SAT errors with potential covariates can be found in Table 14. Wilcoxon Rank-Sum p-values are reported. The number of SAT errors was not found to be significantly related to any of the potential covariates. BMI category was considered for inclusion in all multivariable 
models with SAT errors as the outcome because it was related to the number of SAT errors at a significance level of $p<0.20$.

Table 14. SAT Errors and Potential Covariates

\begin{tabular}{|c|c|c|c|c|}
\hline & n (\%) & Mean (SD) & Median (IQR) & P-value \\
\hline Total & $75(100 \%)$ & $3.3(2.2)$ & $3.0(4.0)$ & \\
\hline Gender & & & & 0.53 \\
\hline Boys & $38(50.7 \%)$ & $3.4(2.0)$ & $3.0(3.0)$ & \\
\hline Girls & $37(49.3 \%)$ & $2.5(3.1)$ & $3.0(3.0)$ & \\
\hline Age & & & & 0.93 \\
\hline 6-10 years & $33(44.0 \%)$ & $3.4(2.6)$ & $3.0(4.0)$ & \\
\hline 11-14 years & $42(56.0 \%)$ & $3.2(1.9)$ & $3.0(2.0)$ & \\
\hline BMI & & & & 0.12 \\
\hline Underweight $<18$ & $25(33.3 \%)$ & $4.0(2.7)$ & $4.0(3.0)$ & \\
\hline Normal 18-25 & $32(42.7 \%)$ & $2.7(1.8)$ & $2.5(2.5)$ & \\
\hline Overweight $>25$ & $18(24.0 \%)$ & $3.3(2.1)$ & $3.0(2.0)$ & \\
\hline Income & & & & 0.56 \\
\hline$\$ 46,111$ or less & $37(49.3 \%)$ & $3.4(2.3)$ & $3.0(3.0)$ & \\
\hline More than $\$ 46,111$ & $38(50.7 \%)$ & $3.1(2.2)$ & $3.0(3.0)$ & \\
\hline Environmental Tobacco Exposure & & & & 0.27 \\
\hline No & $66(88.0 \%)$ & $3.2(2.3)$ & $3.0(3.0)$ & \\
\hline Yes & $9(12.0 \%)$ & $3.8(1.7)$ & $4.0(2.0)$ & \\
\hline Indoor Pets & & & & 0.99 \\
\hline No & $19(25.3 \%)$ & $3.2(2.2)$ & $3.0(3.0)$ & \\
\hline Yes & $56(74.7 \%)$ & $3.2(2.2)$ & $3.0(3.5)$ & \\
\hline Lead Paint & & & & 0.55 \\
\hline No & $58(77.3 \%)$ & $3.3(2.2)$ & $3.0(4.0)$ & \\
\hline Yes & $17(22.7 \%)$ & $3.1(2.5)$ & $3.0(1.0)$ & \\
\hline Frequency of Home Cleaning & & & & 0.64 \\
\hline Less than once a week & $34(45.3 \%)$ & $3.1(2.2)$ & $3.0(2.0)$ & \\
\hline More than once a week & $41(54.7 \%)$ & $3.4(2.3)$ & $3.0(4.0)$ & \\
\hline Prenatal Tobacco Exposure & & & & 0.57 \\
\hline No & $59(78.7 \%)$ & $3.2(2.4)$ & $3.0(4.0)$ & \\
\hline Yes & $10(13.3 \%)$ & $3.4(1.8)$ & $3.5(3.0)$ & \\
\hline Unsure & $6(8.0 \%)$ & $2.5(2.0)$ & $2.0(2.0)$ & \\
\hline
\end{tabular}

(3a): First, the relationship between fly ash exposure and the BARS CPT and SAT outcome measures was assessed. Results from the univariate analysis comparing fly 
ash exposure and potential covariates are shown in Table 15. Chi-square p-values

comparing participants with fly ash to those with no fly ash are reported. There was no significant relationship between any of the potential covariates and presence of fly ash in the home.

Table 15. Fly Ash in Homes and Potential Covariates

\begin{tabular}{|c|c|c|c|c|}
\hline & $n(\%)$ & No Fly Ash & Fly Ash & P-value \\
\hline Total & 75 & 42 & 33 & \\
\hline Gender & & & & 0.9 \\
\hline Boys & $38(50.7 \%)$ & $21(50.0 \%)$ & $17(51.5 \%)$ & \\
\hline Girls & $37(49.3 \%)$ & $21(50.0 \%)$ & $16(48.5 \%)$ & \\
\hline Age & & & & 0.24 \\
\hline $6-10$ years & $33(44.0 \%)$ & $21(50.0 \%)$ & $12(36.4 \%)$ & \\
\hline 11-14 years & $42(56.0 \%)$ & $21(50.0 \%)$ & $21(63.6 \%)$ & \\
\hline BMI & & & & 0.23 \\
\hline Underweight $<18$ & $25(33.3 \%)$ & $16(38.1 \%)$ & $9(27.3 \%)$ & \\
\hline Normal 18-25 & $32(42.7 \%)$ & $19(45.2 \%)$ & $13(39.4 \%)$ & \\
\hline Overweight $>25$ & $18(24.0 \%)$ & $7(16.7 \%)$ & $11(33.3 \%)$ & \\
\hline Income & & & & 0.42 \\
\hline$\$ 46,111$ or less & $37(49.3 \%)$ & $19(45.2 \%)$ & $18(54.6 \%)$ & \\
\hline More than $\$ 46,111$ & $38(50.7 \%)$ & $23(54.8 \%)$ & $15(45.5 \%)$ & \\
\hline Environmental Tobacco & & & & \\
\hline Exposure & & & & 0.46 \\
\hline No & $66(88.0 \%)$ & $38(90.5 \%)$ & $28(84.9 \%)$ & \\
\hline Yes & $9(12.0 \%)$ & $4(9.5 \%)$ & $5(15.2 \%)$ & \\
\hline Indoor Pets & & & & 0.38 \\
\hline No & $19(25.3 \%)$ & $9(21.4 \%)$ & $10(30.3 \%)$ & \\
\hline Yes & $56(74.7 \%)$ & $33(78.6 \%)$ & $23(69.7 \%)$ & \\
\hline Lead Paint & & & & 0.79 \\
\hline No & $58(77.3 \%)$ & $32(76.2 \%)$ & $26(78.8 \%)$ & \\
\hline Yes & $17(22.7 \%)$ & $10(23.8 \%)$ & $7(21.2 \%)$ & \\
\hline Frequency of Home & & & & \\
\hline Cleaning & & & & 0.34 \\
\hline Less than once a week & $34(45.3 \%)$ & $17(40.5 \%)$ & $17(51.5 \%)$ & \\
\hline More than once a week & $41(54.7 \%)$ & $25(59.5 \%)$ & $16(48.5 \%)$ & \\
\hline
\end{tabular}


All linear regression models were adjusted for age and gender. Based on the results of the univariate analyses of potential covariates, additional covariates were also considered for inclusion in final multivariable models. The final multivariable linear regression model with CPT errors as the outcome variable and fly ash presences as the exposure variable also contained gender, age, and income as covariates. No additional covariates were found to significantly improve the fit of the linear regression model with CPT response latency as the outcome variable and fly ash presences as the exposure variable, therefore the final model contained only gender and age as covariates. The final multivariable linear regression model with SAT errors as the outcome variable and fly ash presences as the exposure variable contained gender, age, and BMI as covariates. Adjusted linear regression coefficients for relationship between fly ash and BARS outcomes, 95\% confidence intervals, and p-values are included in Table 16. There was no significant relationship found between fly ash exposure and CPT errors, CPT response latency, or SAT errors. 
Table 16. Linear Regression Coefficients for Fly Ash and BARS Outcomes

\begin{tabular}{|c|c|c|c|c|c|}
\hline & Beta* $(95 \%$ CI $)$ & P-value & Adjusted Beta (95\% CI) & P-value & Covariates \\
\hline \multicolumn{6}{|l|}{ Continuous Performance } \\
\hline Number of Errors ${ }^{a}$ & $0.04(-0.59,0.67)$ & 0.9 & $-0.04(-0.65,0.57)$ & 0.9 & $\begin{array}{l}\text { Age, Gender, } \\
\text { Income }\end{array}$ \\
\hline Response Latency ${ }^{b}$ & $-0.01(-0.06,0.04)$ & 0.66 & $-0.01(-0.06,0.04)$ & 0.66 & Age, Gender \\
\hline \multicolumn{6}{|l|}{ Selective Attention } \\
\hline Number of Errors ${ }^{c}$ & $0.24(-0.08,0.56)$ & 0.15 & $0.25(-0.08,0.57)$ & 0.15 & $\begin{array}{c}\text { Age, Gender, } \\
\text { BMI }\end{array}$ \\
\hline $\begin{array}{l}\text { *Adjusted for gender and age } \\
\text { a Square-root transformed } \\
{ }^{\mathrm{b}} \text { Log-transformed } \\
{ }^{\mathrm{c}} \text { Square-root transformed }\end{array}$ & & & & & \\
\hline
\end{tabular}


(3b): Next, the relationship between $\mathrm{PM}_{10}$ exposure and the BARS CPT and SAT outcome measures was assessed. Descriptive statistics about $\mathrm{PM}_{10}$ exposure are in Table 17. Overall, the geometric mean of $\mathrm{PM}_{10}$ exposure $\left(\mu \mathrm{g} / \mathrm{m}^{3}\right)$ was $16.94(95 \%$ confidence intervals $=(15.1,19.0)$. There was no significant difference in exposure to $\mathrm{PM}_{10}$ indoors by participants' age or gender.

Table 17. $\mathrm{PM}_{10}$ Concentration $\left(\mu \mathrm{g} / \mathrm{m}^{3}\right)$

\begin{tabular}{lccccccccc}
\hline & n & GM & SE & $\mathbf{9 5 \%}$ CI & Min & P25 & Median & P75 & Max \\
\hline $\begin{array}{l}\text { Total } \\
\text { Gender }\end{array}$ & 75 & 16.94 & 0.98 & $(15.1,19.0)$ & 5.37 & 12.09 & 16.34 & 23.28 & 92.24 \\
$\quad$ Males & 38 & 16.84 & 1.33 & $(14.4,19.8)$ & 7.85 & 12.12 & 14.79 & 21.24 & 77.06 \\
$\quad$ Females & 37 & 17.05 & 1.46 & $(14.3,20.3)$ & 5.37 & 12.09 & 17.12 & 23.28 & 92.24 \\
Age & & & & & & & & & \\
$\quad$ 6-10 years & 33 & 17.54 & 1.31 & $(15.1,20.4)$ & 7.85 & 13.58 & 17.70 & 23.89 & 42.46 \\
$\quad$ 11-14 years & 42 & 16.48 & 1.41 & $(13.9,19.6)$ & 5.37 & 11.67 & 13.89 & 22.23 & 92.24 \\
\hline
\end{tabular}

Results from the univariate analysis comparing $\mathrm{PM}_{10}$ exposure and potential covariates are in Table 18. Wilcoxon Rank-Sum p-values comparing participants' $\mathrm{PM}_{10}$ exposure are reported. Participants living in block groups with median incomes of $\$ 46,111$ or less had significantly greater $\mathrm{PM}_{10}$ concentrations indoors compared to participant homes in block groups with a median income of more than $\$ 46,111(\mathrm{p}=0.02)$. Potential covariates that were related to $\mathrm{PM}_{10}$ exposure at a significance level of $\mathrm{p}<0.20$, and thus subsequently considered for inclusion in multivariable linear regression models with $\mathrm{PM}_{10}$ exposure as an independent variable included: income $(\mathrm{p}=0.02)$, environmental tobacco smoke exposure $(\mathrm{p}=0.19)$, indoor pets $(\mathrm{p}=0.14)$, and frequency of home cleaning $(\mathrm{p}=0.09)$. 
Table 18. $\mathrm{PM}_{10}$ Concentration $\left(\mu \mathrm{g} / \mathrm{m}^{3}\right)$ and Potential Covariates

\begin{tabular}{|c|c|c|c|}
\hline & $\mathrm{n}(\%)$ & Geometric Mean PM $10(95 \%$ CI $)$ & P-value \\
\hline Total & $75(100 \%)$ & $16.94(15.1,19.0)$ & \\
\hline Gender & & & 0.76 \\
\hline Males & $38(50.7 \%)$ & $16.84(14.3,19.8)$ & \\
\hline Females & $37(49.3 \%)$ & $17.05(14.3,20.3)$ & \\
\hline Age & & & 0.3 \\
\hline $6-10$ years & $33(44.0 \%)$ & $17.54(15.1,20.4)$ & \\
\hline 11-14 years & $42(56.0 \%)$ & $16.48(13.9,19.6)$ & \\
\hline BMI & & & 0.76 \\
\hline Underweight $<18$ & $25(33.3 \%)$ & $16.91(14.6,19.6)$ & \\
\hline Normal 18-25 & $32(42.7 \%)$ & $17.94(14.5,22.3)$ & \\
\hline Overweight $>25$ & $18(24.0 \%)$ & $15.34(12.0,19.6)$ & \\
\hline Income & & & 0.02 \\
\hline$\$ 46,111$ or less & $37(49.3 \%)$ & $19.61(16.4,23.4)$ & \\
\hline More than $\$ 46,111$ & $38(50.7 \%)$ & $14.69(12.8,16.9)$ & \\
\hline \multicolumn{4}{|l|}{ Environmental } \\
\hline Tobacco Exposure & & & 0.19 \\
\hline No & $66(88.0 \%)$ & $16.38(14.6,18.4)$ & \\
\hline Yes & $9(12.0 \%)$ & $21.70(13.1,36.0)$ & \\
\hline Indoor Pets & & & 0.14 \\
\hline No & $19(25.3 \%)$ & $14.57(12.0,17.6)$ & \\
\hline Yes & $56(74.7 \%)$ & $17.83(15.5,20.5)$ & \\
\hline Lead Paint & & & 1.00 \\
\hline No & $58(77.3 \%)$ & $17.09(14.9,19.6)$ & \\
\hline Yes & $17(22.7 \%)$ & $16.42(13.3,20.3)$ & \\
\hline Frequency of Home & & & \\
\hline Cleaning & & & 0.09 \\
\hline $\begin{array}{r}\text { Less than once a week } \\
\text { More than once a }\end{array}$ & $34(45.3 \%)$ & $15.07(12.8,17.8)$ & \\
\hline week & $41(54.7 \%)$ & $18.67(15.9,21.9)$ & \\
\hline
\end{tabular}


In all linear regression models $\mathrm{PM}_{10}$ concentration was log-transformed and the models were adjusted for age and gender. Based on the results of the univariate analyses of potential covariates, additional covariates were also considered for inclusion in final multivariable models with BARS outcome measures as the dependent variable and log of $\mathrm{PM}_{10}$ concentration as the independent variable. The final multivariable linear regression model with CPT errors as the outcome variable and $\mathrm{PM}_{10}$ as the exposure variable also contained gender, age, and income as covariates. Covariates included in the final multivariable linear regression model with CPT response latency as the outcome variable and $\mathrm{PM}_{10}$ as the exposure variable were age, gender, and frequency of home cleaning. The final multivariable linear regression model with SAT errors as the outcome variable and $\mathrm{PM}_{10}$ as the exposure variable contained gender, age, environmental tobacco smoke exposure, and BMI as covariates. Adjusted linear regression coefficients, 95\% confidence intervals, and p-values for the relationship between $\mathrm{PM}_{10}$ concentration (log-transformed) and BARS outcomes are included in Table 19. There was no significant relationship found between $\mathrm{PM}_{10}$ exposure and CPT errors, CPT response latency, or SAT errors. 
Table 19. Linear Regression Coefficients for $\mathrm{PM}_{10}$ (natural-log transformed) and BARS Outcomes

\begin{tabular}{|c|c|c|c|c|c|}
\hline & Beta* $(95 \%$ CI $)$ & P-value & Adjusted Beta (95\% CI) & P-value & Covariates \\
\hline \multicolumn{6}{|c|}{ Continuous Performance } \\
\hline Number of Errors ${ }^{a}$ & $-0.12(-1.56,1.31)$ & 0.87 & $-0.73(-2.16,0.70)$ & 0.32 & $\begin{array}{c}\text { Income, Age, } \\
\text { Gender }\end{array}$ \\
\hline Response Latency ${ }^{b}$ & $-0.054(-0.17,0.06)$ & 0.36 & $-0.067(-0.19,0.05)$ & 0.28 & $\begin{array}{l}\text { Age, Gender, } \\
\text { Home Cleaning }\end{array}$ \\
\hline \multicolumn{6}{|l|}{ Selective Attention } \\
\hline Number of Errors ${ }^{c}$ & $0.28(-0.47,1.02)$ & 0.46 & $0.26(-0.49,1.03)$ & 0.49 & $\begin{array}{l}\text { Age, Gender, } \\
\text { Environmental } \\
\text { Tobacco, BMI }\end{array}$ \\
\hline $\begin{array}{l}\text { *Adjusted for gender and ag } \\
\text { a Square-root transformed } \\
{ }^{\mathrm{b}} \text { Natural Log-transformed } \\
{ }^{\mathrm{c}} \text { Square-root transformed }\end{array}$ & & & & & \\
\hline
\end{tabular}


4. Specific Aim 4 Results: Assess the relationship between PM10 concentration, fly ash exposure, and deficient emotional self-regulation (DESR)

The primary outcome assessed in Specific Aim 4 is emotional self-regulation, which was assessed using the continuous DESR score calculated from the CBCL. The CBCL was completed and the DESR score was assessed for $\mathrm{n}=75$ participants. Overall, the mean DESR score is $167.5(\mathrm{SD}=21.4)$ and median is $159.0(\mathrm{IQR}=25.0)$.

Results from the univariate analysis comparing the DESR score with potential covariates can be found in Table 20. Wilcoxon Rank-Sum p-values are reported. Participants with indoor pets had significantly higher DESR scores $(\mathrm{p}=0.002)$. Covariates considered for inclusion in negative binomial regression models with DESR score as the outcome included indoor pets $(\mathrm{p}=0.002)$ and lead paint $(\mathrm{p}=0.10)$ because both were significantly related to DESR score at $\mathrm{p}<0.20$. 
Table 20. DESR Score and Potential Covariates

\begin{tabular}{|c|c|c|c|c|}
\hline & $\mathrm{n}(\%)$ & Mean (SD) & Median (IQR) & P-value \\
\hline Total & $75(100 \%)$ & $167.5(21.4)$ & $159.0(25.0)$ & \\
\hline Gender & & & & 0.85 \\
\hline Males & $38(50.7 \%)$ & $166.3(17.8)$ & $158.0(26.0)$ & \\
\hline Females & $37(49.3 \%)$ & $168.8(24.7)$ & $160.0(23.0)$ & \\
\hline Age & & & & 0.73 \\
\hline $6-10$ years & $33(44.0 \%)$ & $165.0(16.1)$ & $160.0(23.0)$ & \\
\hline 11-14 years & $42(56.0 \%)$ & $169.5(24.8)$ & $158.0(27.0)$ & \\
\hline BMI & & & & 0.58 \\
\hline Underweight $<18$ & $25(33.3 \%)$ & $169.3(20.1)$ & $163.5(27.0)$ & \\
\hline Normal 18-25 & $32(42.7 \%)$ & $166.4(24.8)$ & $156.0(21.5)$ & \\
\hline Overweight $>25$ & $18(24.0 \%)$ & $166.4(17.6)$ & $160.5(24.0)$ & \\
\hline Income & & & & 0.28 \\
\hline$\$ 46,111$ or less & $37(49.3 \%)$ & $171.1(27.3)$ & $159.0(32.0)$ & \\
\hline More than $\$ 46,111$ & $38(50.7 \%)$ & $163.1(12.2)$ & $160.0(24.0)$ & \\
\hline $\begin{array}{l}\text { Environmental Tobacco } \\
\text { Exposure }\end{array}$ & & & & 0.74 \\
\hline No & $66(88.0 \%)$ & $168.4(22.5)$ & $159.0(27.0)$ & \\
\hline Yes & $9(12.0 \%)$ & $161.4(8.8)$ & $160.0(11.0)$ & \\
\hline Indoor Pets & & & & 0.002 \\
\hline $\mathrm{No}$ & $19(25.3 \%)$ & $156.6(10.2)$ & $152.0(9.0)$ & \\
\hline Yes & $56(74.7 \%)$ & $171.2(23.0)$ & $164.5(26.0)$ & \\
\hline Lead Paint & & & & 0.10 \\
\hline No & $58(77.3 \%)$ & $165.5(20.4)$ & $159.0(24.0)$ & \\
\hline Yes & $17(22.7 \%)$ & $174.4(23.8)$ & $168.0(24.0)$ & \\
\hline $\begin{array}{l}\text { Frequency of Home } \\
\text { Cleaning }\end{array}$ & & & & 0.55 \\
\hline Less than once a week & $34(45.3 \%)$ & $165.4(18.2)$ & $158.0(23.0)$ & \\
\hline More than once a week & $41(54.7 \%)$ & $169.3(23.8)$ & $161.0(28.0)$ & \\
\hline $\begin{array}{l}\text { Prenatal Tobacco } \\
\text { Exposure }\end{array}$ & & & & 0.35 \\
\hline No & $59(78.7 \%)$ & $165.6(19.3)$ & $159.0(24.0)$ & \\
\hline Yes & $10(13.3 \%)$ & $172.5(21.6)$ & $165.5(24.0)$ & \\
\hline Unsure & $6(8.0 \%)$ & $178.2(37.2)$ & $159.0(68.0)$ & \\
\hline
\end{tabular}

(4a): GLM negative binomial regression was used to assess the relationship between DESR score and fly ash exposure. First, models were constructed with DESR score as the dependent variable and fly ash exposure, age, and gender as independent 
variables. The adjusted linear regression beta coefficient for the relationship between DESR score and fly ash exposure was $\beta=0.005 ; 95 \% \mathrm{CI}=(-0.05,0.06) ; \mathrm{p}$-value $=0.87$.

Next, potential covariates were considered for inclusion in the multivariate negative binomial regression model with DESR score and fly ash exposure. All of the covariates that were considered were included in the final model. The final multivariate negative binomial regression model included age, gender, pets, and lead and the adjusted beta coefficient for the relationship between DESR score and fly ash is $\beta=0.0017$; $95 \% \mathrm{CI}=(-0.04,0.07) ; \mathrm{p}$-value $=0.52$.

(4b): GLM negative binomial regression models were used to assess the relationship between the DESR score and the log-transformed $\mathrm{PM}_{10}$ concentration. In the negative binomial regression model with DESR score as the outcome and $\mathrm{PM}_{10}$ concentration, age, and gender as independent variables the adjusted beta coefficient was $\beta=0.10 ; 95 \% \mathrm{CI}=(-0.03,0.22) ; \mathrm{p}-$ value $=0.12$.

Potential covariates considered for inclusion in the negative binomial regression model with DESR score and $\mathrm{PM}_{10}$ exposure included: age, gender, income, environmental tobacco smoke exposure, indoor pets, and frequency of home cleaning. Covariates that were found to be significant and included in the final multivariate model were age, gender, income, pets in home, and lead paint. While adjusting for these covariates, the adjusted beta coefficient for the relationship between DESR score and logtransformed $\mathrm{PM}_{10}$ concentration is $\beta=0.027 ; 95 \% \mathrm{CI}=(-0.10,0.15)$; $\mathrm{p}$-value $=0.67$. 


\section{Specific Aim 5 Results: Assess the relationship between metal exposure and cognitive control using Bayesian Kernel Machine Regression (BKMR) and linear regression models}

(5a): Table 21 contains a summary of the univariate exposure-response relationships between metal concentrations and BARS outcomes or DESR score that were visualized using BKMR. The observed direction of the relationship is noted in the table for each individual metal and outcome. Output from the BKMR models with the graphs of the exposure-response relationships is included in Appendix: Supplemental Figure 4, Figure 5, Figure 6, and Figure 7. The metals or metalloids that appeared to be related to at least two of the BARS outcomes or DESR score and were investigated further in regression analysis included: aluminum, titanium, copper, and silicon. Because aluminum was the only metal that appeared to be related to all of the BARS outcomes and DESR score, it is the focus in Subaim (5b) and Subaim (6b). Titanium, copper, and silicon were investigated in linear regression models adjusted for age and gender. The results from those models are included in the Appendix: Supplemental Table 4. 
Table 21. Direction of Univariate Exposure-Response Relationship Suggested by BKMR model

\begin{tabular}{cccccccccccc}
\hline & Al & Ti & Cr & Mn & Fe & Ni & Cu & Zn & As & Si \\
\hline CPT Errors & Positive & None & None & None & None & None & None & None & Negative & Negative \\
$\begin{array}{c}\text { Response } \\
\text { Latency }\end{array}$ & Negative & None & None & None & None & None & None & None & None & Negative \\
SAT Errors & Positive & Negative & None & None & None & None & Positive & None & None & None \\
DESR Score & Positive & Negative & None & None & None & None & Negative & None & None & None \\
\hline
\end{tabular}


(5b): The concentration of aluminum was above the LOD on all of the air filters for participants $(\mathrm{n}=75)$ included in this analysis. The mean and median for the aluminum concentration $\left(\mu \mathrm{g} / \mathrm{m}^{3}\right)$ in $\mathrm{PM}_{10}$ is mean $(\mathrm{SD})=0.089(0.12)$ and the median $=0.055(\mathrm{~min}=$ $0.018, \mathrm{Q} 25=0.042, \mathrm{Q} 75=0.093, \mathrm{Max}=0.97)$. The univariate analysis of the relationship between potential covariates and aluminum concentration in $\mathrm{PM}_{10}$ can be found in Table 22. Wilcoxon Rank-Sum p-values are reported. Participants with indoor pets were exposed to significantly greater concentrations of aluminum $(\mathrm{p}=0.03)$. 
Table 22. Aluminum $\left(\mu \mathrm{g} / \mathrm{m}^{3}\right)$ and Potential Covariates

\begin{tabular}{|c|c|c|c|c|}
\hline & $\mathrm{n}(\%)$ & Mean (SD) & Median (IQR) & P-value \\
\hline Total & $\overline{75}$ & $0.089(0.118)$ & $0.055(0.052)$ & \\
\hline Gender & & & & 0.25 \\
\hline Males & $38(50.7 \%)$ & $0.073(0.063)$ & $0.053(0.043)$ & \\
\hline Females & $37(49.3 \%)$ & $0.11(0.160)$ & $0.065(0.071)$ & \\
\hline Age & & & & 0.26 \\
\hline $6-10$ years & $33(44.0 \%)$ & $0.11(0.160)$ & $0.065(0.061)$ & \\
\hline 11-14 years & $42(56.0 \%)$ & $0.076(0.064)$ & $0.053(0.048)$ & \\
\hline BMI & & & & 0.06 \\
\hline Underweight $<18$ & $25(33.3 \%)$ & $0.116(0.184)$ & $0.070(0.057)$ & \\
\hline Normal 18-25 & $32(42.7 \%)$ & $0.085(0.072)$ & $0.057(0.046)$ & \\
\hline Overweight $>25$ & $18(24.0 \%)$ & $0.058(0.042)$ & $0.044(0.019)$ & \\
\hline Income & & & & 0.14 \\
\hline$\$ 46,111$ or less & $37(49.3 \%)$ & $0.109(0.160)$ & $0.060(0.075)$ & \\
\hline More than $\$ 46,111$ & $38(50.7 \%)$ & $0.069(0.048)$ & $0.053(0.049)$ & \\
\hline Environmental Tobacco & & & & 0.12 \\
\hline No & $66(88.0 \%)$ & $0.089(0.126)$ & $0.054(0.048)$ & \\
\hline Yes & $9(12.0 \%)$ & $0.090(0.043)$ & $0.086(0.052)$ & \\
\hline Indoor Pets & & & & 0.03 \\
\hline No & $19(25.3 \%)$ & $0.052(0.028)$ & $0.048(0.036)$ & \\
\hline Yes & $56(74.7 \%)$ & $0.101(0.134)$ & $0.060(0.065)$ & \\
\hline Lead Paint & & & & 0.68 \\
\hline No & $58(77.3 \%)$ & $0.077(0.061)$ & $0.056(0.045)$ & \\
\hline Yes & $17(22.7 \%)$ & $0.128(0.222)$ & $0.054(0.077)$ & \\
\hline $\begin{array}{l}\text { Frequency of Home } \\
\text { Cleaning }\end{array}$ & & & & 0.59 \\
\hline Less than once a week & $34(45.3 \%)$ & $0.069(0.042)$ & $0.054(0.042)$ & \\
\hline More than once a week & $41(54.7 \%)$ & $0.106(0.155)$ & $0.058(0.083)$ & \\
\hline
\end{tabular}

Covariates considered for inclusion in the three linear regression models with BARS outcomes as dependent variables and aluminum exposure as the independent variable were BMI, income, environmental tobacco exposure, indoor pets, age, and gender. The adjusted linear regression beta coefficients for the relationship between the 
BARS outcomes and aluminum exposure, 95\% confidence intervals, and p-values are in Table 23.

The final multivariate linear regression model with CPT errors as the dependent outcome variable and aluminum exposure as the independent exposure variable was adjusted for age, gender and income. Covariates included in the final multivariable linear regression model with CPT response latency as the outcome variable and aluminum concentration as the exposure variable were age, gender, and BMI. The final multivariable linear regression model with SAT errors as the outcome variable and aluminum concentration as the exposure variable contained gender, age, environmental tobacco smoke exposure, and BMI as covariates. There was a significant positive relationship between CPT errors and aluminum exposure, and a significant negative relationship between CPT response latency and aluminum exposure. In addition, there was a significant positive relationship between SAT errors and aluminum concentrations.

When the linear regression models were assessed for outliers with influence, one participant that lives a short distance from one ash landfill was identified with high concentrations of aluminum indoors. Because there are few other participants that live as close to the ash landfill as this participant, it was hard to determine if the concentrations measured indoors accurately reflect exposure at the short distance or if the high concentration was a result of some other indoor source of aluminum exposure. Based on the interactions with the participants and other survey data collected, the study team had no reason to believe that anyone smoked inside the home and there were no other sources of aluminum exposure that could be identified indoors. However, the linear regression models were reconstructed with the BARS outcomes and the participant with the high 
aluminum concentration was assigned the value of the person with the next highest concentration in the same Census block group. The results of this analysis are included in the Appendix: Supplemental Table 5. When the participant was assigned the lower aluminum level the p-values for the beta coefficients were no longer significant, however the estimates did not vary greatly from the original models. Based on the best information available, there is no reason to treat the participant with the high concentration of aluminum as an outlier. As more participants are collected at the shortest distance from the ash landfill, it may become apparent that the concentration of aluminum measured in this home does not greatly vary from surrounding households. Therefore the final model reported in this dissertation is the one with the measured concentrations of aluminum. Once data collection for the larger study has been completed, the outliers will be reassessed and the analysis will be repeated. 
Table 23. Linear Regression Coefficients for Aluminum $\left(\mu \mathrm{g} / \mathrm{m}^{3}\right)$ and BARS Outcomes

\begin{tabular}{|c|c|c|c|c|c|}
\hline & Beta* $(95 \%$ CI $)$ & P-value & Adjusted Beta (95\% CI) & P-value & Covariates \\
\hline \multicolumn{6}{|c|}{ Continuous Performance } \\
\hline Number of Errors ${ }^{a}$ & $3.84(1.30,6.38)$ & 0.004 & $3.33(0.82,5.83)$ & 0.01 & $\begin{array}{l}\text { Age, Gender, } \\
\text { Income }\end{array}$ \\
\hline Response Latency ${ }^{b}$ & $-0.24(-0.45,-0.03)$ & 0.03 & $-0.23(-0.44,-0.01)$ & 0.04 & $\begin{array}{c}\text { Age, Gender, } \\
\text { BMI }\end{array}$ \\
\hline \multicolumn{6}{|l|}{ Selective Attention Test } \\
\hline Number of Errors ${ }^{c}$ & $1.71(0.36,3.06)$ & 0.02 & $1.65(0.30,3.00)$ & 0.02 & $\begin{array}{l}\text { Age, Gender, } \\
\text { Environmental } \\
\text { Tobacco, BMI }\end{array}$ \\
\hline $\begin{array}{l}\text { *Adjusted for gender and age } \\
\text { a Square-root transformed } \\
{ }^{\mathrm{b}} \text { Natural log-transformed } \\
{ }^{\mathrm{c}} \text { Square-root transformed }\end{array}$ & & & & & \\
\hline
\end{tabular}


(5c): In addition to assessing aluminum concentration, the MES score was developed to assess if there was an accumulative effect of the metal mixture in $\mathrm{PM}_{10}$ on cognitive control. The relationship between the potential covariates, BARS outcomes, DESR Score, and MES tertiles was assessed. For many of the covariates and outcomes the lowest tertiles were not significantly different; therefore, the lowest two tertiles were combined due to the low cell counts into a Low Category and the highest tertile represents the High Category. Univariate analysis of the relationship between the MES category and potential covariates is in Table 24. Fisher's Exact p-values are reported. 
Table 24. MES Score and Potential Covariates

\begin{tabular}{|c|c|c|c|c|}
\hline & $\mathrm{n}(\%)$ & Low Category & High Category & P-value \\
\hline Total & 75 & $74.7 \%(56)$ & $25.3 \%(19)$ & \\
\hline Gender & & & & 0.44 \\
\hline Males & $38(50.7 \%)$ & $30(53.6 \%)$ & $8(42.1 \%)$ & \\
\hline Females & $37(49.3 \%)$ & $26(46.4 \%)$ & $11(57.9 \%)$ & \\
\hline Age & & & & 0.43 \\
\hline $6-10$ years & $33(44.0 \%)$ & $23(41.1 \%)$ & $10(52.6 \%)$ & \\
\hline 11-14 years & $42(56.0 \%)$ & $33(58.9 \%)$ & $9(47.4 \%)$ & \\
\hline BMI & & & & 0.52 \\
\hline Underweight $<18$ & $25(33.3 \%)$ & $17(30.4 \%)$ & $8(42.1 \%)$ & \\
\hline Normal 18-25 & $32(42.7 \%)$ & $24(42.9 \%)$ & $8(42.1 \%)$ & \\
\hline Overweight $>25$ & $18(24.0 \%)$ & $15(26.8 \%)$ & $3(15.8 \%)$ & \\
\hline Income & & & & 0.44 \\
\hline$\$ 46,111$ or less & $37(49.3 \%)$ & $26(70.3 \%)$ & $11(57.9 \%)$ & \\
\hline More than $\$ 46,111$ & $38(50.7 \%)$ & $30(79.0 \%)$ & $8(42.1 \%)$ & \\
\hline Environmental & & & & 0.04 \\
\hline $\mathrm{No}$ & $66(88.0 \%)$ & $52(92.9 \%)$ & $14(73.7 \%)$ & \\
\hline Yes & $9(12.0 \%)$ & $4(7.1 \%)$ & $5(26.3 \%)$ & \\
\hline Indoor Pets & & & & 0.03 \\
\hline No & $19(25.3 \%)$ & $18(32.1 \%)$ & $1(5.3 \%)$ & \\
\hline Yes & $56(74.7 \%)$ & $38(67.9 \%)$ & $18(94.7 \%)$ & \\
\hline Lead Paint & & & & 1.00 \\
\hline No & $58(77.3 \%)$ & $43(74.1 \%)$ & $13(76.5 \%)$ & \\
\hline Yes & $17(22.7 \%)$ & $15(25.9 \%)$ & $4(23.5 \%)$ & \\
\hline $\begin{array}{l}\text { Frequency of Home } \\
\text { Cleaning }\end{array}$ & & & & 0.75 \\
\hline Less than once a week & $34(45.3 \%)$ & $44(78.6 \%)$ & $14(73.7 \%)$ & \\
\hline $\begin{array}{r}\text { More than once a } \\
\text { week }\end{array}$ & $41(54.7 \%)$ & $12(21.4 \%)$ & $5(26.3 \%)$ & \\
\hline
\end{tabular}

More participants that were exposed to environmental tobacco smoke $(\mathrm{p}=0.04)$ and had indoor pets $(\mathrm{p}=0.03)$ were in the High MES Category. The covariates included in the final multivariable linear regression models were the same as those included in the final multivariable linear regression model assessing the relationships between the BARS outcomes and aluminum. The adjusted beta coefficients for the relationship between the 
BARS outcomes and MES category, 95\% confidence intervals, and p-values are in Table 25. There were no significant relationships between any of the BARS outcome measures and MES category. 
Table 25. Linear Regression Coefficients for MES and BARS Outcomes

\begin{tabular}{|c|c|c|c|c|c|}
\hline & Beta* $(95 \%$ CI $)$ & P-value & Adjusted Beta (95\% CI) & P-value & Covariates \\
\hline \multicolumn{6}{|c|}{ Continuous Performance } \\
\hline Number of Errors ${ }^{a}$ & $0.010(-0.71,0.73)$ & 0.98 & $-0.086(-0.780,0.609)$ & 0.81 & $\begin{array}{l}\text { Age, Gender, } \\
\text { Income }\end{array}$ \\
\hline Response Latency ${ }^{b}$ & $-0.030(-0.09,0.03)$ & 0.36 & $-0.024(-0.083,0.034)$ & 0.42 & $\begin{array}{c}\text { Age, Gender, } \\
\text { BMI }\end{array}$ \\
\hline \multicolumn{6}{|l|}{ Selective Attention Test } \\
\hline Number of Errors ${ }^{c}$ & $-0.077(-0.45,0.29)$ & 0.69 & $-0.154(-0.54,0.23)$ & 0.44 & $\begin{array}{c}\text { Age, Gender, } \\
\text { Environment } \\
\text { al tobacco, } \\
\text { BMI }\end{array}$ \\
\hline $\begin{array}{l}\text { *Adjusted for gender and a } \\
\text { a Square-root transformed } \\
\text { b Natural Log-transformed } \\
{ }^{c} \text { Square-root transformed }\end{array}$ & & & & & \\
\hline
\end{tabular}




\section{Specific Aim 6 Results}

(6a): Table 21 contains a summary of the univariate exposure-response relationships between metal concentrations and DESR score that were visualized using BKMR. As previously explained in Subaim (5a), the analysis in Subaim (6b) will focus on aluminum exposure and the relationship with the DESR score.

(6b): GLM negative binomial regression was used to assess the relationship between DESR score and exposure to aluminum $\left(\mu \mathrm{g} / \mathrm{m}^{3}\right)$. In the negative binomial regression model with DESR score as the outcome variable and aluminum, age, and gender as independent variables the adjusted linear regression beta coefficient for aluminum is $\beta=0.20 ; 95 \% \mathrm{CI}=(-0.03,0.43) ; \mathrm{p}=0.09$.

Covariates considered for inclusion in the multivariable negative binomial regression model with DESR score as the dependent variables and aluminum exposure as the independent variable were environmental tobacco exposure, indoor pets, lead paint, age, and gender. The final model included age, gender, indoor pets, income and lead paint as covariates. The adjusted beta coefficient for the relationship between the DESR score and aluminum is $\beta=0.05 ; 95 \% \mathrm{CI}=(-0.17,0.27) ; \mathrm{p}=0.65$.

(6c): In the negative binomial regression model with DESR score as the outcome variable and MES category, age, and gender as independent variables the adjusted beta coefficient for MES category is $\beta=0.006 ; 95 \% \mathrm{CI}=(-0.057,0.07) ; \mathrm{p}$-value $=0.85$.

The covariates included in the multivariable negative binomial regression model with DESR score as the outcome and MES category as the independent exposure variable were the same as those included in the multivariable model in Subaim (6b): age, gender, indoor pets, income and lead paint. The adjusted beta coefficient for the relationship 
between the DESR score and MES category is $\beta=-0.002 ; 95 \% \mathrm{CI}=(-0.063,0.060)$; $\mathrm{p}$ value $=0.96$. There was no significant relationship between DESR score and MES category. 


\section{DISCUSSION}

This on-going study is the first to assess indoor exposure to fly ash, metals, $\mathrm{PM}_{10}$, and neurobehavioral outcomes in children living near coal-burning power plants. The findings presented in this dissertation are preliminary, but reveal many areas for further investigation as more data become available.

\section{Summary of Results}

\section{$\underline{\text { 1a. Relationship Between Exposure to } \mathrm{PM}_{10}, \text { Fly Ash, Metals }}$}

Specific aims 1 and 2 were focused on characterizing the relationship between exposure to fly ash, $\mathrm{PM}_{10}$, and metals, as well as beginning to understand the geographical distribution of these exposures. Metals or metalloids that were found to be abundant in fly ash particles included aluminum, iron, titanium, potassium, and silicon which is consistent with other studies assessing the composition of fly ash particles (9). While there was no relationship found between the presence of fly ash in the home and overall $\mathrm{PM}_{10}$ or metal concentration, concentrations of aluminum, titanium, and silicon were present in $\mathrm{PM}_{10}$ above the LOD in a majority of the participants' homes. Given that these three elements were some of the most abundant in fly ash particles, one source of these three elements in $\mathrm{PM}_{10}$ concentrations measured in homes surrounding the power

plants could be fly ash. Because the presence of fly ash was only determined on a small 
section of the air filter, it is possible that some homes with higher concentrations of the elements found in fly ash were misclassified as not having fly ash.

Distance from the homes to the fly ash landfills was not related to fly ash presence in the home, but it was related to the metal/metalloid concentration of $\mathrm{PM}_{10}$. Overall results from univariate analysis of the relationship between the Environmental Indicator and exposure variables suggest that living closer to either power plant was associated with higher $\mathrm{PM}_{10}$ concentrations, as well as higher indoor concentrations of aluminum, chromium, manganese, silicon, and titanium (Supplemental Table 2). To explore this relationship further, univariate analysis of the relationship between distance to each individual landfill and exposure variables was conducted to identify which fly ash landfill (Cane Run or Mill Creek) may be contributing more $\mathrm{PM}_{10}$ into the study area.

Homes closer to Mill Creek had significantly greater concentrations of aluminum, manganese, silicon, and titanium. For each kilometer increase in distance from Mill Creek there was an estimated decrease in aluminum concentration of $-5.54 \%(\mathrm{p}=0.0006)$, a decrease in manganese concentration of $-4.97 \%(\mathrm{p}=0.001)$, a decrease in silicon concentration of $-4.59 \%(\mathrm{p}=0.0001)$, and a decrease in titanium concentration of $-3.44 \%$ $(\mathrm{p}=0.05)$. Homes further away from Cane Run appeared to have more aluminum, manganese, and silicon. However, this observed relationship is likely due to confounding by distance from the Mill Creek landfill. The observed relationships between distance to the Cane Run landfill and metal/metalloid concentrations are likely due to proximity to the Mill Creek landfill (homes further from Cane Run were closer to Mill Creek). For each kilometer increase in distance from Cane Run there was an estimated increase in 
aluminum concentration of $7.14 \%(\mathrm{p}=0.003)$, an increase in manganese concentration of $6.29 \%(\mathrm{p}=0.006)$, and an increase in silicon concentration of $4.71 \%(\mathrm{p}=0.008)$.

The difference in the direction of the relationship between distance and metal concentrations is interesting and an area to investigate further. Results from univariate analysis of the relationship between distance to landfills and exposure variables, suggest that more $\mathrm{PM}_{10}$ emissions are generated from the Mill Creek landfill into the study area than from the Cane Run landfill. Based on this finding it could be hypothesized that the fly ash landfill, which is currently active at Mill Creek, but not at Cane Run, may be a source of indoor aluminum, manganese, and silicon $\mathrm{PM}_{10}$ pollution. Winds prevailing predominately from the southwest could carry $\mathrm{PM}_{10}$ from Mill Creek into the study area. However, there are likely characteristics that are different between Cane Run and Mill Creek beyond the status of the landfill, which could increase fugitive dust emissions from one site and reduce emission into the study area from the other. These factors including wind and direction from the fly ash landfills will be investigated further in future analyses.

The EJ Index was not related to the presence of fly ash in the home, but it was related to total $\mathrm{PM}_{10}$ concentration, as well as the aluminum and titanium concentrations. Participants living in more susceptible block groups were more likely to have greater concentrations of total $\mathrm{PM}_{10}(\mathrm{p}=0.002)$, aluminum $(\mathrm{p}=0.05)$, and titanium $(\mathrm{p}=0.0005)$. The relationship between the EJ Index and $\mathrm{PM}_{10}$, aluminum, and titanium exposure seems to be primarily driven by the association between the exposures and the Environmental Indicator portion of the EJ Index formula (Appendix: Supplemental Table 2 and Table 3). However, there was a positive correlation between distance from Cane 
Run and the Demographic Index and a negative correlation between distance from Mill Creek and the Demographic Index demonstrating that it is hard to completely ignore the role of socio-demographic factors in exposure.

It is apparent that there is a complex relationship between proximity to the coalburning power plants with fly ash, $\mathrm{PM}_{10}$, metal exposure, and socio-demographic factors. Characterizing the relationship between these factors is important in public health research attempting to identify specific environmental hazards and link them to health problems in vulnerable populations. The EJ Index may be a useful tool to consider the impacts of both distance from the two ash landfills and socio-demographic factors on exposure. Future analysis will also assess household characteristics that reduce or increase fly ash and $\mathrm{PM}_{10}$ exposure in Census block groups that may make populations more susceptible to exposure. Other outdoor sources of indoor $\mathrm{PM}_{10}$ pollution, including roadways and industrial factories, could be considered to better characterize sources of $\mathrm{PM}_{10}$ in the home. Substitution methods used for values below the LOD and the impact on estimates of the association between metal exposure, distance, and the EJ Index will also be explored.

1b. Relationship Between Exposure to Fly Ash, PM 10 , Metals and Cognitive Control Specific aims 3 and 5 were focused on characterizing the relationship between cognitive control and exposure to fly ash, $\mathrm{PM}_{10}$, as well as metals. CPT errors, SAT errors, and CPT response latency were not related to fly ash presence in the home (yes/no) or total concentration of $\mathrm{PM}_{10}$ in multivariable linear regression models or models adjusted for only for age and gender. BKMR models suggested a possible 
relationship between aluminum concentration and the BARS outcomes. Thus, the exposure effect was estimated using linear regression models.

To assess the relationship between the BARS outcomes and exposure measures in linear models, the CPT and SAT errors had to be square root transformed and the CPT response latency was transformed by the natural logarithm. In linear regression models adjusting for age and gender, an increase in aluminum concentration from the $25^{\text {th }}$ percentile to the $75^{\text {th }}$ percentile would increase the square-root CPT errors by $0.198(\mathrm{p}=$ 0.004). An example to help interpret this estimated effect of aluminum exposure is to consider that increasing exposure from the $25^{\text {th }}$ percentile to the $75^{\text {th }}$ percentile for a male at the median age of 11 years would result in an estimated $14.5 \%$ increase in CPT errors (from 8.0 to 9.2 errors). Increasing aluminum exposure from the $25^{\text {th }}$ percentile to the $75^{\text {th }}$ percentile for a female at the median age of 11 years would result in an estimated $16.9 \%$ increase in CPT errors (from 5.9 to 6.9 errors). In linear regression models adjusting for age and gender, an increase in aluminum concentration from the $25^{\text {th }}$ percentile to the $75^{\text {th }}$ percentile was associated with a $1.29 \%$ decrease in response latency $(\mathrm{p}=0.03)$. Finally, in linear regression models adjusting for age and gender, an increase in aluminum concentration from the $25^{\text {th }}$ percentile to the $75^{\text {th }}$ percentile would increase the squareroot SAT errors by $0.088(\mathrm{p}=0.02)$. To conceptualize the effect of aluminum exposure on SAT performance in a more practical way, increasing exposure from the $25^{\text {th }}$ percentile to the $75^{\text {th }}$ percentile for a male at the median age of 11 years would result in an estimated $10.8 \%$ increase in SAT errors (from 2.8 to 3.1 errors). Increasing aluminum exposure from the $25^{\text {th }}$ percentile to the $75^{\text {th }}$ percentile for a female at the median age of 11 years would result in an estimated $12.2 \%$ increase in SAT errors (2.2 to 2.5 errors). 
The beta coefficients for the relationship between aluminum and BARS outcomes were only slightly different in multivariable linear regression models compared to estimates in the models only adjusted for age and gender. In a linear regression model adjusted for age, gender, and income, an increase in aluminum concentration from the $25^{\text {th }}$ percentile to the $75^{\text {th }}$ percentile would increase the square-root CPT errors by 0.172 $(\mathrm{p}=0.01)$. In a linear regression model adjusted for age, gender, and BMI, an increase in aluminum concentration from the $25^{\text {th }}$ percentile to the $75^{\text {th }}$ percentile was associated with a $1.18 \%$ decrease in response time. Additionally, in linear regression models adjusted for age, gender, environmental tobacco exposure, and BMI, an increase in aluminum concentration from the $25^{\text {th }}$ percentile to the $75^{\text {th }}$ percentile would increase the square-root SAT errors by 0.085 ( $\mathrm{p}=0.02)$.

The BARS CPT was developed to assess sustained attention and selective attention, while the SAT was developed to assess sustained attention. For this dissertation, the numbers of omission and commission errors for each test were combined to assess general attention problems. Children with higher concentrations of aluminum exposure committed more errors on both the SAT and CPT, indicating a general problem with inattention. In addition, children with higher concentration of aluminum exposure had faster CPT response latencies, which is indicative of problems with impulsivity. Future analysis with a larger sample will assess the omission errors and commission errors separately for each test to garner a more descriptive assessment of cognitive control in children exposed to aluminum. In addition, the association between direct measures of aluminum exposure (toenail and fingernail samples) and cognitive control will be assessed. Using data from the coal ash study, Tompkins (2016) found that the 
concentration of aluminum in the nails of approximately $45 \%$ of participants was above levels previously reported in studies assessing aluminum in nails(104). When data collection for the Coal Ash Study has been completed, there should be ample power to assess the relationship between aluminum exposure and cognitive control.

\section{$\underline{\text { 1c. Relationship Between Exposure to Fly Ash, PM}} 102$, Metals and DESR}

Specific aims 4 and 6 were focused on assessing the relationship between selfregulation and exposure to fly ash, $\mathrm{PM}_{10}$, and metal concentrations. DESR score was not related to the presence of fly ash in the home, $\mathrm{PM}_{10}$ concentration, or metal concentration. Similarly to the assessment of cognitive control and metal exposure, the BKMR model suggested that there might be a relationship between aluminum and DESR. There was no statistically significant relationship in a negative binomial regression model assessing the relationship between DESR and aluminum exposure while adjusting for age and gender $(\mathrm{p}=0.09)$. In the multivariable negative binomial model with age, gender, indoor pets, income, and lead paint the significance of the relationship between aluminum and DESR was diminished further $(\mathrm{p}=0.65)$.

\section{Aluminum and Cognitive Control?}

Aluminum exposure was significantly related to all BARS measures of cognitive control. Despite being one of the most abundant metals in the earth's crust, there is a lack of research on the neurotoxic effect of aluminum exposure in children. Generally,

background atmospheric concentrations of aluminum range from 0.005 to $18 \mu \mathrm{g} / \mathrm{m}^{3}$ with higher concentrations more common in urban and industrialized areas. A study conducted with 46 high school students in Harlem, New York in 1999 measured indoor aluminum 
concentrations of $41 \mathrm{ng} / \mathrm{m}^{3}\left(0.041 \mu \mathrm{g} / \mathrm{m}^{3}\right)$ in winter and $39 \mathrm{ng} / \mathrm{m}^{3}\left(0.039 \mu \mathrm{g} / \mathrm{m}^{3}\right)$ in summer (105). These levels are lower than the median concentration of $0.055 \mu \mathrm{g} / \mathrm{m}^{3}$ measured in this study. It has been generally recognized that populations living near industrial emission sources and hazardous waste sites are exposed to higher concentrations of aluminum (105).

Throughout the general population, exposure to aluminum generally occurs through ingestion of food and water, as well as inhalation of ambient air. There are currently no inhalation Minimal Risk Levels for Hazardous Substances (MRLs) for aluminum due to a lack of studies assessing exposure (105). The few studies that have been conducted in animals and humans, however, suggest that the lungs and nervous system are primary targets of inhaled aluminum particles. Occupational studies with workers exposed to aluminum dust have found a potential relationship between chronic exposure and subclinical cognitive impairments. Some studies have found greater aluminum exposure to be associated with a decline in memory, fine motor skills, and decreased performance on digit-symbol tests (105). Animal studies assessing neurological effects of aluminum exposure have primarily focused on brain mass and histological outcomes and not behavioral impacts (105).

In addition, there is limited data available about the normal levels of aluminum in children's bodies. Children living near industrial emission sources and hazardous waste sites are likely exposed to even greater concentrations of aluminum than adults (105). Because children have a tendency to play near the ground and not wash their hands, they are more likely to ingest dirt, which contains particles with high aluminum concentrations. In addition, many processed foods, for example cheese, that children 
consume contain aluminum additives (105). Aluminum in the body is believed to accumulate primarily in the bones, brain, kidney, liver, spleen, and muscle (106).

Very few studies have assessed the association between aluminum and neurobehavioral outcomes in children. It has been suggested that an increase in aluminum plasma levels in children is associated with decreased verbal and motor skills (106). However, one of the most recent studies that assessed aluminum exposure and attention in Romanian children found that blood levels were not significantly related to dimensions of attention assessed using a computerized test designed to diagnose ADHD (107). It is very apparent that there is a lack of research on the neurological impacts of aluminum exposure in children, especially using instruments specifically designed to detect and measure subclinical neurotoxic effects. Future investigations into the relationship between indoor exposure to aluminum, aluminum concentration in nails, and cognitive control will contribute greatly to the current body of literature.

\section{Strengths and Limitations}

This study has many strengths. First, this study is community-based. Community members have played a role in designing and recruiting participants. This relationship with the community allows for the identification and assessment of real-world health concerns and exposure experiences about which the people are concerned. Using members of the community to assist in studies has been shown to increase participation and increase retention (108-110). As of December 2016, this study has reached $70 \%$ of its recruiting goal. Second, this study uses direct and indirect methods to assess exposure to $\mathrm{PM}_{10}$, fly ash, and metals while being able to consider the geographical impact on 
exposure. Assessing information about $\mathrm{PM}_{10}$ collected indoors and on surfaces in the children's bedroom, as well as in children's nail will help better characterize metal exposure. Third, this study uses both neurobehavioral tests, designed to detect exposure to neurotoxic elements, and parent-reported instruments to assess emotional and behavioral disorders. Lastly, this is the first study to characterize exposure to indoor $\mathrm{PM}_{10}$ and metal concentrations of communities near coal burning power plants.

Some limitations also need to be considered. First, because this study is ongoing the study sample used in this analysis is small. As the study continues, and the sample grows, there will be more statistical power to detect differences in neurobehavioral outcomes and assess the impact of various levels of exposure. Additionally, while the GIS-based sampling method of the study is an overall strength because it will allow for the analysis of the geographical impact on exposure, it presents some challenges when interpreting preliminary results. Because the current sample is incomplete and has been recruited from varying distances and directions it is difficult to distinguish how much variation in exposure measures is due do the differing geography and which participants may in fact actually be outliers. As more participants are recruited near the coal-burning power plants, especially Mill Creek, we will be better able to identify how geography impacts exposure and thus distinguish which exposure measurements are outliers and should be analyzed accordingly.

Another limitation of this analysis is that limited socioeconomic or income information about individual participants was collected. The only collected variable was job history. Therefore, income had to be considered at the Census block group level. While information about income at the block group level may not actually reflect the 
experience of an individual, it at least provides an estimate of the participant's socioeconomic status.

It is important to consider some limitations of the exposure assessment used in this dissertation. First, this analysis only evaluated the impact of distance from the two coal-burning power plants on indoor fly ash and $\mathrm{PM}_{10}$ exposure and did not consider the impact of season, direction, or wind. Second, concentrations of $\mathrm{PM}_{10}$ and metals measured in the home were used to estimate personal exposure. Information about the individual's daily activities (such as time spent indoors, at schools, etc.) is being collected, but was not considered in this exposure assessment. While it has been assumed that the $\mathrm{PM}_{10}$ sample collected for a week in the home is representative of participants' chronic exposure, it is also important to consider that variations in season, activity at the power plants, participants activities (i.e. opening windows, turning on air conditioning, etc.) could all cause the week-long sample to not accurately reflect a stable estimate of the participants' long-term exposure. Third, the air sampling technique used only allows for the analysis of the total $\mathrm{PM}_{10}$ concentration collected over the course of the week and does not provide continuous measurement data at repeated time-intervals. While data is being collected for continuous measurements of $\mathrm{PM}_{10}$, it was not considered in this dissertation research. Therefore, information about the quantity and amplitude of peaks in $\mathrm{PM}_{10}$ concentration over the course of the week cannot be considered. These moments and duration of elevated $\mathrm{PM}_{10}$ concentration may be important to consider when assessing neurotoxic effects.

In addition, it is important to consider some of the limitations of methods used to analyze exposure samples. The presence of fly ash in the home was only considered as a 
dichotomous yes/no variable and determined based on the analysis of a small section of the air filter. Future analysis will also use lift samples taken from the participants' bedrooms to identify homes with fly ash. Furthermore, SEM-EDX, which was used to identify metal concentrations in the fly ash particles, is unable to detect trace elements of metals such as lead, cadmium, and arsenic because the LOD is too high. PIXE analysis may also be unable to detect concentrations of certain metals in $\mathrm{PM}_{10}$ that are known neurotoxins like lead and mercury because the LOD are too high. Despite having high limits of detection for some elements, SEM-EDX and PIXE allow for the detection and quantification of up to 72 elements simultaneously, which is more advantageous than other methods that will only detect a few metals that are preselected by the investigators. Quantifying numerous metals allows for the assessment of metal mixtures, which are more reflective of children's real-world exposures.

Having information about a plethora of metals in fly ash particles and $\mathrm{PM}_{10}$ is beneficial, but figuring out what to do with all of the information is a statistical challenge. The metal score used in this analysis is based on the summed rank of participants' exposure to individual metals. This score does not take into account the varying neurotoxicity of individual metals. Future metal scores should explore applying statistical weights to the ranks based on the known neurotoxicity of the elements. It may also be important to investigate synergistic effects of metal interactions, which were not explored in this dissertation. BKMR was found to be a helpful tool for exploring metal interactions and mixtures and will be used in the future when the full study sample has been collected. Some limitations in the assessment of neurobehavioral performance need to also be considered. The BARS battery of tests was administered once to each child during the 
evening on a weeknight in the children's home. The setting and timing of the test may have an impact on children's test performance. However, in order to reduce variations in testing atmosphere that may impact results, the same child psychologist administers all of the tests to maintain consistency in the testing instruction provided. Furthermore, the DESR score is calculated based on parent-reported information about their child's behavior and therefore is potentially biased. The CBCL, however, is a widely used standardized instrument that will allow us to compare emotional and behavioral outcomes in this study with other populations.

\section{Conclusions}

Current fly ash storage methods may be failing to protect children from unnecessary exposure to $\mathrm{PM}_{10}$ containing neurotoxic metals emitted into the environment surrounding power plants. Characterizing exposure to metals, $\mathrm{PM}_{10}$, and fly ash, as well as assessing the impacts on self-regulation will help us better understand exposure and the potential impacts on behavior for children living near coal burning power plants around the world. This dissertation utilized a range of methods including spatial data analysis, regression models, and BKMR to elicit a more detailed picture of the relationship between living near coal-burning power plants, exposure to $\mathrm{PM}_{10}$ containing metals, and the neuropsychological impacts on children.

Fly ash particles may be a source of indoor aluminum pollution in homes near coal-burning power plants. In this analysis of the preliminary data, greater concentrations of aluminum in $\mathrm{PM}_{10}$ were found to be associated with general inattention problems in children living near two power plants. Occupational studies suggest inhaled aluminum 
may target the lungs as well as nervous system and chronic exposure may be related to subclinical cognitive impairments (105). None of the previously identified metal exposures found to impact attention in previous literature were related to cognitive control in this analysis. Future studies will assess the relationship between aluminum concentration in $\mathrm{PM}_{10}$, children's metal body burden, and cognitive control. 


\section{REFERENCES}

1. Environmental Protection Agency. Hazardous and solid waste management system; Disposal of coal combustion residuals from electric utilities. Fed Regist 2015;80(74):21302-21501. Codified at 40 CFR Parts 257 and 261.

2. American Coal Ash Association. 2014 Coal combustion product (CCP) \& use survey report.

https://www.acaa-usa.org/Portals/9/Files/PDFs/2014ReportFinal.pdf. Published July 2016. Accessed September 11, 2016.

3. Mueller S, Mallard JW, Mao Q, Shaw SL. Fugitive particulate emission factors for dry fly ash disposal. J Air Waste Manag Assoc 2013;63(7):806-818.

4. Environmetnal Protection Agency. Hazardous and solid waste management system; Identification and listing of special wastes; Disposal of coal combustion residuals from electric utilities. Fed Regist 2010;75(118):35128-35264. Codified at 40 CFR Parts 257, 261, 264 et al.

5. Bednar AJ, Averett DE, Seiter JM, Lafferty B, Jones WT, Hayes CA, et al. Characterization of metals released from coal fly ash during dredging at the Kingston ash recovery project. Chemosphere 2013;92(11):1563-1570.

6. Flues M, Moraes V, Mazzilli BP. The influence of a coal-fired power plant operation on radionuclide concentrations in soil. J Environ Radioact 2002;63:285294. 
7. Hatori Y, Matsuyama S, Ishii K, Terakawa A, Kikuchi Y, Fujiwara H, et al. Pixe analysis of individual particles in coal fly ash. Int J PIXE 2010;20(01):57-62.

8. Jones KB, Ruppert LF, Swanson SM. Leaching of elements from bottom ash, economizer fly ash, and fly ash from two coal-fired power plants. Int J Coal Geol 2012;94:337-348.

9. Brown P, Jones T, BéruBé K. The internal microstructure and fibrous mineralogy of fly ash from coal-burning power stations. Environ Pollut 2011;159(12):33243333.

10. Spencer LL, Drake LD. Hydrogeology of an alkaline fly ash landfill in eastern Iowa. Ground Water 1987;25:519-526.

11. Pope III AC, Dockery DW. Acute health effects of PM10 pollution on symptomatic and asymptomatic children. Am Rev Respir Dis 1992;145(5):11231128.

12. Landrigan PJ, Kimmel CA, Correa A, Eskenazi B. Children's health and the environment: public health issues and challenges for risk assessment. Environ Health Perspect 2003;112(2):257-265.

13. Kim S, Arora M, Fernandez C, Landero J, Caruso J, Chen A. Lead, mercury, and cadmium exposure and attention deficit hyperactivity disorder in children. Environ Res 2013;126:105-110.

14. Froehlich TE, Anixt JS, Loe IM, Chirdkiatgumchai V, Kuan L, Gilman RC. Update on environmental risk factors for attention-deficit/hyperactivity disorder. Curr Psychiatry Rep 2011;13(5):333-44. 
15. Bouchard M, Laforest F, Vandelac L, Bellinger D, Mergler D. Hair manganese and hyperactive behaviors: pilot study of school-age children exposed through tap water. Environ Health Perspect 2006;115(1):122-127.

16. Rodriguez-Barranco M, Lacasana M, Aguilar-Garduno C, Alguacil J, Gil F, Gonzalez-Alzaga B, et al. Association of arsenic, cadmium and manganese exposure with neurodevelopment and behavioural disorders in children: a systematic review and meta-analysis. Sci Total Environ 2013;454-455:562-577.

17. Calderon-Garciduenas L, Mora-Tiscareno A, Styner M, Gomez-Garza G, Zhu H, Torres-Jardon R, et al. White matter hyperintensities, systemic inflammation, brain growth, and cognitive functions in children exposed to air pollution. $J$ Alzheimers Dis 2012;31(1):183-191.

18. Rauh VA, Margolis AE. Research review: Environmental exposures, neurodevelopment, and child mental health - new paradigms for the study of brain and behavioral effects. J Child Psychol Psychiatry 2016;57(7):775-793.

19. Zierold KM, Sears CG. Community views about the health and exposure of children living near a coal ash storage site. J Community Health 2015;40(2):357363.

20. Dockery DW. Health effects of particulate air pollution. Ann Epidemiol 2009;19(4):257-63.

21. Sears CG. Coal ash and children's sleep: A community-based study. University of Louisville. Electronic Theses and Dissertations 2014; Paper 1294. 
22. Environmental Protection Agency. Particulate matter (PM) research. http://www.epa.gov/airscience/air-particulatematter.htm. Published May 18, 2012. Accessed April 1, 2013.

23. Pope III AC. Epidemiology of fine particulate air pollution and human health: biologic mechanisms and who's at risk? Environ Health Perspect 2000;108(suppl 4):713-723.

24. Dockery D, Pope III AC, Xu X, Spengler JD, Ware JH, Fay ME, Ferris BG, et al. An association between air pollution and mortality in six U.S. cities. $N$ Engl J Med 1993;329(24):1753-1759.

25. Schikowski T, Sugiri D, Ranft U, Gehring U, Heinrich J, Wichmann HE, et al. Long-term air pollution exposure and living close to busy roads are associated with COPD in women. Respir Res 2005;6:152.

26. Pope III AC, Burnett RT, Thun MJ, Calle EE, Krewski D, Ito K, Thurston GD. Lung cancer, cardiopulmonary mortality, and long-term exposure to fine particulate air pollution. JAMA 2002;287(9):1132-1141.

27. Zanobetti A, Redline S, Schwartz J, Rosen D, Patel S, O'Connor GT, et al. Associations of PM10 with sleep and sleep-disordered breathing in adults from seven U.S. urban areas. Am J Respir Crit Care Med 2010;182(6):819-825.

28. Dockery DW. Epidemiologic evidence of cardiovascular effects of particulate air pollution. Environ Health Perspect 2001;109(Suppl. 4):483-486.

29. Gehring U, Gruzieva O, Agius RM, Beelen R, Custovic A, Cyrys J, et al. Air pollution exposure and lung function in children: the ESCAPE project. Environ Health Perspect 2013;121(11-12):1357-1364. 
30. Jung KH, Hsu SI, Yan B, Moors K, Chillrud SN, Ross J, et al. Childhood exposure to fine particulate matter and black carbon and the development of new wheeze between ages 5 and 7 in an urban prospective cohort. Environ Int 2012;45:44-50.

31. Ostro B, Lipsett M, Mann J, Braxton-Owens H, White M. Air pollution and exacerbation of asthma in Aferican-American children in Los Angeles. Epidemiology 2001;12(2):200-208.

32. Abou-Khadra MK. Association between PM10 exposure and sleep of Egyptian school children. Sleep Breath 2013;17(2):653-657.

33. Lamichhane DK, Leem JH, Lee JY, Kim HC. A meta-analysis of exposure to particulate matter and adverse birth outcomes. Environ Health Toxicol 2015;30:e2015011.

34. Ebisu K, Berman JD, Bell ML. Exposure to coarse particulate matter during gestation and birth weight in the U.S. Environ Int 2016;94:519-24.

35. Flues M, Sato IM, Scapin MA, Cotrim MEB, Camargo IMC. Toxic elements mobility in coal and ashes of Figueira coal power plant, Brazil. Fuel 2013;103:430-436.

36. Environmental Protection Agency. Clean Air Act. Fed Regist 1970;42(85). Codified at 40 CFR Part 70.2. https://www.ecfr.gov/cgi-bin/textidx $?$ SID=94b28bb49906500a30668bdb0e2d625a\&mc=true \&node=se40.17.70_12 \&rgn=div8. Published July 1992. Accessed March 31, 2017. 
37. Smith KR, Veranth JM, Kodavanti UP, Aust AE, Pinkerton KE. Acute pulmonary and systemic effects of inhaled coal fly ash in rats: comparison to ambient environmental particles. Toxicol Sci 2006;93(2):390-399.

38. Borm PJA. Toxicity and occupational health hazards of coal fly ash (CFA). A review of data and comparison to coal mine dust. Ann Occup Hyg 1997;41(6):659-676.

39. Bencko V, Symon K, Stalnik L, Batora J, Vanco E, Svandova E. Rate of malignant tumor mortality among coal burning power plant workers occupationally exposed to arsenic. J Hyg Epidemiol Microbiol Immunol 1980;24(3):278-284.

40. Bencko V, Wagner V, Wagnerová M, Bátora J. Immunological profiles in workers of power plant burning coal rich in arsenic content. J Hyg Epidemiol Microbiol Immunol 1988;32(2):137-146.

41. Zeneli L, Sekovanic A, Ajvazi M, Kurti L, Daci N. Alterations in antioxidant defense system of workers chronically exposed to arsenic, cadmium and mercury from coal flying ash. Environ Geochem Health 2016;38(1):65-72.

42. Celik M, Donbak L, Unal F, Yuzbasioglu D, Aksoy H, Yilmaz S. Cytogenetic damage in workers from a coal-fired power plant. Mutat Res 2007;627(2):158163.

43. Evans L, Becher M, Lee B. State of failure: How states fail to protect our health and drinking water from toxic coal ash. EARTHJUSTICE. http://earthjustice.org/sites/default/files/StateofFailure_2013-04-05.pdf. Published August 2011. Accessed January 4, 2014. 
44. LG\&E and KU. Power Plant Information: Cane Run Station. http://lgeku.com/plant_info.asp. Published 2014. Accessed January 6, 2014.

45. LG\&E and KU. Neighbor to Neighbor: Cane Run Generating Station. http://www.lge-ku.com/neighbor2neighbor/cane_run_plantinformation.asp. Published 2014. Accessed January 6, 2014.

46. LG\&E and KU. Cane Run Generating Station. https://lge-ku.com/ourcompany/community/neighbor-neighbor/cane-run-generating-station. Published 2016. Accessed July 15, 2016.

47. Herron DE. Notification of Intent to Close-Inactive CCR Unit [letter]. Stantec. https://ccr.lgeku.com/sites/default/files/W_CR_ATB_CPCC_NOICLIN_121715.pdf. Published December 17, 2015. Accessed July 14, 2016.

48. Peterson E. LG\&E Fined for Coal Ash Violations at Cane Run...Again. 89.3 WFPL. http://wfpl.org/lge-fined-coal-ash-violations-cane-runagain/. Published June 7, 2013. Accessed July 15, 2016.

49. Peterson E. LG\&E fined $\$ 65,000$ for odor problems at cane run power plant. 89.3 WFPL. http://wfpl.org/lge-fined-65000-odor-problems-cane-run-power-plant/. Published August 5, 2013. Accessed July 15, 2016.

50. Louisville Gas \& Electric Company. CCR Fugitive Dust Control Plan Cane Run Generating Station. https://ccr.lgeku.com/sites/default/files/ccr/documents/W_CR_GNST_OR_FUGDST_101915.p df. Published October 2015. Accessed July 15, 2016 
51. LG\&E and KU. Mill Creek Generating Station. https://lge-ku.com/ourcompany/community/neighbor-neighbor/mill-creek-generating-station. Published 2016. Accessed July 15, 2016.

52. Louisville Gas \& Electric Company. CCR Fugitive Dust Control Plan Mill Creek Generating Station. https://ccr.lgeku.com/sites/default/files/ccr/documents/W_MC_GNST_OR_FUGDST_101915. pdf. Published October 2015. Accessed July 15, 2016.

53. Zimmerman P. CCR Rule Annual Inspection Report: Louisville Gas and Electric Mill Creek Ash Treatment Basin. https://ccr.lge-ku.com/MC/ATB/OR. Published 2015. Accessed July 15, 2016.

54. Holm J. CCR Rule Annual Inspection Report: Louisville Gas and Electric Mill Creek Landfill. https://ccr.lge-ku.com/MC/LF/OR. Published 2015. Accessed July 15, 2016.

55. Zimmerman P. CCR Rule Annual Inspection Report: Louisville Gas and Electric Mill Creek Clearwell Pond. https://ccr.lge-ku.com/MC/CWP/OR. Published 2015. Accessed July 15, 2016.

56. Zimmerman P. CCR Rule Annual Inspection Report: Louisville Gas and Electric Mill Creek Construction Runoff Pond. https://ccr.lge-ku.com/MC/CROP/OR. Published 2015. Accessed July 15, 2016.

57. Environmental Protection Agency. Frequent Questions about the Coal Ash Disposal Rule. https://www.epa.gov/coalash/frequent-questions-about-coal-ashdisposal-rule\#4. Updated Febuary 9, 2017. Accessed March 31, 2017. 
58. Patra KC, Rautray TR, Tripathy BB, Nayak P. Elemental analysis of coal and coal ash by PIXE technique. Appl Radiat Isot 2012;70(4):612-616.

59. Chakraborty R, Mukherjee A. Mutagenicity and genotoxicity of coal fly ash water leachate. Ecotoxicol Environ Saf 2009;72(3):838-842.

60. Ruhl L, Vengosh A., Dwyer GS. Hsu-Kim H, Deonarine A, Bergin M, Kravchenko J. Survey of the potential environmental and health impacts in the immediate aftermath of the coal ash spill in Kingston,TN. Environ Sci Technol 2009;43(16):6326-6333.

61. Liang F, Zhang G, Tan M, Yan C, Li X, Li Y, Li Y, Zhang Y, Shan Z. Lead in children's blood is mainly caused by coal-fired ash after phasing out of leaded gasoline in Shanghai. Environ Sci Technol 2010;44(12):4760-4765.

62. Tang D, Li T, Liu JJ, Zhou ZJ, Yuan T, Chen YH, et al. Effects of prenatal exposure to coal-burning pollutants on children's development in China. Environ Health Perspect 2008;116(5):674-679.

63. Block ML, Calderon-Garciduenas L. Air pollution: mechanisms of neuroinflammation and CNS disease. Trends Neurosci 2009;32(9):506-516.

64. Calderon-Garciduenas L, Franco-Lira M, Torres-Jardon R, Henriquez-Roldan C, Barragan-Mejia G, Valencia-Salazar G, et al. Pediatric respiratory and systemic effects of chronic air pollution exposure: nose, lung, heart, and brain pathology. Toxicol Pathol 2007;35(1):154-162.

65. Grandjean P, Landrigan PJ. Neurobehavioural effects of developmental toxicity. Lancet Neurol 2014;13(3):330-338. 
66. Lanphear BP. The impact of toxins on the developing brain. Annu Rev Public Health 2015;36:211-230.

67. Winneke G. Developmental aspects of environmental neurotoxicology: lessons from lead and polychlorinated biphenyls. J Neurol Sci 2011;308(1-2):9-15.

68. Calderon-Garciduenas L, Mora-Tiscareno A, Ontiveros E, Gomez-Garza G, Barragan-Mejia G, Broadway J, et al. Air pollution, cognitive deficits and brain abnormalities: a pilot study with children and dogs. Brain $\operatorname{Cog} n$ 2008;68(2):117127.

69. Calderon-Garciduenas L, Reynoso-Robles R, Vargas-Martinez J, GomezMaqueo-Chew A, Perez-Guille B, Mukherjee PS, et al. Prefrontal white matter pathology in air pollution exposed Mexico City young urbanites and their potential impact on neurovascular unit dysfunction and the development of Alzheimer's disease. Environ Res 2016;146:404-417.

70. Pujol J, Martinez-Vilavella G, Macia D, Fenoll R, Alvarez-Pedrerol M, Rivas I, et al. Traffic pollution exposure is associated with altered brain connectivity in school children. Neuroimage 2016;129:175-184.

71. Margolis AE, Herbstman JB, Davis KS, Thomas VK, Tang D, Wang Y, et al. Longitudinal effects of prenatal exposure to air pollutants on self-regulatory capacities and social competence. J Child Psychol Psychiatry 2016;57(7):851860.

72. Arnsten AFT, Rubia K. Neurobiological circuits regulating attention, cognitive control, motivation and emotion: disruptions in neurodevelopmental psychiatric disorders. J Am Acad Child Adoles Psychiatry 2012;51(4):356-367. 
73. Arnsten AFT. The emerging neurobiology of attention deficit hyperactivity disorder: the key role of the prefrontal association cortex. J Pediatr 2009;154(5):I-S43.

74. Barkley R. ADHD and the Nature of Self-Control. New York, New York: The Guilford Press, A Division of Guilford Publication, Inc.; 1997.

75. Casey B, Durston S, Fossella JA. Evidence for a mechanistic model of cognitive control. Clin Neurosci Res 2001:267-282.

76. Bari A, Robbins TW. Inhibition and impulsivity: behavioral and neural basis of response control. Prog Neurobiol 2013;108:44-79.

77. Aron AR, Robbins TW, Poldrack RA. Inhibition and the right inferior frontal cortex. Trends Cogn Sci 2004;8(4):170-177.

78. Chambers CD, Garavan H, Bellgrove MA. Insights into the neural basis of response inhibition from cognitive and clinical neuroscience. Neurosci Biobehav Rev 2009;33(5):631-646.

79. Verbruggen F, Logan GD. Response inhibition in the stop-signal paradigm. Trends Cogn Sci 2008;12(11):418-424.

80. Nachev P, Wydell H, O'Neill K, Husain M, Kennard C. The role of the presupplementary motor area in the control of action. Neuroimage 2007;36 Suppl 2:T155-163.

81. Aron AR, Durston S, Eagle DM, Logan GD, Stinear CM, Stuphorn V. Converging evidence for a fronto-basal-ganglia network for inhibitory control of action and cognition. J Neurosci 2007;27(44):11860-11864. 
82. Barkley R. Response inhibtion in attention-deficit hyperactivity disorder. Ment Retard Dev Disabil Res Rev 1999;5:177-184.

83. Stewart P, Reihman J, Gump B, Lonky E, Darvill T, Pagano J. Response inhibition at 8 and $91 / 2$ years of age in children prenatally exposed to PCBs. Neurotoxicol Teratol 2005;27(6):771-780.

84. Rohlman DS, Gimenes LS, Eckerman DA, Kang S-K, Farahat FM, Kent Anger W. Development of the behavioral assessment and research system (BARS) to detect and characterize neurotoxicity in humans. NeuroToxicology 2003;24(45):523-531.

85. Epstein J, Erkanli A, Conners CK, Klaric J, Costello JE, Angold A. Relations between continuous performance test performance measures and ADHD behaviors. J Abnorm Child Psychol 2003;31(5):543-554.

86. Davidson RJ, Putnam KM, Larson CL. Dysfunction in the nerual circuitry of emotion regulation: a possible prelude to violence. Science 2000;289:591-594.

87. Spencer TJ, Faraone SV, Surman CB, Petty C, Clarke A, Batchelder H, et al. Toward defining deficient emotional self-regulation in children with attentiondeficit/hyperactivity disorder using the Child Behavior Checklist: a controlled study. Postgrad Med 2011;123(5):50-59.

88. Biederman J, Spencer TJ, Petty C, Hyder LL, O'Connor KB, Surman CB, et al. Longitudinal course of deficient emotional self-regulation CBCL profile in youth with ADHD: prospective controlled study. Neuropsychiatr Dis Treat 2012;8:267276. 
89. $\mathrm{Xu}$ X, Ha SU, Basnet R. A review of epidemiological research on adverse neurological effects of exposure to ambient air pollution. Front Public Health 2016;4:157.

90. Wang S, Zhang J, Zeng X, Zeng Y, Wang S, Chen S. Association of trafficrelated air pollution with children's neurobehavioral functions in Quanzhou, China. Environ Health Perspect 2009;117(10):1612-1618.

91. Suades-Gonzalez E, Gascon M, Guxens M, Sunyer J. Air pollution and neuropsychological development: a review of the latest evidence. Endocrinology 2015;156(10):3473-3482.

92. Saenen ND, Provost EB, Viaene MK, Vanpoucke C, Lefebvre W, Vrijens K, et al. Recent versus chronic exposure to particulate matter air pollution in association with neurobehavioral performance in a panel study of primary schoolchildren. Environ Int 2016;95:112-119.

93. Hong SB, Im MH, Kim JW, Park EJ, Shin MS, Kim BN, et al. Environmental lead exposure and attention deficit/hyperactivity disorder symptom domains in a community sample of South Korean school-age children. Environ Health Perspect 2015;123(3):271-276.

94. Bhang SY, Cho SC, Kim JW, Hong YC, Shin MS, Yoo HJ, et al. Relationship between blood manganese levels and children's attention, cognition, behavior, and academic performance--a nationwide cross-sectional study. Environ Res 2013;126:9-16. 
95. Rodriguez-Barranco M, Gil F, Hernandez AF, Alguacil J, Lorca A, Mendoza R, et al. Postnatal arsenic exposure and attention impairment in school children. Cortex 2016;74:370-382.

96. Rodriguez-Barranco M, Lacasana M, Gil F, Lorca A, Alguacil J, Rohlman DS, et al. Cadmium exposure and neuropsychological development in school children in southwestern Spain. Environ Res 2014;134:66-73.

97. Sanders AP, Claus Henn B, Wright RO. Perinatal and childhood exposure to cadmium, manganese, and metal mixtures and effects on cognition and behavior: A review of recent literature. Curr Environ Health Rep 2015;2(3):284-294.

98. Ciesielski T, Weuve J, Bellinger DC, Schwartz J, Lanphear B, Wright RO. Cadmium exposure and neurodevelopmental outcomes in U.S. children. Environ Health Perspect 2012;120(5):758-63.

99. Khan K, Factor-Litvak P, Wasserman GA, Liu X, Ahmed E, Parvez F, et al. Manganese exposure from drinking water and children's classroom behavior in Bangladesh. Environ Health Perspect 2011;119(10):1501-1506.

100. Boucher O, Burden MJ, Muckle G, Saint-Amour D, Ayotte P, Dewailly E, et al. Response inhibition and error monitoring during a visual go/no-go task in inuit children exposed to lead, polychlorinated biphenyls, and methylmercury. Environ Health Perspect 2012;120(4):608-15.

101. Bobb JF, Valeri L, Claus Henn B, Christiani DC, Wright RO, Mazumdar M, et al. Bayesian kernel machine regression for estimating the health effects of multipollutant mixtures. Biostatistics 2015;16(3):493-508. 
102. Elemental Analysis, Inc. PIXE applications and theory.

http://www.elementalanalysis.com/services/proton-induced-x-ray-emission-pixe/. Published 2016. Accessed July 15, 2016.

103. Farahat FM, Rohlman DS, Storzbach D, Ammerman T, Anger WK. Measures of short-term test-retest reliability of computerized neurobehavioral tests.

Neurotoxicology 2003;24(4-5):513-521.

104. Tompkins LK. Memory and fine motor skill test performance among children living near coal ash storage sites. University of Louisville. Electronic Theses and Dissertations 2016; Paper 2499.

105. Agency for Toxic Substances and Disease Registry. Toxicological profile for aluminum. https://www.atsdr.cdc.gov/toxprofiles/tp.asp?id=191\&tid=34.

Published 2008. Accessed March 21, 2017.

106. Kumar V, Gill KD. Aluminium neurotoxicity: neurobehavioural and oxidative aspects. Arch Toxicol 2009;83(11):965-978.

107. Nicolescu R, Petcu C, Cordeanu A, Fabritius K, Schlumpf M, Krebs R, et al. Environmental exposure to lead, but not other neurotoxic metals, relates to core elements of ADHD in Romanian children: performance and questionnaire data. Environ Res 2010;110(5):476-483.

108. Bach M, Jordan S, Hartung S, Santos-Hovener C, Wright MT. Participatory epidemiology: the contribution of participatory research to epidemiology. Emerg Themes Epidemiol 2017;14:2. 
109. Schulz AJ, Parker EA, Israel BA, Becker AB, Maciak BJ, Hollis R. Conducting a participatory community-based survey for a community health intervention on Detroit's east side. J Public Health Management Practice 1998;4(2):10-24.

110. Tajik M, Minkler M. Environmental justice research and action: a case study in political economy and community-academic collaboration. Int Q Community Health Educ 2006;26(3):213-231. 
APPENDIX A: Supplemental Tables

Supplemental Table 1. Descriptive Statistics for EJ Index and Components

\begin{tabular}{cccccccc}
\hline & Mean & SD & Min & P25 & Median & P75 & Max \\
\hline Environmental Indicator & 0.37 & 0.21 & 0.16 & 0.24 & 0.29 & 0.41 & 0.89 \\
Demographic Index & 27.96 & 15.07 & 8.00 & 18.00 & 23.50 & 32.50 & 76.00 \\
EJ Index & 10.72 & 8.27 & 2.18 & 4.39 & 7.93 & 16.48 & 26.52 \\
\hline
\end{tabular}

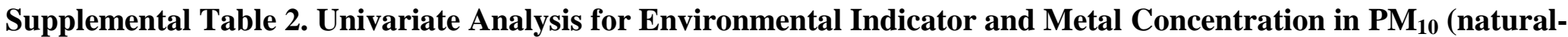
log transformed)

\begin{tabular}{llcc} 
& & Beta $(\mathbf{9 5 \%}$ CI) & P-value \\
\cline { 2 - 4 } & Aluminum & $1.39(0.66,2.11)$ & 0.0004 \\
& Arsenic & $0.56(-0.07,1.20)$ & 0.08 \\
$\vec{\omega}$ & Chromium & $1.44(0.68,2.21)$ & 0.0004 \\
& Manganese & $1.57(0.91,2.23)$ & 0.0001 \\
Silicon & $1.03(0.49,1.58)$ & 0.0004 \\
& Titanium & $1.56(0.83,2.30)$ & 0.0001 \\
\hline
\end{tabular}




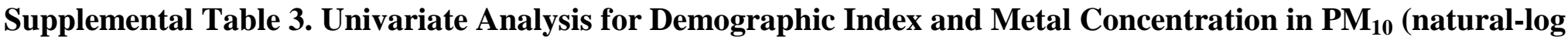
transformed)

\begin{tabular}{lcc}
\hline & B (95\% CI) & P-value \\
\hline Aluminum & $-0.0064(-0.017,0.005)$ & 0.25 \\
Arsenic & $-0.0033(-0.012,0.006)$ & 0.47 \\
Chromium & $0.005(-0.0062,0.0168)$ & 0.37 \\
Manganese & $-0.0002(-0.011,0.010)$ & 0.97 \\
Silicon & $-0.007(-0.015,0.002)$ & 0.12 \\
Titanium & $0.004(-0.008,0.015)$ & 0.51 \\
\hline
\end{tabular}


Supplemental Table 4. Adjusted Regression Coefficients for the association between Metal Concentrations $\left(\mu \mathrm{g} / \mathrm{m}^{3}\right)$ and Neurobehavioral outcomes

\begin{tabular}{|c|c|c|c|c|c|c|}
\hline & \multicolumn{2}{|l|}{ Silicon } & \multicolumn{2}{|l|}{ Titanium } & \multicolumn{2}{|l|}{ Copper } \\
\hline & Beta $(95 \%$ CI $)$ & P-value & Beta $(95 \%$ CI) & P-value & Beta $(95 \%$ CI) & P-value \\
\hline \multicolumn{7}{|l|}{ Continuous } \\
\hline \multicolumn{7}{|l|}{ Performance $^{1}$} \\
\hline Number of Errors ${ }^{a}$ & $0.60(-0.71,1.91)$ & 0.37 & $15.3(-9.46,40.1)$ & 0.23 & $-11.8(-46.5,22.8)$ & 0.51 \\
\hline Response Latency ${ }^{b}$ & $-0.11(-0.006,-0.21)$ & 0.04 & $-0.89(-2.92,1.14)$ & 0.39 & $-0.32(-3.16,2.51)$ & 0.82 \\
\hline \multicolumn{7}{|l|}{$\begin{array}{l}\text { Selective Attention } \\
\text { Test } 1\end{array}$} \\
\hline Number of Errors ${ }^{c}$ & $0.38(-0.30,1.06)$ & 0.28 & $-3.26(-16.30,9.77)$ & 0.63 & $11.2(-6.72,29.17)$ & 0.22 \\
\hline \multicolumn{7}{|l|}{ Child Behavior } \\
\hline DESR Score ${ }^{d}$ & $0.11(-0.006,0.22)$ & 0.06 & $-0.4(-2.63,1.83)$ & 0.72 & $0.15(-2.95,3.25)$ & 0.92 \\
\hline $\begin{array}{l}\text { Models adjusted for age a } \\
{ }^{1} \text { Beta coefficients, } 95 \% \mathrm{C} \\
{ }^{2} \text { Beta coefficients } 95 \% \mathrm{Cl} \\
{ }^{\mathrm{a}} \text { Square-root transformed } \\
{ }^{\mathrm{b}} \text { Natural Log-transformec } \\
{ }^{\mathrm{c}} \text { Square-root transformed }\end{array}$ & $\begin{array}{l}\text { gender } \\
\text { and p-values estimated fro } \\
\text { and p-values estimated fro }\end{array}$ & $\begin{array}{l}\text { n linear regr } \\
\text { negative bi }\end{array}$ & $\begin{array}{l}\text { ssion models } \\
\text { omial regression models }\end{array}$ & & & \\
\hline
\end{tabular}


Supplemental Table 5. Linear Regression Coefficients for Aluminum $\left(\mu \mathrm{g} / \mathrm{m}^{3}\right)$ and BARS Outcomes with Outlier Adjusted

\begin{tabular}{|c|c|c|c|c|c|}
\hline & Beta* $^{*}(95 \%$ CI $)$ & P-value & Adjusted Beta (95\% CI) & P-value & Covariates \\
\hline \multicolumn{6}{|l|}{$\begin{array}{l}\text { Continuous } \\
\text { Performance }\end{array}$} \\
\hline Number of Errors ${ }^{a}$ & $4.13(-0.50,8.77)$ & 0.08 & $3.11(-1.45,7.67)$ & 0.19 & $\begin{array}{l}\text { Age, Gender, } \\
\text { Income }\end{array}$ \\
\hline Response Latency ${ }^{b}$ & $-0.27(-0.65,0.11)$ & 0.17 & $-0.087(-0.61,0.44)$ & 0.74 & $\begin{array}{c}\text { Age, Gender, } \\
\text { BMI }\end{array}$ \\
\hline \multicolumn{6}{|l|}{$\begin{array}{l}\text { Selective Attention } \\
\text { Test }\end{array}$} \\
\hline Number of Errors ${ }^{c}$ & $2.09(-0.33,4.51)$ & 0.1 & $2.06(-0.38,4.50)$ & 0.1 & $\begin{array}{l}\text { Age, Gender, } \\
\text { Environmental } \\
\text { Tobacco, BMI }\end{array}$ \\
\hline $\begin{array}{l}\text { * Adjusted for gender and } \\
\text { a Square-root transformed } \\
{ }^{\mathrm{b}} \text { Natural Log-transformed } \\
{ }^{\mathrm{c}} \text { Square-root transformed }\end{array}$ & & & & & \\
\hline
\end{tabular}


APPENDIX B: Supplemental Figures 
Supplemental Figure 1. Comparison of Environmental Justice Index and Arsenic Concentration Environmental Justice Index and Concentration of Arsenic in Home

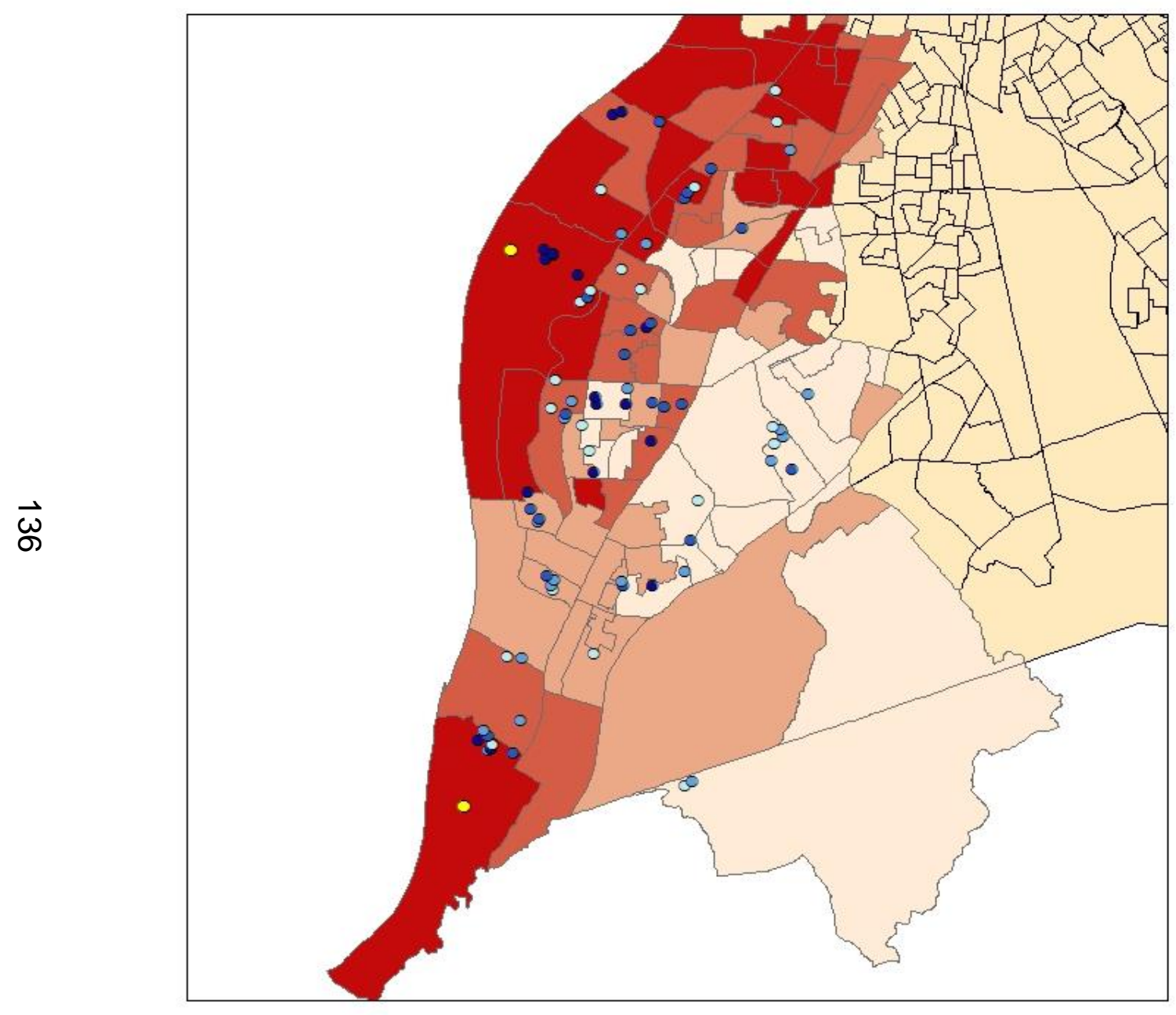

Concentration of Arsenic $\left(\mu \mathrm{g} / \mathrm{m}^{3}\right)$

- $0.00021-0.00047$

- $0.00048-0.00092$

- $0.00093-0.00130$

- $0.00131-0.02090$

EJ Index Quartile $\square$ First

Second

Third

Fourth

Coal Ash

Storage Facility 
Supplemental Figure 2. Comparison of Environmental Justice Index and Chromium Concentration Environmental Justice Index and Concentration of Chromium in Home

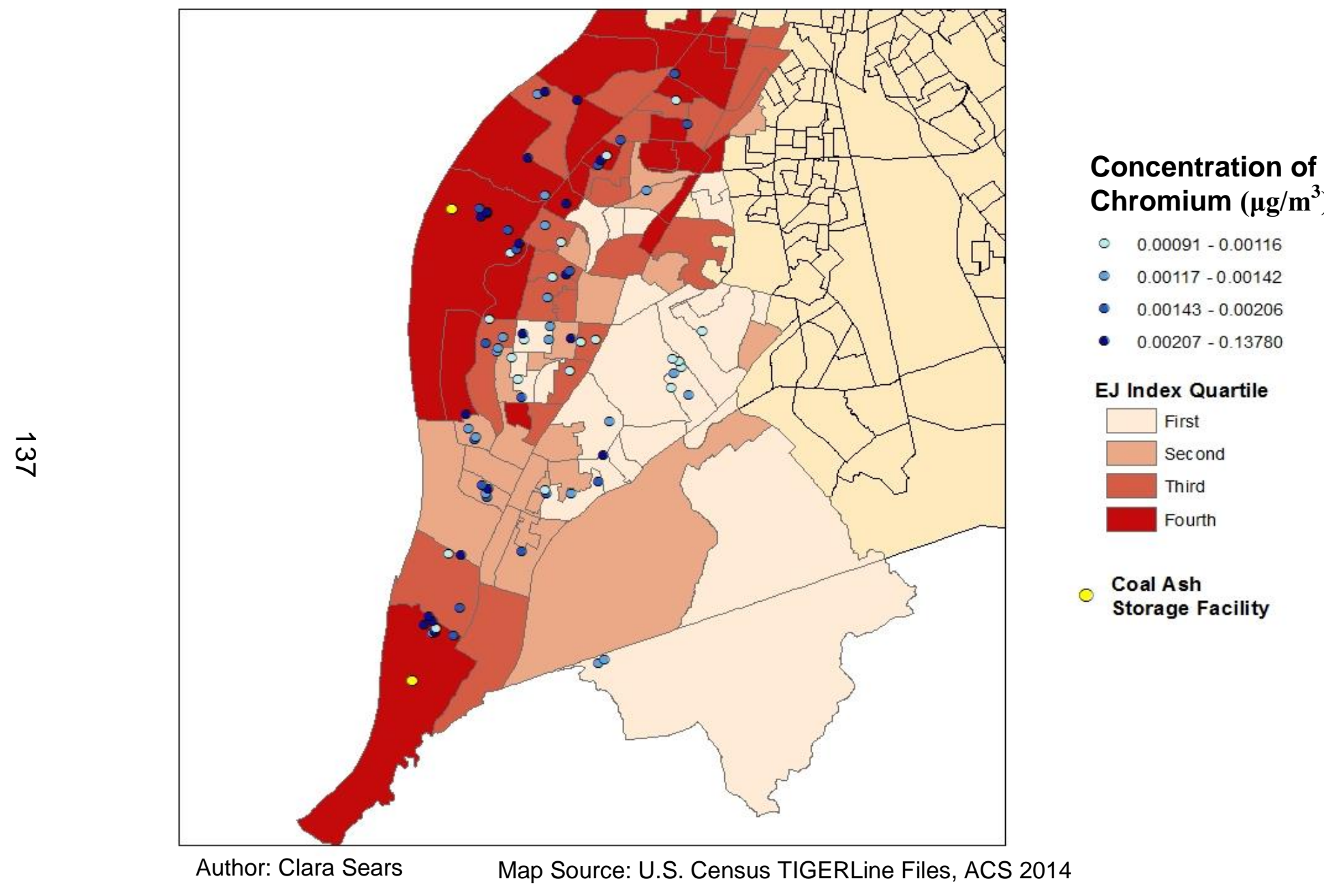


Supplemental Figure 3. Comparison of Environmental Justice Index and Manganese Concentration Environmental Justice Index and Concentration of Manganese in Home

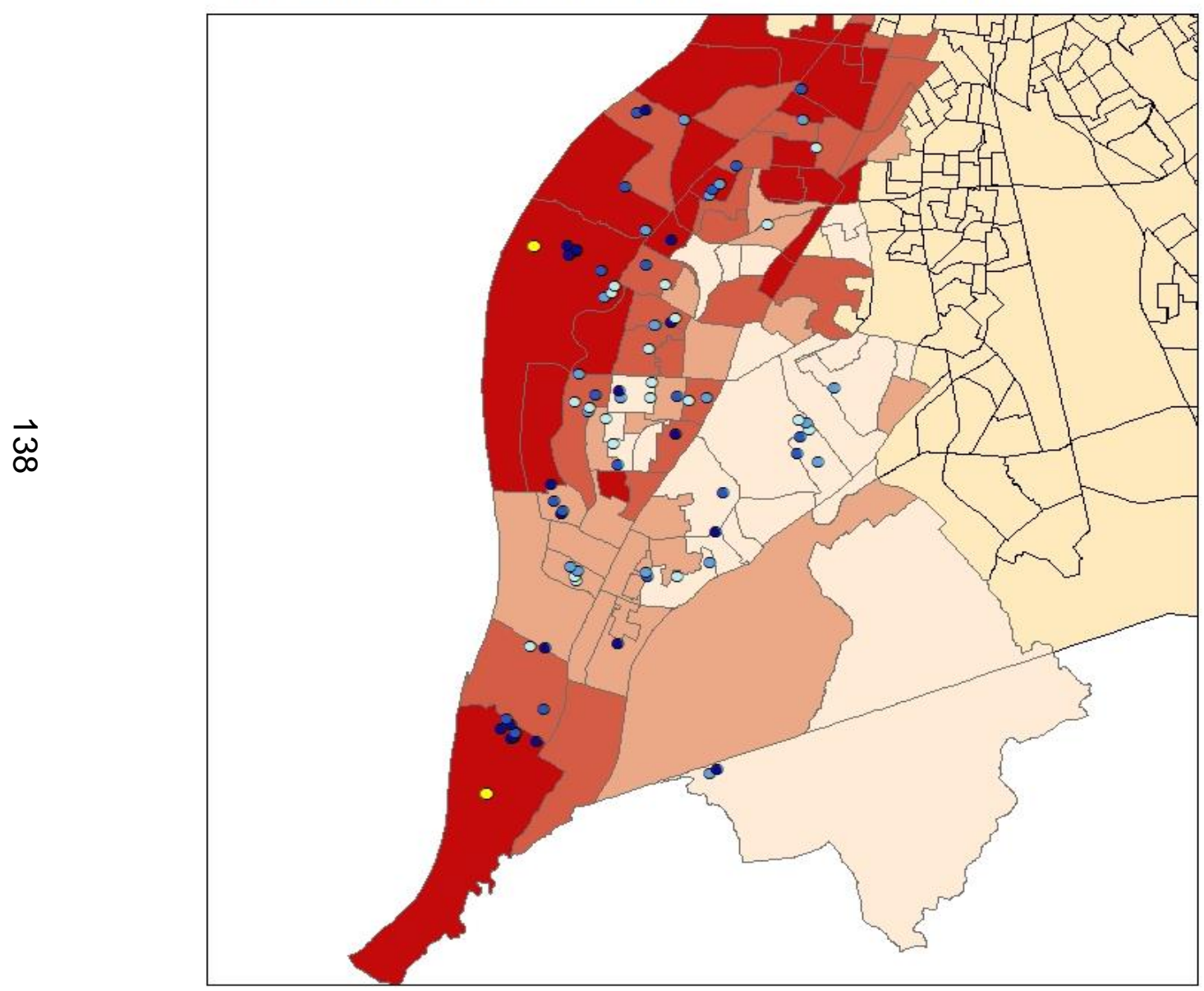

\section{Concentration of} Manganese $\left(\mu \mathrm{g} / \mathrm{m}^{3}\right)$

- $0.00054-0.00091$

- $0.00092-0.00140$

- $0.00141-0.00250$

- $0.00251-0.01810$

EJ Index Quartile

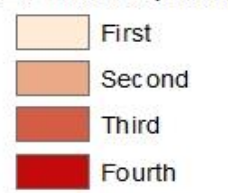

Coal Ash

Storage Facility 
Supplemental Figure 4. BKMR Univariate Analysis with CPT Errors and Metal Concentrations $\left(\mu \mathrm{g} / \mathrm{m}^{3}\right)$
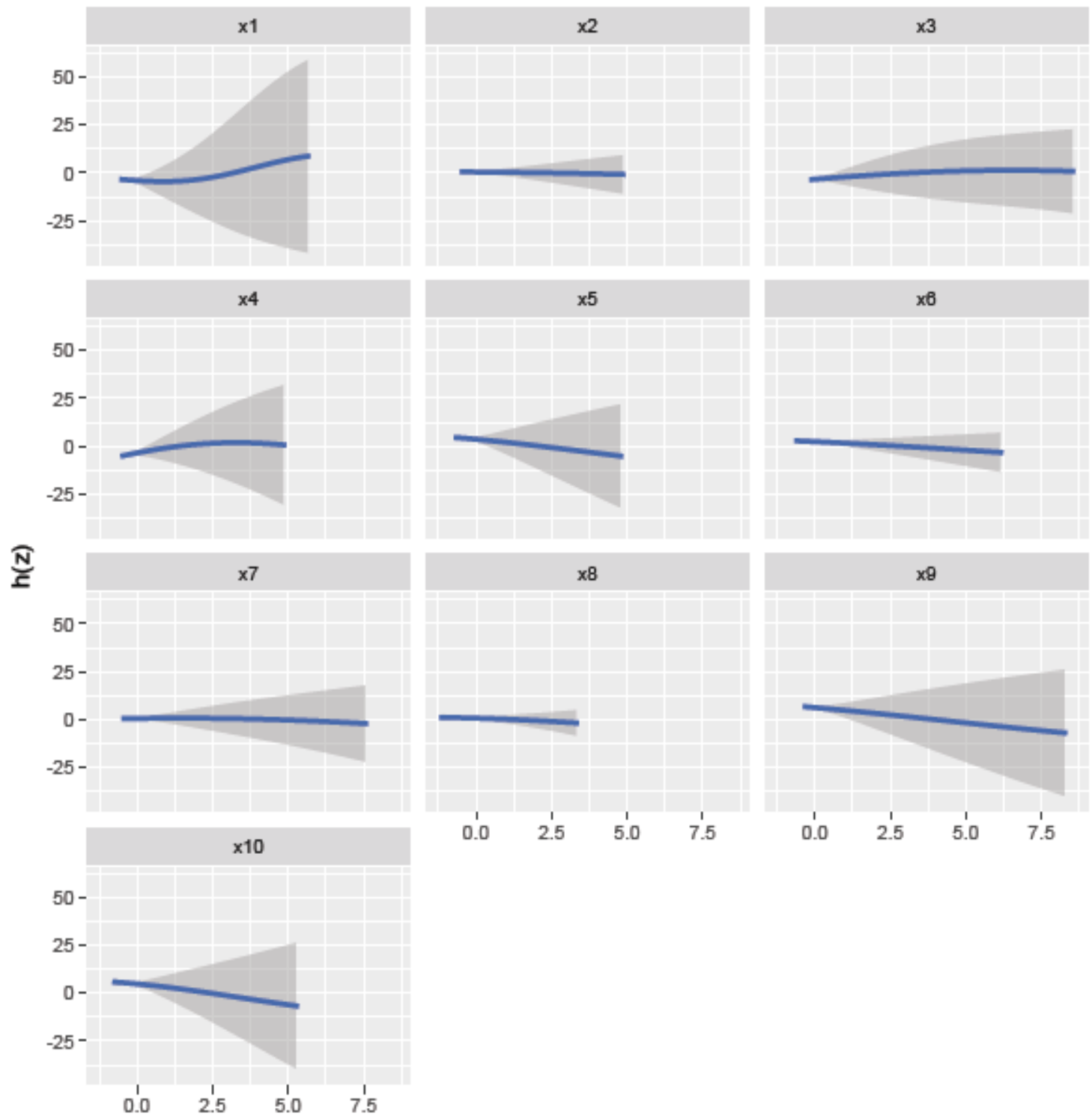

Metals in Figure: $x 1=$ Aluminum, $x 2=$ Titanium, $x 3=$ Chromium, $x 4=$ Manganese, $x 5=$ Iron, $\mathrm{x} 6=$ Nickel, $\mathrm{x} 7=$ Copper, $\mathrm{x} 8=$ Zinc, $\mathrm{x} 9=$ Arsenic, $\mathrm{x} 10=$ Silicon 


\section{Supplemental Figure 5. BKMR Univariate Analysis with CPT Response Latency and Metal Concentrations $\left(\mu \mathrm{g} / \mathrm{m}^{3}\right)$}

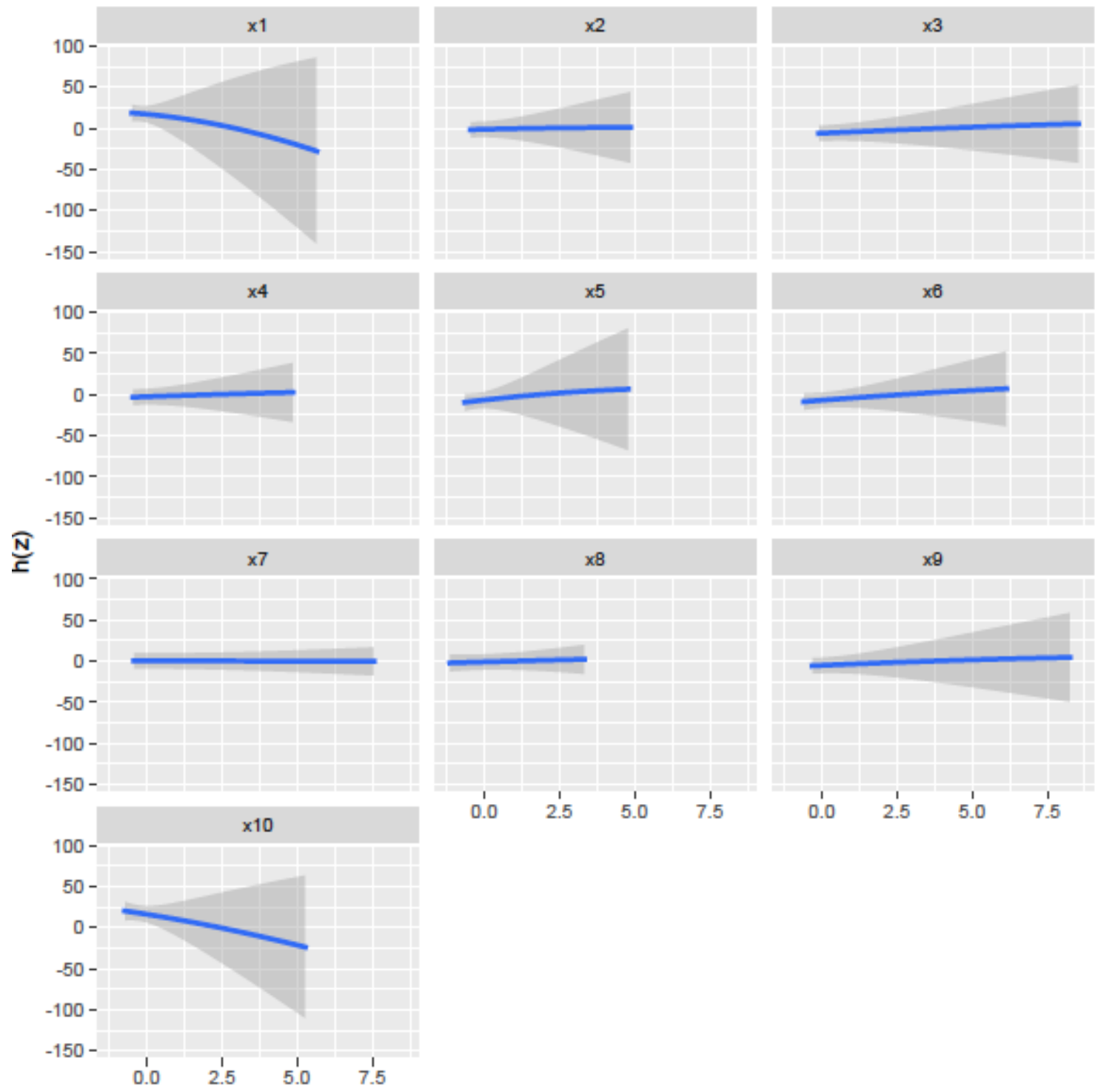

Metals in Figure: $\mathrm{x} 1=$ Aluminum, $\mathrm{x} 2=$ Titanium, $\mathrm{x} 3=$ Chromium, $\mathrm{x} 4=$ Manganese, $\mathrm{x} 5=$ Iron, $\mathrm{x} 6=$ Nickel, $\mathrm{x} 7=$ Copper, $\mathrm{x} 8=$ Zinc, $\mathrm{x} 9=$ Arsenic, $\mathrm{x} 10=$ Silicon 
Supplemental Figure 6. BKMR Univariate Analysis with SAT Errors and Metal Concentrations $\left(\mu \mathrm{g} / \mathrm{m}^{3}\right)$

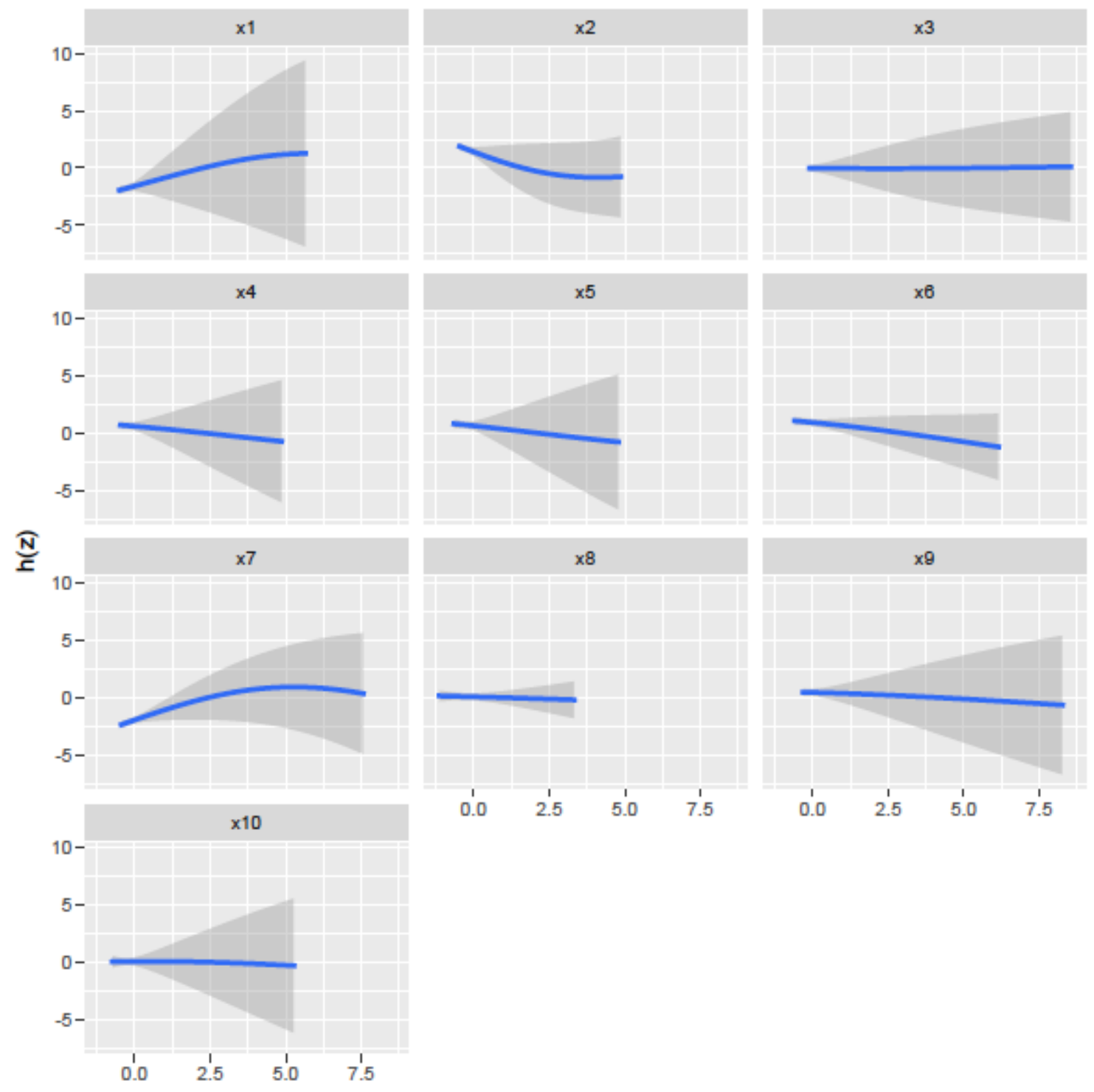

Metals in Figure: $\mathrm{x} 1=$ Aluminum, $\mathrm{x} 2=$ Titanium, $\mathrm{x} 3=$ Chromium, $\mathrm{x} 4=$ Manganese, $\mathrm{x} 5=$ Iron, $\mathrm{x} 6=$ Nickel, $\mathrm{x} 7=$ Copper, $\mathrm{x} 8=$ Zinc, $\mathrm{x} 9=$ Arsenic, $\mathrm{x} 10=$ Silicon 
Supplemental Figure 7. BKMR Univariate Analysis with DESR Score and Metal Concentrations $\left(\mu \mathrm{g} / \mathrm{m}^{3}\right.$

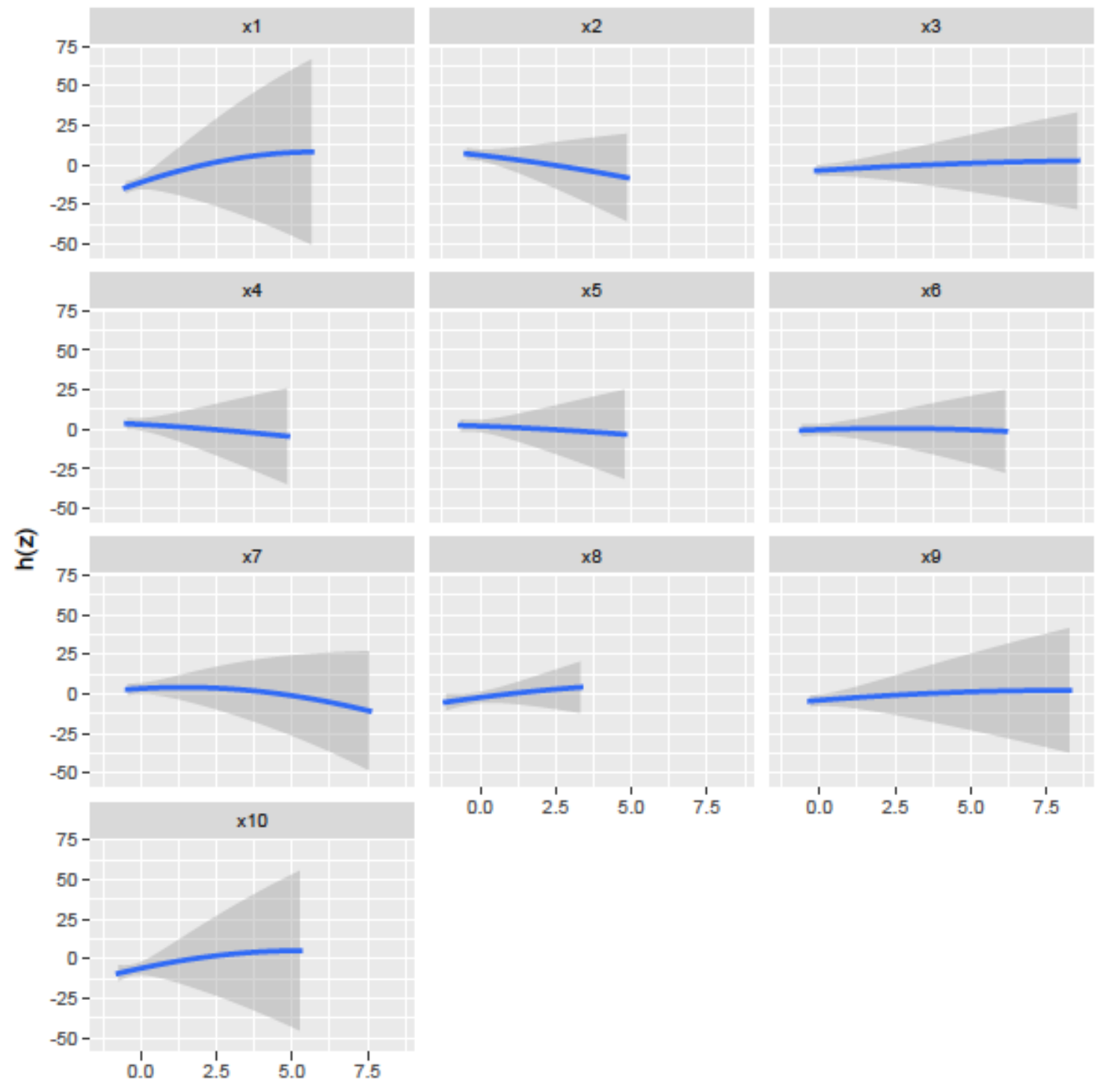

Metals in Figure: $\mathrm{x} 1=$ Aluminum, $\mathrm{x} 2=$ Titanium, $\mathrm{x} 3=$ Chromium, $\mathrm{x} 4=$ Manganese, $\mathrm{x} 5=$ Iron, $\mathrm{x} 6=$ Nickel, $\mathrm{x} 7=$ Copper, $\mathrm{x} 8=$ Zinc, $\mathrm{x} 9=$ Arsenic, $\mathrm{x} 10=$ Silicon 


\author{
CURRICULUM VITAE \\ Clara G. Sears \\ Email: clara.sears@louisville.edu
}

\title{
EDUCATION
}

\section{Ph.D. Public Health Sciences, Epidemiology and Population Health}

University of Louisville, Louisville, Kentucky

Dissertation: The particulars about particulates: Exposure to metals and self-regulation of children living near coal ash storage

\section{M.S. Epidemiology}

University of Louisville, Louisville, Kentucky

Thesis: Coal ash and children's sleep: a community-based study

\author{
2012 B.A. Biology (Minor: Business) \\ Goshen College, Goshen, Indiana \\ Cum Laude
}

\section{RESEARCH EXPERIENCE}

2014 - Present $\quad$ Research Assistant, Department of Epidemiology and Population Health School of Public Health and Information Sciences, University of Louisville, Louisville, Kentucky

Description: Community-based research evaluating health, neurobehavioral symptoms, and exposure to metals in children living near coal ash storage facilities. Research supported by a $\$ 2.82$ million grant from the National Institute for Environmental Health Sciences.

2014 - Present Graduate Research Assistant, American Heart Association Tobacco Regulation and Addiction Center, Department of Communication, University of Louisville, Louisville, Kentucky Description: Transdisciplinary research evaluating perception, language, and communication surrounding tobacco use. Two primary mixed-methods studies aim to: 1) assess perceptions of tobacco and e-cigarette use among low-income youth from 12 
2014

2013-2014

2012-2013

2011, 2009

2010 middle and high schools across three Appalachian states and 2) investigate e-cigarette use behaviors of adults in vape (e-cigarette) shops. Studies funded by a $\$ 19.6$ million center grant from the National Institutes of Health and the US Food and Drug Administration.

Research Assistant, Department of Nursing, University of Louisville, Louisville, Kentucky Description: Home-based asthma intervention study evaluating motivational interviewing as an asthma intervention tool for lowincome black children of mothers with depression.

Research Assistant, Department of Epidemiology and Population Health, School of Public Health and Information Sciences, University of Louisville, Louisville, Kentucky

Description: Community-based mixed-methods research evaluating the health of adults and children living in low-income neighborhoods near coal ash storage facilities.

Research Assistant and Graduate Co-Investigator, Eck Institute for Global Health, Institute for Latino Studies, University of Notre Dame, Notre Dame, Indiana

Description: Collaboration between the University of Notre Dame, local health information exchange, state officials, and area hospitals to address health disparities and perinatal mortality in north central Indiana.

Research Assistant, Biology Department

Goshen College, Goshen, Indiana

Description: Laboratory research on cell membrane transport in mammalian and avian erythrocytes, and development of laboratory procedures for undergraduate students studying cell membrane transport and spirometry in an educational facility.

Research Assistant, Department of Pediatrics, University of Louisville, Louisville, Kentucky Description: Medical chart review evaluating neuropsychological and biomedical functioning in children diagnosed with developmental disabilities.

\section{PUBLICATIONS}

1. Sears CG, Walker KL, Hart JL, Lee AS, Siu A, Smith C. (2017-in press). Clean, cheap, convenient: promotion of electronic cigarettes on YouTube. Tobacco Prevention and Cessation. 
2. Hart JL, Walker KL, Sears CG, Lee AS, Smith C, Siu A, Keith R, Ridner SL. (2017). Vape shop employees: public health advocates?. Tob Prev Cessation;

2(Supplement):7. doi: 10.18332/tpc/67800.

3. Sears CG, Hart JL, Walker KL, Lee AS, Keith R, Ridner SL. (2016). A dollars and "sense" exploration of vape shop spending and e-cigarette use. Tob Prev Cessation; 2(Supplement):7. doi: 10.18332/tpc/67435.

4. Zierold KM, Sears CG. (2015). Are healthcare providers asking about environmental exposures?: a community-based mixed methods study. J Environ Public Health; 2015:189526. doi: 10.1155/2015/189526.

5. Zierold KM, Sears CG. (2015). Community views about the health and exposure of children living near a coal ash storage site. J Community Health; 40(2):357-63. doi: 10.1007/s10900-014-9943-6.

6. Zierold KM, Sears CG, Brock G. (2015). Exposure reducing behaviors among residents living near a coal ash storage site. Health Educ Behav. pii:

1090198115610573.

\section{PUBLICATIONS - under review}

1. Sears CG, Zierold KM. (2016 - accepted, pending revisions). Health of children living near coal ash. Global Pediatric Health.

2. Sears CG, Hart JL, Walker KL, Lee AS, Ridner SL, Keith RJ. (2016 - accepted, pending revisions). E-cigarette users: better health through vaping?. Western Journal of Nursing Research.

\section{PUBLISHED ABSTRACTS}

1. Sears CG, Walker KL, Hart JL, Lee AS, Siu A, Smith C, Bhatnagar A, Robertson RM. (2016). Perceptions and use of electronic cigarettes among middle and high school students in Appalachia. Circulation; 134:A14605.

2. Hart JL, Sears CG, Lee A, Smith C, Siu A, Walker KL. (2015). Appalachian youth and tobacco products: Perceptions, attitudes, and behaviors. Circulation; 132:A18094. 
1. Sears CG, Zierold KM. (April 2017). Health of children living near coal ash. [Oral Presentation]. Children's Environmental Health Network 2017 Translational Research Conference: New Challenges, Arlington, Virginia.

2. Sears CG, Hart JL, Walker KL, Lee AS, Ridner SL, Keith RJ. (April 2017). Ecigarette users: Better health through vaping?. [Oral Presentation]. 87 $7^{\text {th }}$ Annual Southern States Communication Association Convention, Greensville, South Carolina.

3. Sears CG, Lee AS, Hart JL, Walker KL, Giachello AL, Payne TJ, Tompkins LT, Groom A, Smith C, Siu A, Landry R, Seals S, Kesh A, Robertson RM. (March 2017). "You can't go anywhere without seeing someone light up a cigarette": Influences on Appalachian youth tobacco views and use. [Poster Presentation]. Society For Research On Nicotine and Tobacco 2017 Annual Meeting, Florence, Italy.

4. Hart JL, Walker KL, Sears CG, Lee AS, Smith C, Siu A, Keith R, Ridner SL. (March 2017). Vape shop employees: Assisting customers, encouraging cessation, promoting community, and supporting regulations. [Poster Presentation]. Society For Research On Nicotine and Tobacco 2017 Annual Meeting, Florence, Italy.

5. Groom A, Sears CG, Morgan M, Miller C, Robertson RM, Payne TJ, Giachello AL, Hart JL, Walker KL, Landry R, Robb K, Kesh A, Salazar-Mitchell P, Lee AS. (March 2017). Media channel correlation with perception or tobacco risk. [Poster Presentation]. Society For Research On Nicotine and Tobacco 2017 Annual Meeting, Florence, Italy.

6. Groom A, Sears CG, Morgan M, Miller C, Robertson RM, Payne TJ, Giachello AL, Hart JL, Walker KL, Tompkins LK, Lee AS, Landry R. (March 2017). Marital status and parent influence on youth tobacco use in vulnerable populations. [Poster Presentation]. Society For Research On Nicotine and Tobacco 2017 Annual Meeting, Florence, Italy.

7. Sears CG, Tompkins LK, Walker KL, Hart JL, Lee AS, Smith C, Siu A, Bhatnagar A, Robertson RM. (November 2016). Perceptions and use of electronic cigarettes among middle and high school students in Appalachia. [Oral Presentation]. American Heart Association Scientific Sessions, New Orleans, Louisiana.

8. Sears CG, Hart JL, Walker KL, Lee A, Smith C, Keith R, Ridner SL. (November 2016). A dollar and "sense" exploration of vape shop spending and e-cigarette use. [Oral Presentation]. National Communication Association $102^{\text {nd }}$ Annual Convention, Philadelphia, Pennsylvania.

9. Sears CG, Hart JL, Walker KL, Lee AS, Tompkins LK, Groom A, Giachello AL, Payne TJ, Kesh A, Robertson RM. (November 2016). "You got a dip in your mouth, 
you ain't gonna get no sugar": Tobacco-related views of Appalachian middle and high school youth. [Poster Presentation]. FDA-NIH Tobacco Regulatory Science Meeting, Bethesda, Maryland.

10. Giachello AL, Navas-Matcher E, Estrella M, Payne TJ, Robertson RM, Vu T, Groom A, Hart JL, Walker KL, Rodriguez C, Wang W, Sears CG, Okomina V, Kesh A, Sims M. (November 2016). Perception and use of e-cigarettes among Hispanics/Latinos: Focus groups and survey findings in four U.S. cities. [Poster Presentation]. FDA-NIH Tobacco Regulatory Science Meeting, Bethesda, Maryland.

11. Groom A, Morgan M, Miller C, Robertson RM, Payne TJ, Giachello A, Hart JL, Walker KL, Lee AS, Sears CG, Okomina V, Kesh A, Smith C, Siu A. (November 2016). Marital status and parent influence on youth tobacco use in vulnerable populations. [Poster Presentation]. FDA-NIH Tobacco Regulatory Science Meeting, Bethesda, Maryland.

12. Burns A, Sears CG, Zierold KM. (October 2016). Self-reported respiratory illness in adults living in the surrounding area of a coal ash storage facility. [Poster Presentation]. American Public Health Association Annual Meeting, Denver, Colorado.

13. Sears CG, Lee AS, Walker KL, Hart JL, Tompkins L, Smith C, Siu A. (September 2016). To vape or not to vape?: That is the burning question. [Oral Presentation]. The Annual Meeting of the Kentucky Communication Association, Bowling Green, KY.

14. Lee AS, Sears CG, Hart JL, Walker KL, Giachello AL, Payne TJ, Groom A, Tompkins L, Smith C, Siu A, Kesh A, Robertson RM. (September 2016). Assessing "the state" of tobacco: views and experiences of Kentucky youth. [Oral Presentation]. The Annual Meeting of the Kentucky Communication Association, Bowling Green, KY.

15. Sears CG, Sears L, Hanchette C, Polivka B, Zierold KM. (June 2016). Identifying attention problems in children and adolescents with the behavioral assessment and research system (BARS). [Poster Presentation]. Developmental Neurotoxicology Society Annual Meeting, San Antonio, Texas.

16. Sears CG, Lee A, Smith C, Walker KL, Hart JL, Keith R, Ridner SL. (June 2016). Modified e-cigarettes: A comparative analysis of electronic cigarettes and tobacco use behaviors between subcultures. [Poster Presentation]. Epidemiology Congress of the Americas, Miami, Florida.

17. Groom A, Hart JL, Giachello AL, Walker KL, Wang W, Robb K, Kesh A, Sims M, Lee AS, Sears CG, Rodriguez C, Langdon S, Smith C, Siu A, Payne TJ, Robertson RM. (May 2016). Health and tobacco information resources in vulnerable 
populations. [Poster Presentation]. FDA-NIH Tobacco Regulatory Science Meeting, Bethesda, MD.

18. Hart JL, Walker KL, Sears CG, Lee AL, Tompkins LK, Smith C, Siu A, Keith R, Ridner SL. (May 2016). Vape shop employees: Public health advocates?. [Poster Presentation].

FDA-NIH Tobacco Regulatory Science Meeting, Bethesda, MD.

19. Hart JL, Sears CG, Lee AS, Smith C, Siu A, Walker KL. (November 2015). Appalachian youth and tobacco products: Perceptions, attitudes, and behaviors. [Poster Presentation]. American Heart Association Scientific Sessions, Orlando, Florida.

20. Hart JL, Walker KL, Payne TJ, Giachello AL, Sears CG, Lee A, Smith C, Siu A, May WL, Groom A, Kesh A, Robertson RM. (October 2015). Appalachian youth and tobacco: Perceptions, attitudes, and behaviors. [Poster Presentation]. FDA-NIH Tobacco Regulatory Science Meeting, Bethesda, Maryland.

21. Keith R, Lee A, Sears CG, Walker KL, Hart JL, Bhatnagar A, Smith C, Siu A, Ridner SL, Robertson RM. (October 2015). Knowledge and perceptions of e-cigarette users. [Poster Presentation]. FDA-NIH Tobacco Regulatory Science Meeting, Bethesda, Maryland.

22. Giachello AL, Payne TJ, Rodriguez C, Wang W, Navas-Nacher EL, Quiroz C, Walker KL, Hart JL, Sears CG, Groom A, Lee A, Kesh A, Robertson RM. (October 2015). Influence of religious beliefs and behaviors among Hispanic/Latinos of different backgrounds or ethnicities: Results of A-TRAC Project 3 focus groups. [Poster Presentation]. FDA-NIH Tobacco Regulatory Science Meeting, Bethesda, Maryland.

23. Sears CG, Lee A, Smith C, Siu A, Walker KL, Hart JL. (September 2015). Underrepresented in research, but overrepresented in use: Telling the story of Appalachian youth views of tobacco. [Oral Presentation]. The Joint Meeting of the Kentucky Communication Association and the Tennessee Communication Association, White Bluff, Tennessee.

24. Walker KL, Hart JL, Lee A, Smith C, Sears CG, Siu A. (September 2015). Tobacco fields and fieldwork: Tobacco country youth perceptions of tobacco. [Oral Presentation]. The Joint Meeting of the Kentucky Communication Association and the Tennessee Communication Association, White Bluff, Tennessee.

25. Sears CG, Zierold KM. (June 2015). Mental well-being of adults residing near a coal ash storage facility. [Poster Presentation]. Society for Epidemiologic Research $48^{\text {th }}$ Annual Meeting, Denver, Colorado. 
26. Sears CG, Zierold KM. (June 2015). Sleep disruptive behaviors reported in children residing near a coal ash storage facility. [Poster Presentation]. Society for Epidemiologic Research $48^{\text {th }}$ Annual Meeting, Denver, Colorado.

27. Lee A, Sears CG, Siu A, Smith C. (April 2015). Smokin' hot: E-cigs and digital media art and craft. [Oral Presentation]. $85^{\text {th }}$ Annual Southern States Communication Association Convention, Tampa, Florida.

28. Walker KL, Hart JL, Lee A, Sears CG, Siu A, Smith C. (April 2015). The dark art of crafting tobacco recruitment messages. [Oral Presentation]. $85^{\text {th }}$ Annual Southern States Communication Association Convention, Tampa, Florida.

29. Sears CG, Siu A, Smith C, Walker KL, Hart JL. (September 2014). A smoking hot issue: Electronic cigarettes and youth. [Oral Presentation]. Kentucky Communication Association Annual Conference, Gays Creek, Kentucky.

30. Zierold KM, Sears CG. (March 2014). Are healthcare providers asking the right questions of people living near environmental hazards?. [Poster Presentation]. American Academy of Health Behavior Meeting, Charleston, South Carolina.

31. Zierold KM, Sears CG. (March 2014). Exposure-reducing behaviors among residents living near a coal ash storage site. [Poster Presentation]. American Academy of Health Behavior Meeting, Charleston, South Carolina.

32. Sears CG, Zierold, KM. (November 2013). A community-based approach to assessing emotional and behavioral disorders in children chronically exposed to coal ash. [Poster Presentation]. American Public Health Association Annual Meeting, Boston, Massachusetts.

33. Sears CG, Zierold KM. (September 2013). Coal ash exposure and health in west Louisville, KY: A community-based mixed-methods study. [Poster Presentation]. Research! Louisville, Louisville, Kentucky.

34. Tomcheck SD, Sears L, Sears CG. (May 2012). Characteristic of toddlers screening false positive on the Modified Checklist for Autism in Toddlers (M-CHAT). [Poster Presentation]. International Meeting for Autism Research, Toronto, Canada.

\section{HONORS AND AWARDS}

2017 School of Public Health and Information Sciences Dean's Award, University of Louisville

2017 The Graduate Dean's Citation Award, School of Interdisciplinary and Graduate Studies, University of Louisville

2016 Conference Travel Award, University of Louisville 
2015 School of Interdisciplinary and Graduate Studies Student Spotlight, University of Louisville

2015 Conference Travel Award, University of Louisville

2014 School of Public Health and Information Sciences Dean's Award, University of Louisville

\section{TEACHING AND MENTORING EXPERIENCE}

2016

2015

2011-2012
Undergraduate Honors Thesis Advisor

University of Louisville, Louisville, Kentucky

Description: Mentor for Elizabeth Paige Hart, Biology and

Communication double-major, conducting honors thesis research evaluating electronic cigarette use among college students.

Guest Lecture, PHEP 655: Emerging Issues in Epidemiology, School of Public Health and Information Sciences University of Louisville, Louisville, Kentucky Description: "Coal Ash in Kentucky: A community-based study about the health of people living near a coal ash storage facility."

Teaching Assistant, Biology Department, Goshen College, Goshen, Indiana

Description: Assisting in grading, instruction, laboratory preparation, and lab supervision for:

-Biology 303, Vertebrate Physiology (1 semester)

-Biology 301, Genetics (1 semester)

SERVICE ACTIVITES

2016, 2015, 2014 Sun Safety Initiative Volunteer

Out Run the Sun, Indianapolis, Indiana

Description: Distributing sunscreen and discussing sun safety with spectators at the Indianapolis Motor Speedway.

2015-2016

\section{Data Analyst and Grant Writing Volunteer}

Southern Indiana Community Healthcare, Paoli, Indiana Description: Assisting the primary care clinic with the preparation and writing of a Health Resources \& Services Administration (HRSA) grant proposal to serve a rural, low-income community as a Federally Qualified Health Center.

2012, 2011

AIDS Awareness Benefit Organizer

Goshen College, Goshen, Indiana 
Description: Organizing and leading the campus community benefit to raise money for AIDS relief and educational programs in Africa.

Community Health Volunteer

Central America Study and Service Term, Semilla: The Latin American Anabaptist Seminary, San Pedro, Guatemala Description: Volunteering with community health education programs at Accion Medica Integral San Lucas, San Pedro, Guatemala. Assisting with sex education and health courses for youth. Traveling to surrounding indigenous communities to assess sanitation efforts. Assisting with educational courses on skin-toskin contact after delivery for midwives and healthcare professionals in obstetrics. 